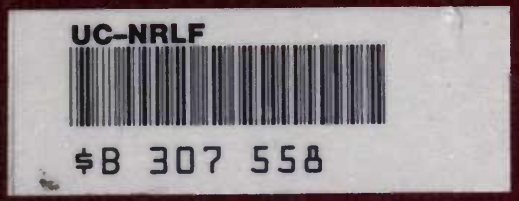




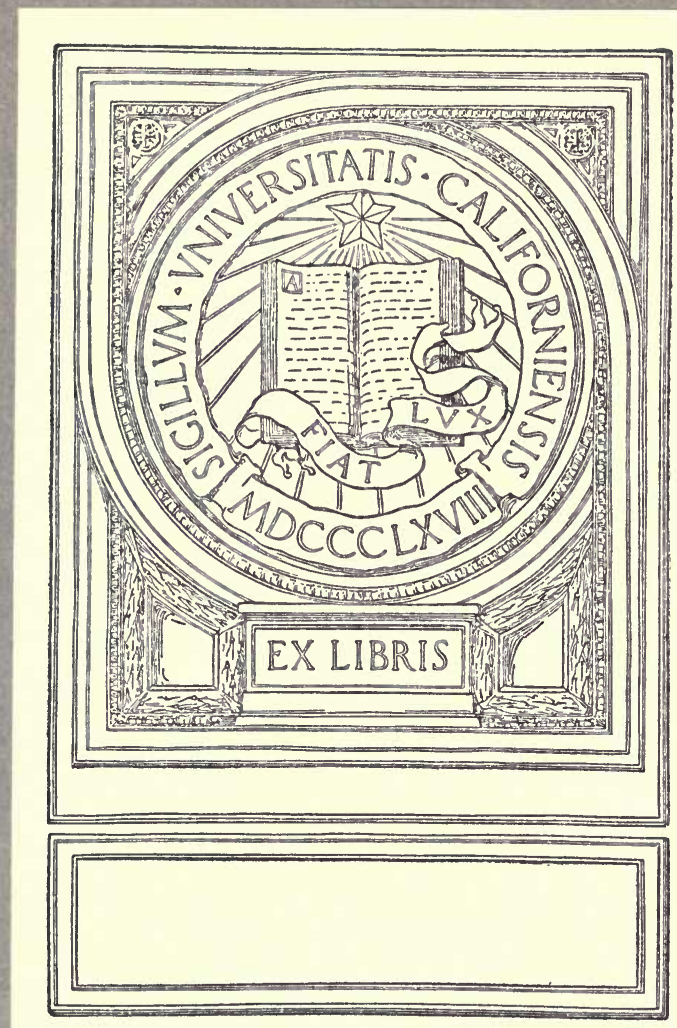



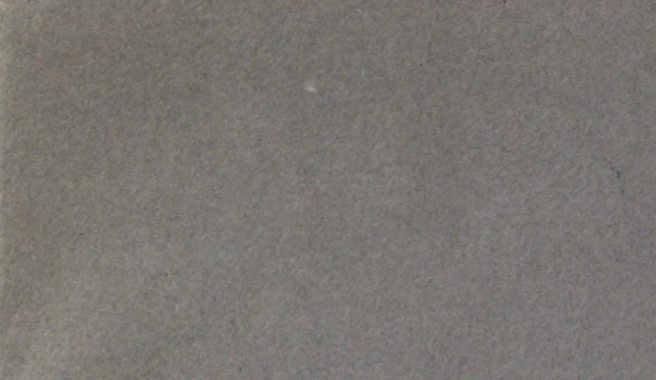


\section{sitisis}

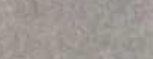

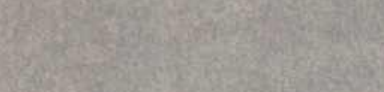

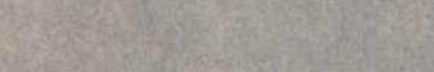

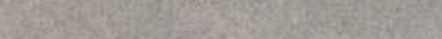




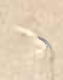

( 



\section{THE WHOLE ART OF RUBBER-GROWING}





\section{THE WHOLE ART OF}

\section{RUBBER - GROWING}

BY

W. WICHERLEY, F.R.H.S.

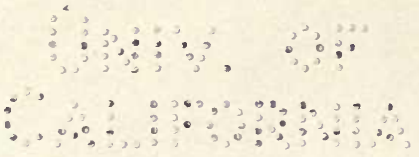

PHILADELPHIA

J. B, LIPPINCOTT COMPANY

LONDON

THE WEST STRAND PUBLISHING CO. LTD.

I 9 I I 
$x^{2}+N^{2}$

サ

a 


\section{CONTENTS.}

PAGE

Preface

CH APTER

I.-Introductory: Early Experiments in Plantation and Tapping . . . . . . .

11.-Trees Tilat Count-Hevea Brasiliensis: A Tantalising Puzzle-Hevea Rivals-DiseasesMachinery - Inconsistencies - Remarkable Growths-Hints to Planters . . . .

III.-Hevea Brasiliensis : Tapping Systems-Important Discoveries.

IV.-Hevea Brasiliensis: Preparing a Clearing-Close and Wide Planting-The Effect of Wind-Holing and Weeding-Manuring. . . . .

V.-Trees That Count-Manihot Glaziovil : Flourishing in Alien Lands-The Manihot at HomeA Tree for the Enterprising Planter-Treating the Seed-Sowing - The Young Tree-No Interplanting-How and When to Tap

VI.-Mavinot Glaziovir : Tapping Freaks-Propagation in India, East Africa and Elsewhere-Experiments-The West Indies, Hawaii, and Ceylon-Peculiar Habits of the Manihot-Propagation and Rate of Growth-Value to the Manufacturer.

VII.-Manihot Glaziovil : Sovereignty as Plantation Rubber-Planting and Environment-Tapping Methods

VIII. -Trees That Count-The Ficus: The Rubber Tree of the East-Age for Tapping-Value of the Latex-An Epiphyte-The Seed-Growth-In Plantations-Uncertainty of Yield-Habits in Various Lands 
IX.-Trees That Count-Castilloa Elastica: The Despised Darien-Castilloa Elastica Compared with Hevea-Character of Latex-Method of Tapping.

X.-Trees That Count-Funtumia Elastica : A Tragic Story-Purely an African Species-A Forest Autocrat-Ruthless Native Action-Prospects and Acclimatisation. . . . . . . 100

XI.-Trees That Count-The New Manihots: (a) M. Dichotoma; (b) M. Piauhyensis ; (c) M. Heptaphylla.

XII.-Interplanting: The Catch Crop-The Chinese
and Tapioca-Disappointments-The Value of
Tapioca Land-Gambier, Coffee, Pepper, Cotton,
Pineapples, Coconuts, Tea-What Experience
Teaches.
XIII.-Assimilative And SEcondary RubBers : Guayule-
Jelutong-The Landolphias-Palo Amarillo-
Ecanda or B'tinga-Blikrodea Tonkinensis-

XII.-Interplanting: The Catch Crop-The Chinese
and Tapioca-Disappointments-The Value of
Tapioca Land-Gambier, Coffee, Pepper, Cotton,
Pineapples, Coconuts, Tea-What Experience
Teaches.

XII.-Interplanting: The Catch Crop-The Chinese
and Tapioca-Disappointments-The Value of
Tapioca Land-Gambier, Coffee, Pepper, Cotton,
Pineapples, Coconuts, Tea-What Experience
Teaches.

XII.-Interplanting: The Catch Crop-The Chinese
and Tapioca-Disappointments-The Value of
Tapioca Land-Gambier, Coffee, Pepper, Cotton,
Pineapples, Coconuts, Tea-What Experience
Teaches.

XII.-Interplanting: The Catch Crop-The Chinese
and Tapioca-Disappointments-The Value of
Tapioca Land-Gambier, Coffee, Pepper, Cotton,
Pineapples, Coconuts, Tea-What Experience
Teaches.

XII.-InTERPlanting: The Catch Crop-The Chinese
and Tapioca-Disappointments-The Value of
Tapioca Land-Gambier, Coffee, Pepper, Cotton,
Pineapples, Coconuts, Tea-What Experience
Teaches.

XII.-Interplanting: The Catch Crop-The Chinese
and Tapioca-Disappointments-The Value of
Tapioca Land-Gambier, Coffee, Pepper, Cotton,
Pineapples, Coconuts, Tea-What Experience
Teaches.

XII.-Interplanting: The Catch Crop-The Chinese
and Tapioca-Disappointments-The Value of
Tapioca Land-Gambier, Coffee, Pepper, Cotton,
Pineapples, Coconuts, Tea-What Experience
Teaches. Mangabeira.

XIV.-Clearing and Planting Forest Lands: Cost of Laying out Estates-(1) Hevea Brasiliensis(2) Manihot Glaziovii.

XV.-Future Prospects: Demand for Rubber-Pos-
sible Plantation Production-Planting Must Continue

XVI.-The Soya Bean-A Chance for the Capitalist. 146 


\section{ILLUSTRATIONS.}

PAGE

Giant Hevea Brasiliensis at Heneratgoda, Ceylon . . 10

Para trees : $5^{\frac{1}{2}}$ years old ; 5 feet by 10 feet ; tapped on halfherring-bone system of bark excision . . . 25

Para trees : 25 years old; 8 feet by ro feet ; tapped principally by bark incision . . . . . . . 35

Para : vertical tapping system to reduce bark excision and

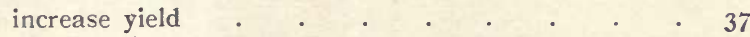

Pollarded Para tree: showing vigorous shoots and extraordinary girth . . . . . . . . 39

Young trees decapitated by storm throwing out healthy

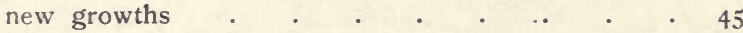

The Author showing correct way of tapping M. Glaziovii $5^{6}$ An East African plantation : the Mkumbi . . . 57 How not to grow Ceara $\quad . \quad \ldots \quad . \quad . \quad .63$

How not to tap Ceara : effect of bark excision on young tree . . . . • • • • . . 69

Ceara tree $: 2 \frac{1}{2}$ years old ; effect of wrong tapping . $\quad 73$

Ceara tree : 20 years old; yields $4 \mathrm{lb}$. to $5 \mathrm{lb}$. of rubber

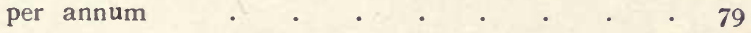

Castilloa elastica : yield 4 oz. per tree . . . 93

Castilloa elastica : 7 years old ; yield under $2 \mathrm{oz}$. per tree 95 
PAGE

Funtumia elastica: 7 years old; not yet fit to tap . . Io3 High-tapping Funtumia (Mabira Forest) . . . 105 Manihot Dichotoma : wrongly tapped; tree dying . . 112 Correct method of tapping M. Dichotoma . . . II3 Leaves of Manihot Dichotoma, showing extraordinary varieties in type . . . . . . II6-II7 M. Dichotoma : effect of wind and storm on wide planting 128 Ceara: effect of close planting . . . . . 129 Jelutong tree (Pulo-Rimau, Sumatra) showing native tapping . . . . . . . . . . . 133 


\section{P R E F A C E.}

THIS work, which is issued at the request of a wide circle of friends interested in Tropical Agriculture, is intended as a handbook and guide to the selection, planting, and exploitation of those species of rubberyielding trees which Tend themselves to successful alienation in countries and climates other than those to which they are indigenous. I have avoided as far as possible the use of technical terms, endeavouring, however, at the same time to present to the eye of the scientific a faithful picture of the already farreaching and momentous results of perhaps the most remarkable instance of successful plant emigration the world has ever known.

I am much indebted to the officials of the Ceylon Experimental Gardens for the facilities freely offered for examining and photographing many of the subjects herein produced, and also to those planters and friends, whose name is legion, who have on every occasion given a welcome and ready access to estates and properties which in the course of a long itinerary I had visited for investigation and experiment.

I have only to add that the majority of these essays have already appeared in THE RUBBER WORLD during the latter part of I9Io and the early months of I9II.

\section{WILLIAM WICHERLEY.}

Kandy, Ceylon: March 391 I. 


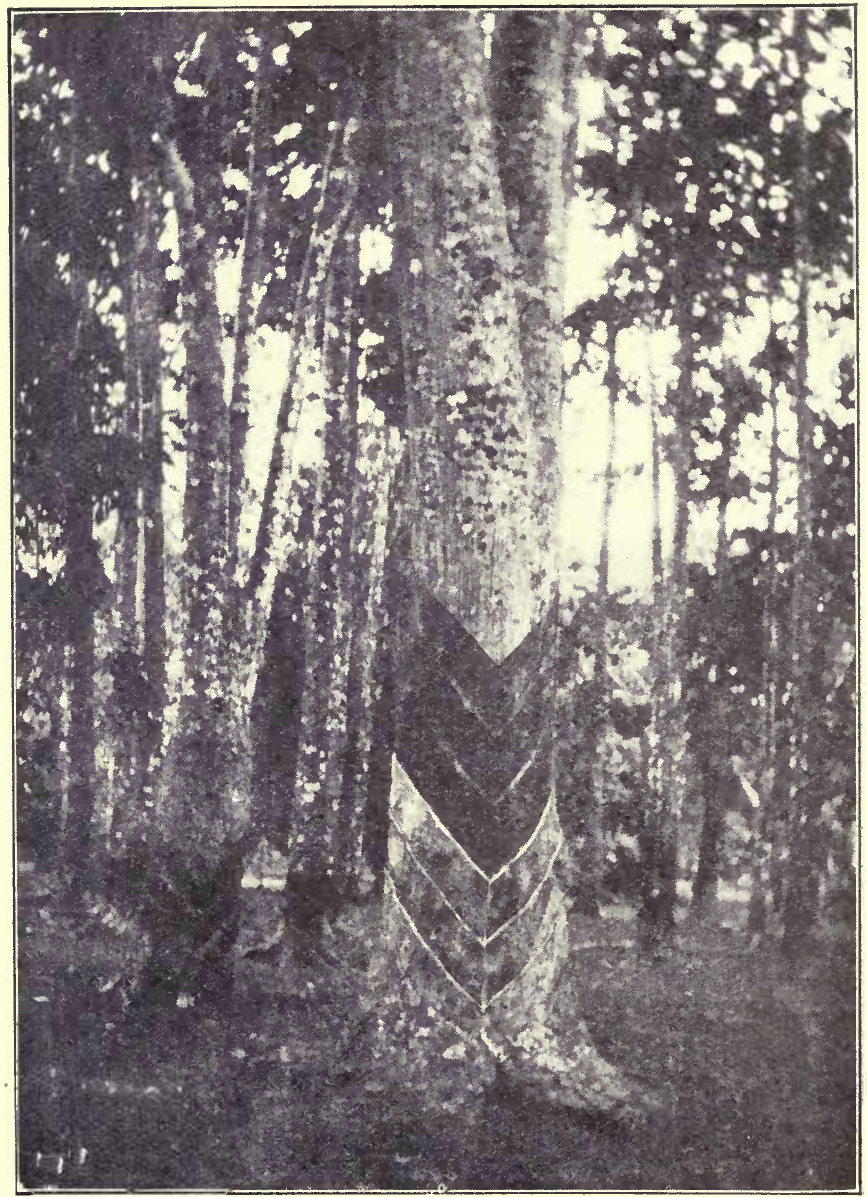

Giant Hevea Brasiliensis at Heneratgoda, Ceylon. Yielded during 1910961 lb. dry rubber. The tree is over 30 years old, is in a grove planted 8 feet by 8 feet, and measures 114 inches four feet from the ground. 
THE

\section{WHOLE ART OF RUBBER-GROWING.}

\section{CHAPTER I.}

\section{Introductory.}

EARLY EXPERIMENTS IN PLANTATION AND TAPPING.

$\mathrm{T}^{\mathrm{T}}$ is a fitting commentary upon the enterprise and wisdom of the Ceylon and Mid-East planterand inter alia upon the genius of Sir Joseph Hooker and the industry of our own magnificent staff at Kew, to whose initiative we owe the genesis of plantation rubber-that the Brazilian Government has decided among other things to preserve its own immense natural resources by compelling owners of seringhals to plant rubber extensively wherever estradas, new or old, are being exploited. The result of this regulation will be that in a few years an estrada at present containing, say, 100 to ${ }_{5} 50$ trees, all scattered about the seringhal in an uneven, zigzag fashion and showing probably only ten trees to the acre, will present plantations as symmetrical as those of Ceylon, standing the while as thick as the Hevea brasiliensis has a mind to. Such a simple method 
of conservation can only have one effect in the case of a country which already produces two-thirds of the world's supply of rubber, whilst it must ultimately excrcise an influence on the price of the commodity not at all in keeping with the optimism that reigns to-day.

Now we know all too little of the art of rubbergrowing to ignore the hard facts of an awakened and alert Brazil. And though it were idle to discuss at this stage the possibilities of output in this connexion, it may not be unprofitable to consider for a moment certain aspects of the question which appeal more directly to those readers who are in one way or another closely associated with the industry.

lake first in order the present position of our Eastern plantation rubber together with the relative importance of the trees grown there-the trees that count. Here, for no other reason than that it is the best known, the best understood, and therefore the most favoured by our planters, I give pride of place to the Hevea brasiliensis. It acclimatises satisfactorily, and thrives equally well both in Ceylon and the Malay States, on the soddened plain and at altitudes varying from 60 feet to i 800 feet above sealevel, thus disposing of the long and snugly nursed fallacy that only in damp marshy land could it ever exist as an alien. Our own experiments in this direction make interesting reading. Of a truth we almost managed to bungle the whole business at the beginning, so far as Southern India was concerned, and we find Sir W. T. Thiselton-Dyer, of the Royal 
Gardens at Kew, writing under date 18 June 1890 to the India Office as follows respecting a proposal to introduce the Sapium (Colombian rubber tree) into our Eastern possessions. He advises the Government to reject the offer, and goes on to say :

"I still remain of the opinion expressed in my letter of 8 July last year that the slender results which have accrued from the large outlay incurred by the Government of India in introducing South American rubber plants into that country are not such as to justify any further present expenditure in the matter." The Sapium was rejected accordingly, but the situation was saved by the remarkable success of another tree-the Manihot Glaziovii-of which more anon. Meanwhile planters and Government experts alike were struggling bravely with such of the Heveas as had by accident been planted in soils and situations suitable to their nature. And here it would be as well to recount the story of the introduction of the rubber tree into our Eastern possessions, if only for the excellent reasons that it will always bear re-telling and because it is a tale soon told.

It was in 1875 that, acting under a commission from the Government of India, Mr. Wickham the botanist, who was then living at Santarem, set out to obtain seeds of the Hevea brasiliensis in the seringhals of the River Tapajos. He arrived at Kew with 70,000 seeds on I4 June $18 ; 6$. They were immediately sown; not more, however, than 4 per cent. germinated. But their vitality was great, for 
in less than five days many of them were $I_{2} \frac{1}{2}$ feet in height. The following year about 2000 plants raised from these seeds were sent to Ceylon at Sir Joseph Hooker's suggestion and planted at Peradeniya in the Government Botanical Gardens there.

About the same time Mr. Cross was given a commission by the Indian Government to procure live plants of the Manihot Glaziovii from Brazil. He arrived at Kew on 21 November 1876 , bringing Io80 seedlings without soil. About 40 per cent. survived and roo plants from these were subsequently sent to Ceylon. The following year witnessed the beginning of the rubber-growing industry in our Eastern possessions, and both in 1878 and 1879 Dr. Thwaites, the Director at Peradeniya, was busy distributing cuttings from the Kew consignments to planters in Ceylon. Propagations from cuttings supplied in 1877 from the Peradeniya plants were also successfully made at the Heneratgoda Gardens. It was here in April I 88I that the first acclimatised Hevea flowered, thirty-six seeds being secured. At Peradeniya the trees showed no flowers till I884. From that year onwards, however, the output of seeds increased enormously and supplies were distributed broadcast all over the rubber zone in Southern India and the Mid-East. The authorities, guided no doubt by the faithful report of their expert, who had found the trees in Brazil flooded at their base for a considerable period of the year, induced planters to select sites liable to be covered with water when the river was in flood. In every case disaster followed. Three days' flooding was enough 
completely to kill the whole of the plantation at Edangoda. A second trial was made the next year, with similar results, when the land was abandoned in favour of higher ground at Yattipowa. Here in three years the trees attained an average girth of $9 \frac{1}{2}$ inches at three feet from the ground, while experimental tapping made when they were six years old produced $2 \frac{1}{2} \mathrm{oz}$. of dry rubber per tree. Such a small yield was considered to be very disappointing, and these particular trees were not tapped again until I888, when they were eleven years old! As a matter of fact, both experts and planters were puzzled to know what to do with the tree when it had reached maturity. Many amusing stories are told of men who, having their own ideas on tapping, subjected the rubber trees to the most extraordinary treatment at the hands of natives armed with vicious axes, cutlasses, knives and other deadly engines of plant extermination. Thousands of healthy promising trees, that would to-day be worth a king's ransom, were ruthlessly felled, chiefly because the first tappings did not happen to fill the bucket set down to receive the milk! In a circular issued by the Ceylon Forest Department in 1888 , planters were advised not to attempt to tap the Hevea until it was ten years old. Now the planter is not out to make a living on mere sentiment. He wants something more solid. Moreover, no man, unless he is in the tropics for his health and has no expectations, can afford to wait a decade for a return of his capital. It is not surprising, therefore, that a mild panic against rubber set in, and plantations galore were 
rooted up to make way for a less shadowy and less uncertain product. Those plantations that were allowed to remain became the experimental ground for every enthusiast who professed to have discovered the one and only way to tap a rubber tree. The Government men led off by scraping away a little of the bark of their eleven-year-old trees where these happened to have a circumference of not less than 4 feet at a yard from the ground! The tree was then attacked with a $\frac{3}{1}$-inch chisel, by means of which forty or more $\mathrm{V}$-shaped incisions were made in the inner bark. The milk was mostly allowed to dry in tears on the trees after the manner pursued by the Ceara seringueiros with regard to the Manihot Glaziovii in North-East Brazil, whilst those portions which failed to dry were caught in cups of coconutshells fastened to the trunk with clay. The driest months of the year were always chosen for the operation, which extended over a period of about seventeen days, so that these magnificent trees barely yielded each $\mathrm{I} \frac{1}{2} \mathrm{lb}$. of dry rubber. Then the scarring of the bark from the numerous incisions must have somewhat alarmed the experts as to the fate of the trees, since no further attempt was made to tap them until the bark had healed. Thereafter regular tappings every other year became the recognised thing! Commenting on these operations, in a circular issued to the planters at this period, the authorities venture (not too confidently) to recommend an extension of plantations in the following words : "A yield of over IO $\frac{1}{2}$ ib. of first-class rubber from a single tree in six years fully warrants a belief 
that the cultivation of large plantations would be profitable. Nor is there any reason to suppose that the trees would not easily bear tapping annually, and continue to yield for many years." Just so. But we have learned much about plantation rubber since then. 


\section{CHAPTER II.}

\section{Trees that Count-Hevea Brasiliensis.}

A TANTALISING PUZZLE-HEVEA RIVALS-DISEASESMACHINERY - INCONSISTENCIES - REMARKABLE GROWTHS-HINTS TO PLANTERS.

T $\mathrm{T}$ is a fallacy to suppose that you may " tap a tree to death"'. Doubtless where the tapping has been carelessly performed, and the vital camium injured, its health may be affected; but you cannot " milk" a rubber tree to excess. The lactiferous system is distributed in a region apart altogether from the " nerves" and other life tissues that depend first and last upon the flow of the sap, and experts are beginning to recognise that it is on this wonderfully constructed line of what might be termed "lactic tubes", that permeate the inner bark and root, and also the fruit and flowers and leaves of the tree, that we shall have to fix our attention in order to arrive at a solution of the tantalising puzzle which the Hevea and others of its order at the moment present to the botanist and planter alike.

Regarding it from a commercial point of view, the Hevea does not occupy the pre-eminent position 
it held only a short ten years ago. At that period its status from every standpoint was apparently unassailable. But in the interval a great deal has been learned about its great rival and relative the Manihot Glaziovii, and also concerning the Castilloa and other trees whose latex, when treated in an up-todate scientific manner, has proved to be equal to, if not exceeding in many respects, that of the finest forest-cured Para. But the Hevea for many reasons will always be a favourite with the planters in the old world, especially in such places as the Federated Malay States, Borneo, and the Dutch East Indies. Here the Hevea appears to have found a far more congenial home than that afforded by the varying altitudes and fickle soils of Ceylon, where for some reason or other the Hevea is prone to change its habits and customs, especially as to the fall of the leaf and the phenomena of the flowering period. It is nevertheless extremely doubtful whether the Hevea in the Straits Settlements will make such a good fight against the ravages of disease as its neighbour in Ceylon and Southern India is doing. Disquieting admissions have already been made at many company meetings respecting this danger: and planters should be warned in time. Perhaps the most dreaded of these diseases is the fungoid pest Helicobasidium, sp., which attacks the roots and rapidly spreads by aid of strands of living mycelium in the soil. The remedy is immediately to destroy all the affected parts by burning, and then to dig a trench round the tree a foot deep, into which every particle of suspected soil should be buried and 
treated with powdered sulphur before being covered in. An occasional spraying of the base of the tree with Bordeaux mixture is also to be recommended as a preventive; but the drastic remedy of destroying and burning the tree altogether, immediately the disease has acquired a firm hold, will alone prevent a repetition of the disaster that exterminated the coffee tree in Ceylon.

In a recent "Bulletin" issued by the Director of the Botanic Gardens, Singapore, mention is made of the appearance of the terrible Irpex flava, a wellknown coffee pest, among Hevea, and rubber planters are warned against interplanting with coffee, which is also liable to attacks of Corticium. Moreover, we are told that many trees have been visited by Fomes, Termites, and the dangerous parasitic fungi the Diplodia rapax and the Hymenochæte, none of which are ever found in Brazil or in the native habitats of the Hevea. It is quite possible, therefore, that unless planters themselves take the matter in hand by penalising estate managers who invite disease by neglecting the few rules of cleanliness that will ensure immunity in this respect, they will be inviting their own ruin. In this connexion some concerted action ought to be taken without delay, with a view to utilising the opportunities which the Rubber Exhibition and Congress in London during I9I I will, it is hoped, provide for dealing officially with this and kindred subjects of vital interest to the industry.

When we come to consider the Hevea as a rubber producer we are faced with the undoubted eccen- 
tricity of yield which is a feature of the tree in alien lands. In the majority of cases where the Hevea has reached a tapping stage, when I $1 \mathrm{~b}$. of dry rubber at the lowest computation ought to have been produced, only one-half of this amount has been realised, a result entirely owing to faulty " milking " and ignorance of the treatment the tree ought to receive. A plantation six years old, where the trees are 12 feet by 12 feet and showing an average girth of 18 inches, ought to yield $250 \mathrm{lb}$. of dry rubber to the acre per annum. At seven years old the plantation should be in its prime and possess no tree less than 20 inches in girth. Such a plantation will easily give dry rubber $400 \mathrm{lb}$. per annum to the acre - a highly satisfactory return in all conscience. With the high price lately realised for the product, there has become associated with the planter's art an elaborate system of machinery, the purpose of which is to place on the market in the shortest possible period a finished rubber, clean and attractive to look at, whilst possessing at the same time all the best qualities of the Brazilian Para. It is too early to make a final pronouncement relative to this bold departure on the part of the Anglo-Saxon planter; but it is encouraging to find that fine crêpe from the Mid East at present fetches a price not exceeded by smoked Para, whilst "Lanadron blocks " run both very close in a keen market. It is quite possible that this question of machinery will in time revolutionise the market in respect to the grading and pricing of rubbers, and the value of a tree-the tree that counts in a plantation-will be 
determined by the behaviour of its latex under the manipulation of the coagulator, the macerator, the washer, and the crêping machine, rather than by the historical facts associated with its name, its origin, its character, and its botanical order.

Perhaps one of the most extraordinary features in connexion with the acclimatising of the Hevea in the old world is the remarkably inconsistent behaviour of the tree. Thus we find it flourishing exceedingly in one district whilst in another, where the soil and climatic associations were in every way similar, the plant stubbornly refused to live. Especially was this the case in many parts of Ceylon and Southern India in the early 'eighties, when the Government of India, in partnership with Kew, was carrying out its epoch-making experiments.

In India the only localities in which the tree was found to succeed were Lower Burma (Mergui) and Malabar (Nilambur), whilst in Ceylon the most promising plantations were found to be those perched at altitudes hitherto regarded as absolutely unfitted for rubber of any kind. Utter failure attended every attempt to cultivate the Hevea in Bengal, where there is a distinct cold season, which, of course, is altogether unsuitable for so delicate a plant. The same disappointment was experienced in the Travancore and Cochin districts; but in this case ignorance in regard to the aftertreatment of trees when established was largely responsible for the failure. Indeed a pronounced failing in the otherwise excellent labours of the various experimental staffs attached to the Govern- 
ment of India at this period was the entire absence of any co-ordinate effort to educate the planter and the native agriculturist in the art of rubber-growing pure and simple. It is true that generous supplies of seeds and plants were distributed wholesale, but the one element to secure success - the man on the spot who could show how the thing was done-was absent in the majority of cases, with the result that disaster generally followed, save only where sheer good luck intervened.

All this is altered now, however, and there is no more mindful, no more enterprising, no more assiduous staff in the whole world of tropical agriculture than that of the Government of India. It is well to record here that the system originally adopted in acclimatising the rubber tree undoubtedly lent itself to slipshod haphazard work on the part of the individual planter, who kept no records, so that we have to turn to the Government Departments at Kew and elsewhere for any reliable data as to the methods employed in the cultivation of the plant and the commercial development of its product.

According to these authorities, the first experimental tapping of the Heveas sent out by Kew to Peradeniya, Ceylon, in Wardian cases (these permit uninterrupted growth during the travelling period) was made in October I 882 by Dr. Trimen, when the trees were six years old. Five trees were so tapped, and the dry rubber secured amounted to about $2 \frac{1}{2} \mathrm{oz}$. The sample was sent home and reported by Messrs. Silver (of the Silvertown Indiarubber and Gutta- 
percha Works) to be "fully equal to good Para rubber as regards strength and elasticity".

It would appear that the general custom was to plant at intervals of $\mathrm{I} 2$ feet, and to clean-weed until the tree had attained sufficient height to afford enough shade to keep down the undergrowth. In view of the very pronounced objection that obtains in many quarters-chiefly by laymen primed by secondhand impressions - to so-called close planting, it is interesting to find that in no case do the Government staff plant less than $25^{\circ}$ Heveas to the acre. As a matter of fact the rule is to plant 8 feet by ro feet. In a minute on this subject issued in 1906 by Dr. Trimen's successor, Dr. J. C. Willis, F.L.S., the following occurs :

"Various distances apart have been tried in planting Hevea. . . . The best results have been obtained by planting 8 or ro feet apart each way. The trees thus form their own shade and keep down weeds. ... Another advantage of close planting is that the trees grow up straight without forming many branches low down, and this very greatly facilitates tapping."

The same authority emphasises the opinion the present writer has always expressed against interplanting of any kind with Hevea.

"Para rubber", he states, "is a surface-feeding tree, and catch-crops should not therefore be grown between the trees, which require all the nourishment that the soil can afford." At Heneratgoda Gardens, 


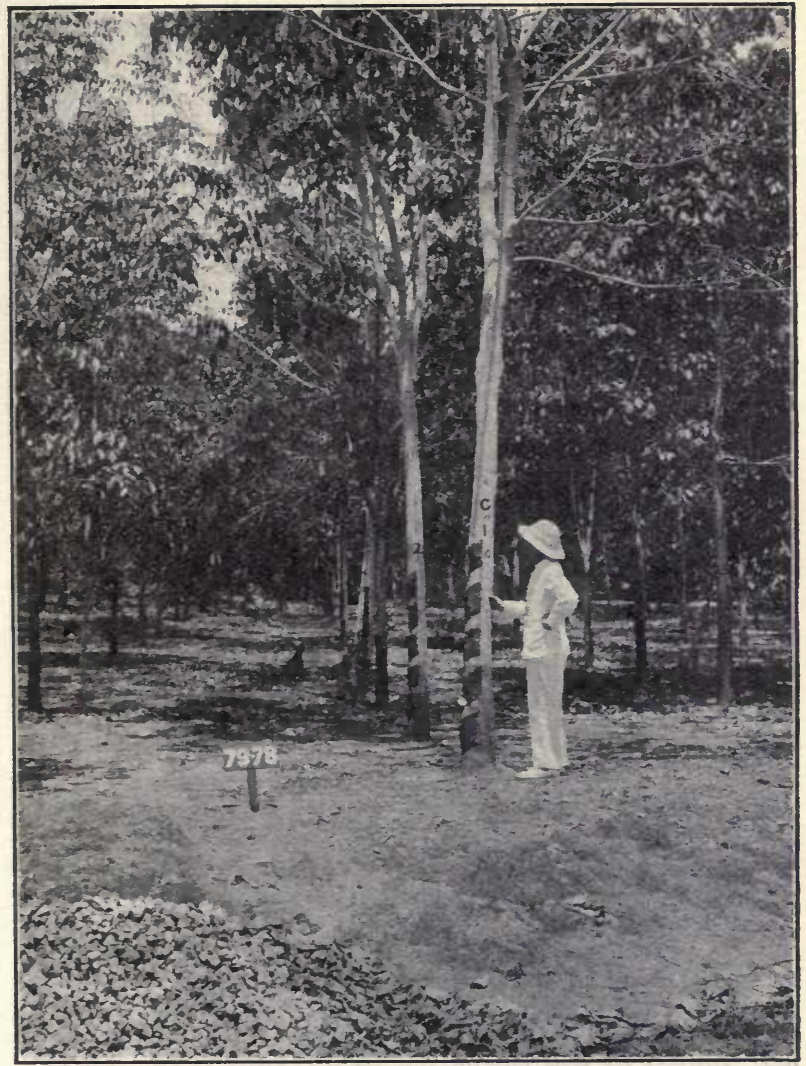

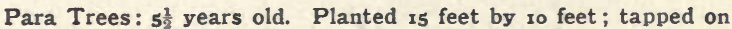
half-herring-bone system of bark excision. 
where these experiments were carried out, there is at present a belt of magnificent Heveas-the matured infants that Kew sent out in 1876 . In two years from the date of planting they had attained 30 feet in height and 14 inches in girth. By 1882 they were 50 feet high and 30 inches in girth. In 1893 they measured in girth no less than $79 \frac{1}{2}$ inches. One of these fine trees yielded during igro $96 \frac{1}{2} \mathrm{lb}$. dry rubber. It was measured by the writer-a photograph taken by him on 20 March last appears as a frontispiece-and found to be not less than i i 4 inches four feet from the base. When it is stated that the largest tree measured in Brazil by Mr. Cross was 82 inches, it is clear that we have here an unanswerable argument in favour of the system followed by the Government experts in the treatment of the Hevea in Ceylon and elsewhere. The seed of the Para rubber trees readily germinates, and seedlings are planted out in wet soil when they have reached a stature of 18 inches to 24 inches. Propagation by cuttings is to be recommended where it is desired to plant out a large area at once. The method employed is to take cuttings near the ends of the branches, but further back than any of the leaves. Each cutting is about a foot long and as thick as a lead pencil, and is cut off at both ends by oblique cuts just below the leaf scars. The cuttings are placed in the nurseries to develop their tap-root before being planted out. A wise planter selects the rainy season for this work, which should be done as follows : 
The land having been lined and measured, holes to receive the plants should be dug 18 inches wide and $\mathrm{I} 2$ inches deep and filled with good soil and a little manure. The stump, seedling, or cutting is then placed in position, care being taken not to injure the tap-root, which should lie in a bed of soil all to itself, with the surface roots lightly resting an inch or two beneath the freshly made earth. Shading and protection from the wind is afforded by placing straw openwork matting round each plant. At the end of the sixth year the trees should be 20 to 30 feet high, and show a mean girth of at least 18 inches three feet from the ground, in which case they may be tapped with every confidence. Tapping should not be attempted unless a girth of this measurement is attained, no matter what the age or stature of the tree may be. Quite recently we have had many instances recorded of plantations being attacked by fungoid and other diseases, and in nearly every case, after investigation goes to prove that the predisposing cause (if nothing else) of these dreaded attacks is the tapping of immature trees. Then, again, incalculable mischief is being done by the absence of a recognised system of tapping the Hevea brasiliensis. In scarcely two places where the tree has been successfully acclimatised do we find the same method pursued. The swift but clumsily skilful manner in which the seringueiro goes "hacking" through his estradas in the seringhals of Brazil would never answer in the case of plantation rubber, although it is quite 
possible that a neater and more scientific application of the principle he adopts (which is a magnified "pricking" with the machette) would be found to

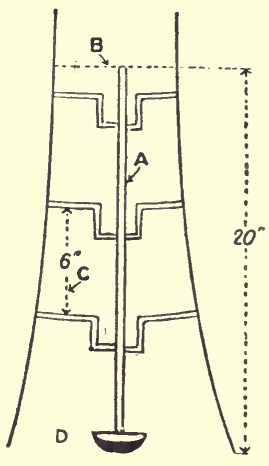

A Vertical incision from tapping line to base of tree, 20 inches in length convey. ing the latex to the cup at base of tree.

B Tapping line, 20 inches from base of tree.

c Space between lateral incisions $=6$ inches.

D Latex Cup give results much more satisfactory than those associated with the herring-bone, halfherring-bone and spiral systems now in general use among planters. From personal experience ranging over a long period in the whole realm of the rubber zone, which embraces countries as far apart as Brazil and North Borneo, I am persuaded that the good method is to be found in a modification of the system pursued by the seringueiro in the tapping of the Hancornia or Mangabeira rubber trees. There is no need to describe this particular method in detail. Suffice it to say that it has some likeness to the sketrh submitted herewith.

In no case should the trees subjected to this system be tapped at a greater height than 20 inches from the base. The incisions should be made half-way around the trunk 6 inches apart, leaving room for the long vertical cut in the centre. As soon as the incisions are made a spray of ammonia water (I to Ioo solution) may with advantage be applied to the 
wound prior to fixing the collecting vessel, which should also contain a few drops of the solution to prevent premature coagulation. The latex cups should be collected within three hours of the incisions being made, so as to conserve as far as possible those latent qualities which assist coagulation in the factory.

The following morning fresh incisions must be made in the intervals between those already formed, the process being repeated next morning, when the whole of the tapping space will have been utilised. At the end of the sixth day the original wounds should be re-opened-an operation which is also performed on each of the other wounds in turn. This work can be done at intervals of six days until the latex has ceased to flow. Altogether a period of a hundred days may be so employed, and not less than forty tappings profitably applied to any one tree in a single season. As a rule it will be found that the yield from the reopened incision-technically called wound response-is much greater than that originally made, with a corresponding increase at each additional reopening. Tapped in this manner Hevea trees not more than six and a half years old have been made to yield $2 \frac{1}{2} \mathrm{lb}$. dry rubber without in any way injuring the tree or interfering with the subsequent yield. The proportion of increase of latex secured by the operation of wound responses is shown from the following table taken from a company's return published privately a short time ago. Thirty incisions of the open $\mathrm{V}$ type were made, and, taking 
the letter $x$ as defining a hidden quantity, the results were as follows :

\section{QUANTITY OF DRY RUBber.}

1st tappings, 1 March, $x \quad 40$ incisions pure and simple. 2nd $, \quad 5 \quad, \quad x \quad 60$ result of wound openings.

3rd " $12 \quad, \quad x 105 \quad, \quad, \quad$,

4th $\quad 19 \quad, \quad x 228 \quad, \quad, \quad$,

5 th $\quad, \quad 26 \quad, \quad x 375 \quad, \quad, \quad$,

6th $\quad$, $30 \quad, \quad x 420 \quad, \quad x \quad, \quad, \quad, \quad$,

and so on until, at the twentieth time of opening the latex began to gradually decrease and the flow of latex returned to a figure approaching the original output $x$ 40. It is interesting to compare this system with the elaborate method originally pursued by planters on many estates in the Mid East.

The tree was first carefully and slightly shaved of its outer bark with a knife to a height of 6 feet from the ground, so as to form a perfectly smooth surface. When the shaving was completed the wood was polished, the object being to provide a nice clean road over which the latex may travel easily into a clay channel prepared for it at the base of the tree, 6 inches or so from the ground. The average yield of latex from this system worked out at about $2 \frac{1}{2} \mathrm{oz}$. of dry rubber from a six-year-old tree, and certainly not more than $I_{2} \frac{1}{2} \mathrm{lb}$. from a tree in its prime.

Another great advantage presented by the method recommended is the complete preservation of the bark with a certainty and rapidity of wound healing. 


\section{CHAPTER III.}

\section{Hevea Brasiliensis.}

TAPPING SYSTEMS-DR. FITTING'S METHOD-IMPORTANT DISCOVERIES.

$\mathrm{I}^{\mathrm{T}}$ was inevitable that with the introduction of the 1 Hevea into the tropical planter's category of exploitable plants there should be associated with the industry it created new methods, employed not only with the manipulation of the product it represented, but also with the treatment of the tree itself.

Thus very early in the history of plantation rubber the problem of tapping Hevea so as to yield a fair profit vexed many anxious investors. In the first place, little or nothing was known of the methods practised from time immemorial in Brazil, the home of the plant, and, again, no definite line of action was in evidence at the Government Experimental Gardens that are scattered about the Far Eastern seas. In many of these places ready facilities appear to have been offered for any peregrinating crank to obtrude his ideas on tapping upon a patient staff, and the handiwork of these mischievous visitors afflicts the vision on every hand. A careful system of progres- 
sive experiments was, however, inaugurated in the Ceylon Gardens by that rare enthusiast, Dr. Trimen, whose work has been so worthily carried on by a band of devoted successors that the whole world of plantation rubber may be said without exaggeration to have been created by the small staff of clever, brainy men at Peradeniya and Heneratgoda. Here to-day are to be seen the parents of those millions of trees-veritable boles of gold-which are rapidly converting Malaya and Ceylon into botanical Golcondas, and in themselves providing living evidence of the enormous possibilities of the new industry. In the early stages of their existence these trees were only tapped every other year. Now-weather permitting - they are tapped not even every other day but every day, Sundays included. The system employed was that of the small open $\mathrm{V}$-now absolutely discarded. The work must have been very clumsily done, for the bark of the tree continually expanded and became so gnarled and blistered that it was almost impossible to tap it for nearly six years. At the end of that time " high tapping" by means of ladders and scaffolding became the fashion, many excisions being made full 30 feet from the ground. So far as the actual yield of latex was concerned, the experiment was satisfactory, but the work was slow and the cost quite prohibitive when applied to any considerable area of ground.

Then came the full herring-bone, full spiral, halfherring-bone and half-spiral systems, all of which applied to the tree the dangerous necessity of bark excision, instead of that safe and simple methor of 
bark incision employed by the seringueiro in the Amazon forests.

Bark-paring is now the general rule throughout the Mid-East, and if in this connexion it were possible to say that the great and irritating problems of bark conservation has now been solved, then planters have to thank Dr. Fitting, an eminent and painstaking scientist, whose little brochure on the subject, written after a visit to Ceylon and Malaya, and as the result of a long series of experiments on the spot, should be in every planter's bungalow. It is, however, too early to declare for any system where bark excision is the rule, for the simple reason that the tree itself has not yet had time to answer the questions applied to it in this matter.

The fundamental principles of the "Fitting" system of tapping are based on bark conservation and daily or bi-daily access to the tree for latex gathering. With this end in view, planters are exploiting their Heveas in the following manner.

At the commencement of the season all trees that have attained a girth of 17 inches three feet from the base are marked for tapping in consecutive numbers. Each tree is then divided, so far as the tapping area is concerned, into three parts representing three years' work in bark excision and latex extraction. During the first year part one only is exploited. The next year part two is operated upon, part one being allowed to rest for bark renewal, whilst in the third year the remaining section of the tree is tapped, section two resting, and section one, supposed now to have fully recovered after the removal of the bark 
and the drastic treatment of two years ago, is again marked out for next season's operations. Thus the whole circumference of the tree is deprived of its bark and tapped over a period of three years. The system employed is that of the half-herring-bone. Dr. Fitting's method is being very widely adopted in the Mid-East, but one cannot yet make any definite pronouncement as to its merits or demerits. For the moment the planter is content to regard it as an excellent way of keeping the coolies more con. stantly to the grindstone, and his trees under purview hourly and daily throughout the season.

A sketch of Dr. Fitting's method as applied to each of the three sections in turn is appended :

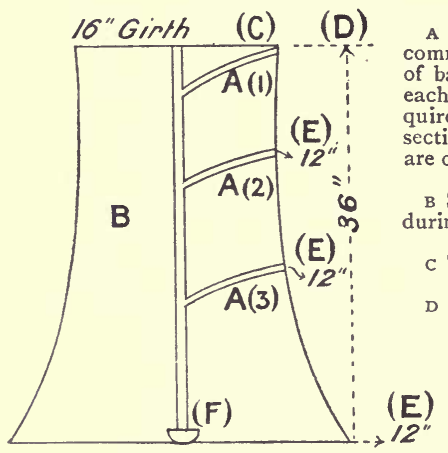

A First season's section. The tapping commences at $(\mathrm{t}),(2)$ and $(3)$, the amount of bark removed each day being $\frac{1}{8}$ inch in each case. Thus 82 operations are required before the whole of the bark in the section is removed, but the actual tapping: are often too or more.

B Shows the section to be operated upon during the second season.

C Tapping girth of exploitable trees.

D Length of tapping bole 36 inches.

E Sections of 12 inches, $\frac{7}{8}$ inch of which is daily stripped of its bark and tapped throughout the season.

F Latex cup at base of channel.

In some cases planters are dividing their trees into two sections only, whilst in others I found that a decided timidness and uncertainty had directed the owners towards operating on as small an area as possible, so that they were marking off their trees 


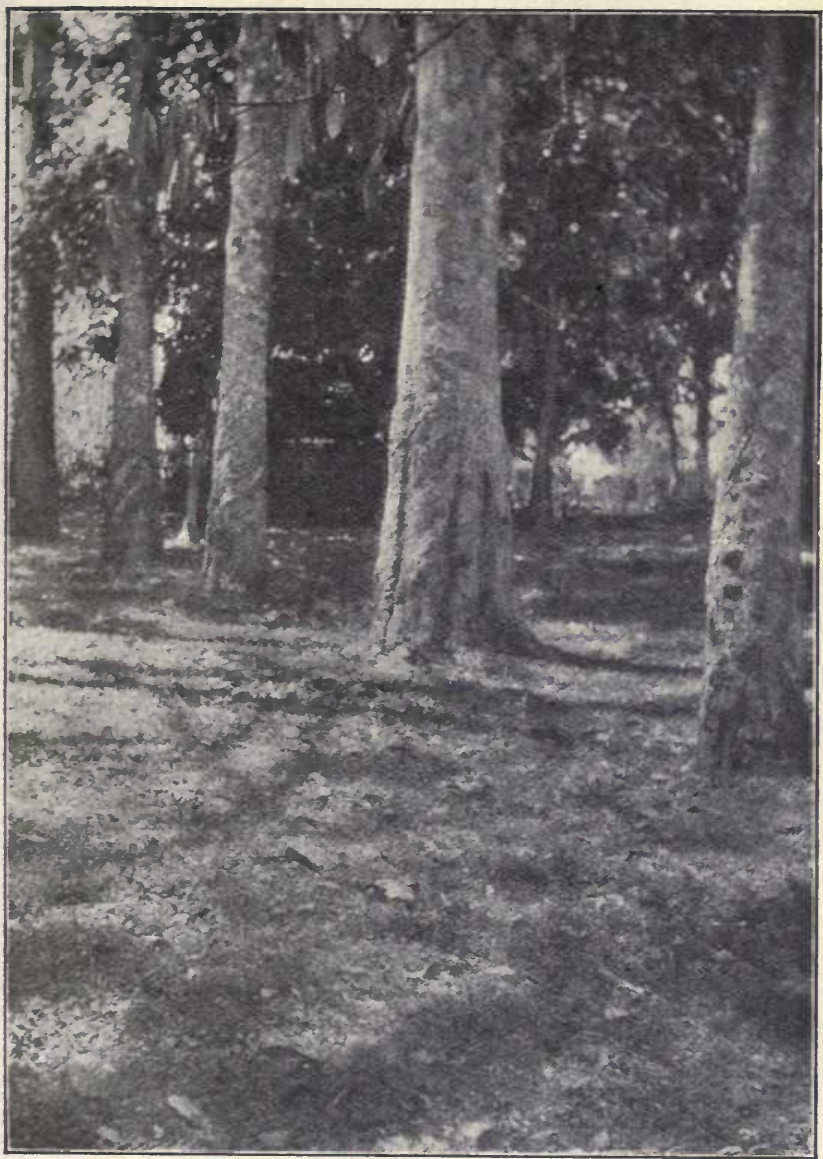

Para Trees: Peradeniya Gardens (Ceylon). These trees are 25 years old. Tapped principally by bark incision; planted 8 feet by ro feet. 
into quarter sections and only remoring the bark every other day. The yielc in these cases of course is very small, but the dangers attendant on bark removal is reduced to a minimum, and that is everything to a man who cannot shut his eyes to the fact that in the absence of any real practical knowledge on the subject of the safe tapping of plantation Hevea the future of the industry and with it his own fortune lies largely in the lap of the gods.

I had the opportunity of examining carefully a number of estates that for over a year had been subjected to the Fitting method, and in every case I found evidences either of damage to the cambium or pest attack by " borer" where the coolie had exposed the soft tissues behind the lactic vessels to rain or water (which is now universally used to induce flow of latex) and other foreign agent.

Mr. Kelway Bamber, perhaps one of the most capable and clearest-headed men in the MidEast, has been conducting some very interesting experiments at Peradeniya Gardens with a view to obviating the dangers to which I have referred. His most promising system, which is fully illustrated herewith, is that of straight vertical cuts, each 6 feet in length and $\frac{5}{8}$ inch broad. Two such cuts are made in the tree every third day, and as much as $\frac{3}{4} 1 \mathrm{~b}$. of dry rubber has been obtained under this method from trees only $4 \frac{1}{2}$ years old. Many are inclined to believe that vertical tapping carefully conducted may eventually supersede every other method. It is cheaper, easier, and certainly safer than any system ever yet tried in Ceylon, whilst the actual 


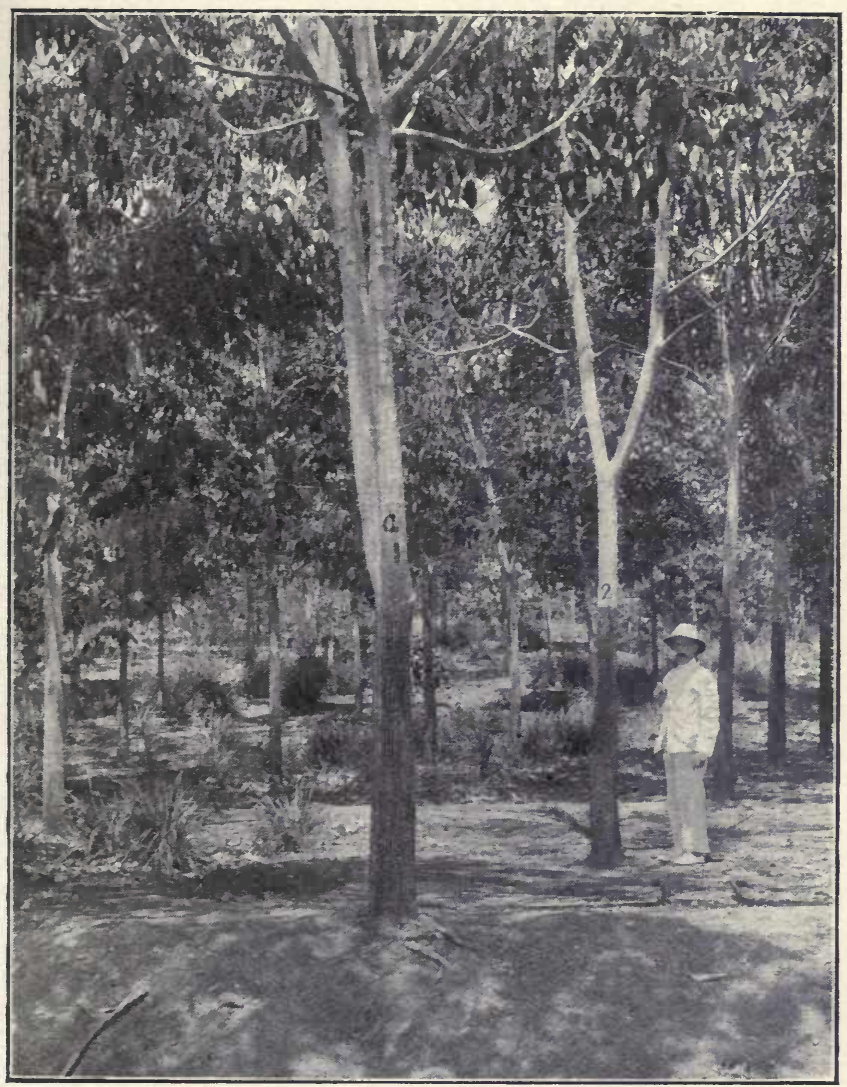

Para Trees: Vertical (new) system of tapping, object being to reduce bark excision to minimum and increase yield of young trees. 
yield of rubber carries with it eloquent and positive recommendations.

The most complete and therefore most interesting experiments in tapping Hevea were those carried out under the direction of $\mathrm{Mr}$. Herbert Wright at Heneratgoda in the early part of the present century. Mr. Wright was at that period curator at the Government Experimental Gardens. He brought to his task at once an intense enthusiasm, a wide knowledge of tropical agriculture and an untiring application to the difficult problems to be solved. Here was a man who evidently felt that as the Government had given the planter a priceless possession in the alienated rubber tree, it was now the duty of the authorities to show him how to make the most of his prize. It may be said at once that practically all these experiments were carried out with no other object in view; and if Mr. Wright and his confrères, Dr. Willis and Mr. MacMillan, desire to see the result of their labours they have only to look at the enormous expansion of the industry since 1906, when, following the holding of the famous Rubber Exhibition at Peradeniya, the knowledge thus obtained from Heneratgoda was given freely to the planting community of Ceylon and the Mid-East.

Three important discoveries in regard to tapping Hevea were made from the Heneratgoda experiments, viz. (I) that high tapping was not necessary, and that it was moreover conducive to the production of non-coagulable latex; (2) that tapping on alternate days, with a maximum of $\mathrm{I} 20$ tappings, gave best results; (3) that bark renewal of excised 


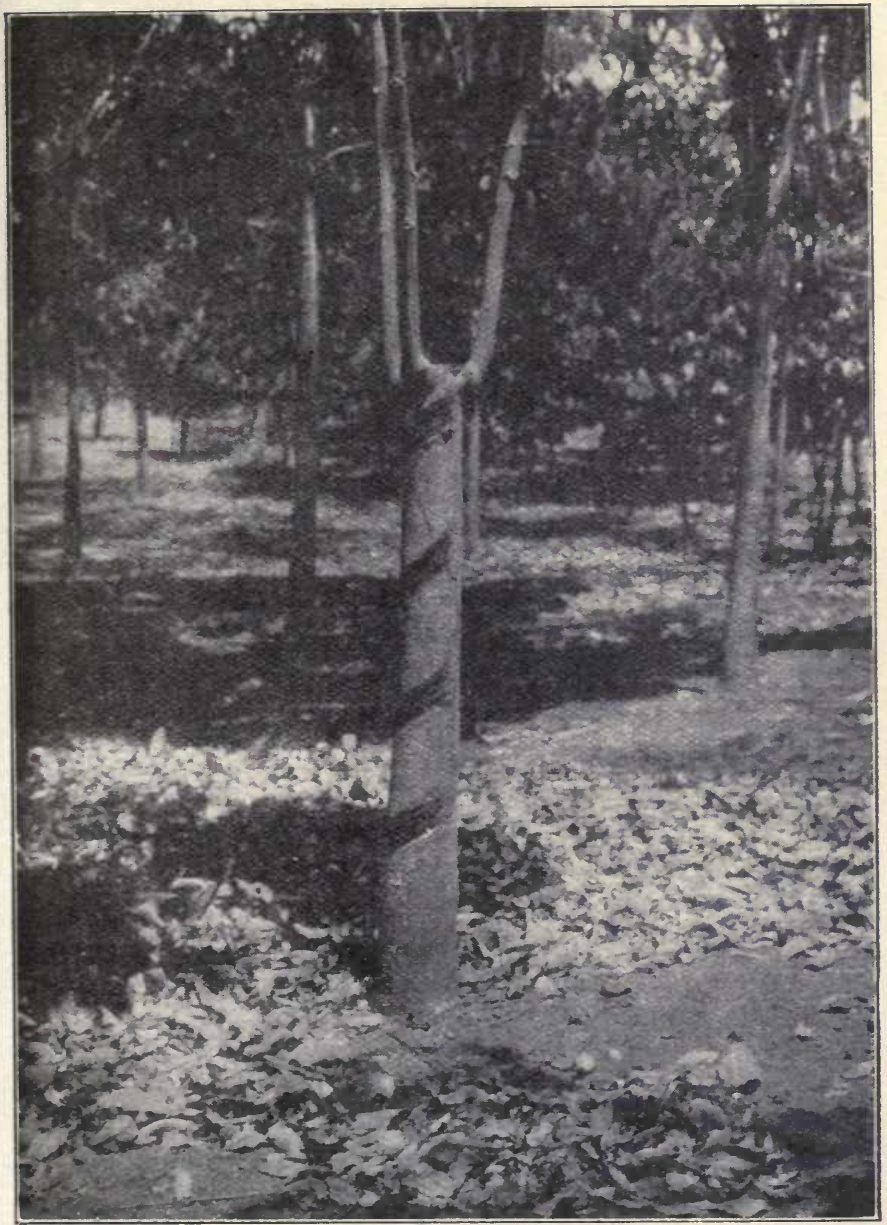

Para Tree: Pollarded at $3^{\frac{2}{2}}$ years old owing to extravagant growth; showing three vigorous shoots. Tree put on extraordinary girth; tapped at 5 years, half-spiral system. 
trees occurred at the rate of $\frac{1}{4}$ inch in nine months, providing the cambium had not been pierced.

Upon these discoveries are based the leading principles which to-day govern the exploitation of the rubber tree in the Mid-East, and although the leading plantations are doing well under the ordeal, and in the mass increasing heavily their monthly outputs, the wiser heads in the industry are nervously asking "Will it last?", Shortly stated, the tapping principles referred to are: (a) Tapping to commence when the tree has gained a girth, three feet from the ground, of 17 inches; (b) no tapping operations to be carried at a point higher than six feet from the ground; (c) tapping by bark excision of at least a quarter of the circumference of the tree in one season.

If disaster ever does come it will be brought about by the extension of the latter principle by greedy and impatient speculators, many of whom, having to justify inflated estimates in their prospectuses, are already planning to double the yield of their young trees in the first year of working by excising the bark of a full half of the tapping area, and trusting to luck for what may happen in consequence! 


\section{CHAPTER IV.}

\section{Hevea Brasiliensis.}

PREPARING A CLEARING-CLOSE AND WIDE PLANTINGTHE EFFECT OF WIND-HOLING AND WEEDINGMANURING.

I $\mathrm{N}$ speaking of a "clearing " one has in mind an area of stripped jungle such as is to be met with in the Mid-East, where the mass of alienated Para rubber is located. This work is most economically performed by contract, and the cost, which should include roading and draining, ought never to exceed $30 \mathrm{Rs}$. $\left(f^{2}\right)$ per acre. Operations are usually commenced in the dry season, so that the cleared land may be ready for planting during the rainy period that follows. Perhaps the most serious problem present-day planters are faced with in this connexion is that of the distance at which his trees should stand. It is a problem which for the last seven years has caused more controversy than any other question associated with the industry, and it is as burning a topic in the tropical bungalows to-day as ever it was, with never a sign of agreement in sight. The reason is not far to seek, and if there be any call to frame a complaint in the matter, it should be laid at the doors of the Kew authorities 
themselves, since they and they alone were responsible for the cultural policy associated with the introduction of the rubber tree into the Mid-East. But I am one of those who do not admit that there is blame to lay at anybody's door, because I regard the whole question of " close versus wide planting " as a more or less manufactured bogey. On the one hand we are warned against placing Para trees at distances less than 30 feet each way. Wickham himself told the writer that there was danger where Hevea was planted more than 40 to the acre, since at these intervals fungoid and other disease pests have less chance of contaminating, the roots have freer play, and the branches more elbow-room. Well, I have seen plantations set out on this scale, and I have the proprietor's authority to say that he is in perfect sympathy with me when I describe these trees as a disgrace to their kind and as the greatest botanical frauds that ever burdened a plantation. On the other hand, not many miles further on I saw a plantation of fifteen-year-old Para trees standing 8 feet by ro feet, tall, straight, and well boled, the most beautiful things the eye of a rubber man might behold, and I was not at all surprised to learn from the visiting agent that these trees gave over $6 \mathrm{lb}$. of dry rubber per year on the quarter half-herringbone system of tapping! Moreover, we have clamorous evidence in the Heneratgoda giant, a photograph of which appears as the frontispiece to this book. This tree stands less than 8 feet from its neighbours-all fine trees-in the plantation, and yields nearly roo $\mathrm{lb}$. of dry rubber per year ! 
What, then, is all this quarrelling about? Can anyone but the planter himself decide the quiestion? For instance, take the case of the planter who has occasion hourly to curse the genius who persuaded him to place his trees 30 feet apart. The land here lies on two hill slopes, the openings of which provide perfect pockets for every gust of wind which comes that way, with the result that for every day during the prevalence of the S.W. monsoons these poor trees are swept by the wickedest little toy-cyclones imaginable, whilst during the N.E. monsoons, through the vagaries of the opening at the other end of the range, this unfortunate plantation is deprived of fully 25 per cent. of its allotted rainfall, and the rubber only exists on sufferance in consequence.

I was able to convince my friend that in Brazil the seringueiro is not troubled in this respect with the torments of distances, for the Hevea brasiliensis although found but two to ten to the acre, is yet invariably so crowded on all sides by forest giants and undergrowths that it is often very difficult to obtain an adequate basal tapping of the tree. He has accordingly decided to carry out my suggestionsfirst, to blot out the wind scourge by planting up Darien Castilloa 20 deep across these openings, and then to fill up the intervals of the old plantation so that the trees are as nearly as possible i4 feet by 10 feet in the plantation. Let me at once say that to my mind this is the ideal distance at which Hevea brasiliensis should stand on sloping windswept ground. Where, however, the land is flat and 
sheltered they may be planted is feet apart each way. The Hevea cannot tolerate the wind. Under its influences the plant becomes stubborn and barkbound, and refuses to grow save in a fantastic fashion all its own, and in a manner inimical to any chance of its ever becoming a profitable tree. Hence the first principle in successful cultivation is the prevention of any wind exposure and the planting of the tree at distances in conformity with the lie of the land. This work should be undertaken as soon as the contractor can hand over the ground as it is cleared.

We begin by staking out the plantation with whitepainted "stubs" or sticks, which are placed just where the trees will stand, and always in an easterly by westerly direction. " Holing", is the next operation. This consists of the removal of a circle of earth around the mark stake at a diameter of I 8 inches and a depth of 9 inches. New soil is introduced, and well pulverised, and where the seed is raised direct and "sowing to stake" methods are in operation, the soil is carefully filled in, and the seed put $2 \frac{1}{2}$ inches deep, germination taking place generally in about 20 days. If " stumps " are used the shortened saplings-for such are stumps-are placed in the hole, the tap-root being allowed to lie in a narrow funnel of earth, so that the tender surface feeding rootlets rest evenly 6 inches from the surface, the soil of which must be well pressed down without unduly cramping the young plant.

When the plantation has received the final touches at the hands of the contractor, and the seed, or 


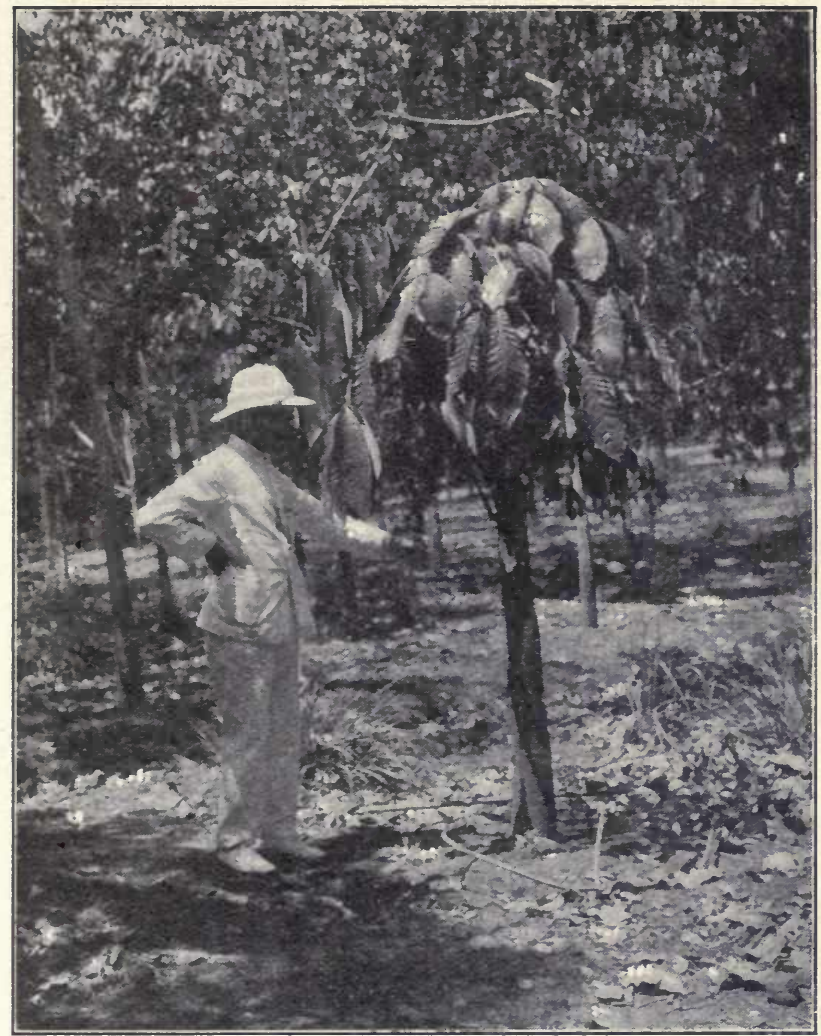

Para: Young trees decapitated by wind storm, having recovered, are throwing out vigorous healthy new growths. 
saplings, placed in position, it is then that the planter must exercise the greatest and most careful supervision in order to provide against animal and insect ravages, and the dangers arising from abnormal growth of the rank weeds and grasses that are always on hand ready to battle out the problem of existence with cultivated rubber. It is a good plan to weed around the plants at a diameter of 6 feet every month and to cut down every two months all other growth and lay it as top mulch over the roots of growing trees. Nothing benefits the plants so much as this treatment. At the end of the season the trees should be of a stature sufficient to enable them to take care of themselves for the next three months, when they will have attained an age of one year. This is the period when the proprietor should go carefully over his plantation and condemn out of hand all trees that have failed to " bole" or that show inclination to branch near the ground. These must be destroyed, together with any that exhibit signs of insect or fungoid ravages, and should be burnt straightway.

When the trees are six months old they may be manured lightly with potash conglomerates, or a mixture of lime, castor cake and basic slag. These should be " dusted " by hand over the whole line of rubber represented by a 3 -feet boundary of each side of the tree and be repeated every six months until the trees are $3 \frac{1}{2}$ years old, when they may safely be asked to live the remaining year of a playtime existence in a loyal endeavour to rejoice the heart of the patient planter when first he applies the knife at the experimental tapping stage. 


\section{CHAPTER V.}

\section{Trees that Count-Manihot Glaziovii.}

FLOURISHING IN ALIEN LANDS-THE MANIHOT AT HOME -A TREE FOR THE ENTERPRISING PLANTER-TREATING THE SEED-SOWING-THE YOUNG TREE-NO INTERPLANTING-HOW AND WHEN TO TAP.

$\mathrm{N}$ the fascinating annals of the Kew Experimental Gardens the Manihot Glaziovii will always take a foremost place, if only for the fact that it was the first rubber tree to show flower and to produce its latex in the Middle East.

The plant was added to the Kew catalogue on 23 November 1876 , when Mr. Cross safely deposited at the Gardens his collection obtained on behalf of the Government of India at Maracanahu, thirty miles from the town of Ceara, North-East Brazil. The collection comprised some sixty plants, or rooted stems, and 700 seeds. On II June the following year the authorities were able to distribute their original stock, raised both from seed and cuttings. Singapore received the first consignment, of four plants only, but by the end of September several hundreds more were available for distribution, and supplies were accordingly despatched to Calcutta, Ceylon, and Madras. In Ceylon the plant appears 
to have very quickly manifested its remarkable powers, for in April 1878 it began to flower, and by the end of the year Dr. Thwaites, who was then in charge of the Botanical Gardens there, was distributing copious supplies of seeds to Burmah, Madras, and Singapore, all produced from the fifty plants sent from Kew in September I 877. Meantime, living plants of Manihot having been despatched from England to Fiji Islands, Jamaica, Dominica, Java, Sydney, Trinidad, Queensland, and Zanzibar, the Kew authorities regarded their work finished as regards the Ceara rubber, and were content to await results of their labours from reports as to the behaviour of the tree throughout the wide extent of the alien lands to which it had been despatched.

Many of these reports were subsequently incorpor. ated in the familiar Kew "Bulletins " which appear from time to time. They were unanimous in praise of the Manihot as a hardy precocious plant adaptable to any soil, capable of withstanding great drought and yet providing withal a most valuable asset in any scheme of tropical plantation work. It is interesting to record that at this period experiments which were carried out in the Straits Settlements, and which should have at the most merely settled once and for all the oft-disputed point as to whether or no the Hevea and Manihot can flourish together on soil and in situations suitable to the first-named, were regarded by the authorities in the light of a verdict for the rejection of the Manihot in favour of the Hevea. The former was found to be utterly unsuitable for the damp moist lands of these parts, 
and at Singapore particularly it was a complete failure. Nevertheless, many of the planters to whom the tree had been originally introduced placed it afterwards on the heights as a shading to their main crops, without the slightest regard to its utility as a rubber-producer. They were agreeably astonished to find that it soon beat the Hevea standing in the lower situations both in growth and productiveness. In these respects the plant was simply maintaining its native reputation.

Manihot Glaziovii is a euphorbiaceous plant. It was described by Mueller in Martius' "Flora Brasiliensis " and identified by the botanist Dr. Glaziow (after whom the species is named), who had it under cultivation at Rio de Janeiro, whence he sent specimens to Kew for study and confirmation as to its order and family in the botanical world. Under cultivation the tree attains a height of about 30 feet ; the bark is purple-grey, and when fully grown the stem resembles that of the birch, especially in its habit of a periodical peeling of the outer bark.

In its native habitat Manihot Glaziovii delights in the dry, arid climate that is a feature of the Sertao or wilderness of the Ceara region. Here Cross found it flourishing in situations where almost every other form of vegetation had ceased to exist. He tells us that he found at Pacatuba, about forty miles from Ceara (the actual place where some of his specimens were obtained), "the forest tolerably high, but the sparse, small foliage did not afford much shade from the fierce rays of the sun. The soil was in places a sort of soft sandstone or gravel, which was bound up 
in the most extraordinary manner. Neither grass nor weeds grew among this underwood, and there was an entire absence of ferns, mosses, and other plants ". Further inland, Mr. Cross came (as he says) upon " a large tract of land covered by immense masses of grey granite, some of which might be fifty tons or more in weight. Rounded masses of the same rock also cropped out in many places, and many good-sized trees were growing in the spaces between these granite masses. The situation was very dry, but no doubt some seedlings had sprung up which, owing to numerous thickets of shrubs, were not perceived ".

The late Dr. Trimen was in charge of the Peradeniya Gardens, Ceylon, when the Manihot was first introduced into the island. He became enamoured of it, and in a Sessional paper he bears out the statements of $\mathrm{Mr}$. Cross respecting the general behaviour of the tree, concerning which he says: " Experience of the plant in the botanic garden here has proved the general accuracy of his (Mr. Cross') remarks. There can be no doubt of the hardiness of the species, its readiness of culture and adaptability to circumstances. It grows equally readily from seed or from cuttings, and thrives well here in Ceylon up to at least a level of 3000 feet and on the most barren soils.

" It would seem specially adapted for the dry and barren districts of our Eastern and Northern provinces or in the higher districts, but it would not be wise to risk it in localities where, the temperature is liable to fall below $60^{\circ} \mathrm{F}$." 
It is not surprising to find that Cross himself possessed the profoundest faith in its adaptability to any and every circumstance obtaining in the rubber zone. In his report to Kew he suggests " the formation of plantations by cuttings, which will take root as easily as a willow. These should be taken from the points of strong shoots and may be one foot in length. In planting, each cutting may be put down in the soil to a depth of six inches. If scarce, the entire shoot may be cut into pieces, each possessing a bud, all of which will grow if covered with half an inch or so of soil. On loose sandy soils or exhausted coffee land plantations may be formed at little expense. Hard, dry, gravelly wastes, if found to support any kind of bush, are also suitable sites. On bare or thinly covered portions of rock the cuttings might be laid down flat and a little heap of stones or any kind of débris about the size of a molehill piled over each, care being taken that the extreme point of each cutting with a bud is left uncovered. With an occasional sprinkling from a monsoon shower the tree is likely to prosper ".

Compare this with the hazardous methods associated with the propagation of Hevea plants, which are also extremely difficult to raise from cuttings, and it will be readily conceded that the Manihot Glaziovii is pre-eminently a tree for the enterprising planter who has neither overwhelming riches in the land he owns nor a chronically swollen balance at the bank.

Manihot Glaziovii produces its seed abundantly, D 2 
usually beginning in its third year. The seedcoat is of remarkable thickness, very tough and hard, and if not properly understood germination is long and difficult. Accordingly the art of raising the plant from seed was for many years a sealed book to many people who desired to introduce the tree to agriculturists in the tropical zone.

In Ceylon splitting the seed-coat was tried, but it was not a great success. This was effected by rasping off with a file the radicule edges of the seed. It required much skill and care, as if the ends were cut off, the embryo was of course injured and the seed effectually destroyed. At Beira I have seen the difficulty overcome in an original if hardly commendable manner. Here the Portuguese planter distributed his seed to the native workers (man, woman and child were alike favoured), who were instructed to carry the seed in their mouths all day and every day until salivation had made them amenable to ready and rapid germination. Usually this novel preparation lasted a whole week, and it was amusing to watch the aviado carefully check over the seed returned at the end of the period, which was generally six or seven days, and woe betide any unfortunate native who had surreptitiously disposed of any of those not over-delicate morsels.

One of the most effective ways of preparing the seed for cultivation is to soak them in a weak solution of warm soda-water for a few hours, and then place them in pure water for three or four days, when they will be found quite soft and ready for immediate propagation. 
Another excellent method is to spread the seed upon felt or any blanket material that has been previously well damped; cover the whole with a sheet of corrugated iron raised a few inches from the ground, and expose to the sun. Sprouting will generally take place in a few days, when the seeds will be ready for planting.

In " sowing to stake "-which, in other words, means putting the seed into the actual position in the plantation where it is destined to remain and become the mature tree, a system largely followed in East Africa-the ground must first be cleared. It is then measured and "lined". Lining is the process of marking out the place and distances at which the tree is to grow. This having been accomplished, the workers should be marshalled in rows equal to the distances of the "lining ". Thus, if the Manihot is to grow 8 feet by 8 feet, the workers will line the field 8 feet apart, each with his cultivator in hand. He commences at the extreme end of the plantation, "dibs" two holes 4 inches deep and paces forward another 8 feet, and so on until the line is completed. Immediately following the " dibber" is the woman or boy with the seed, two of which are dropped into the ground and the soil replaced with the foot. In this way plantations are very quickly sown.

When the young plants are 6 to 8 inches high the stronger of the pair is allowed to remain, whilst the other is taken away and set out in another plantation. They make rapid growth, often reaching 20 feet in eight months. A careful planter will tend 
his ground in such a manner as to ensure a long bole to every tree, and a vigorous use of the pruning-knife to all growth that threatens to develop early branches will be necessary. This should be done when the tree is "resting" and the leaf falling. It sometimes occurs that here and there an individual tree will exhibit signs of stagnation of growth in the bole whilst at the same time a vigorous development of the lower branches is apparent. When this happens the soil should be removed from the base of the plant and the roots, which consist of a number of bulbous, starch-filled textures, examined. All those which have developed the slightest deformity should be cut out and the soil replaced. Root-tapping and root-pruning in this way is also a fine and certain corrective to trees that have grown stubborn and refuse to give their latex, which now and again happens in cases where the Manihot is living in over-rich or over-damp soil. At this stage, and right onward until the tree is $2 \frac{1}{2}$ years old, light manuring with potash mixtures and kainit is to be recommended.

The Manihot Glaziovii, like all good rubber trees, does not in the early stage of its growth relish a strong wind, and where this is persistent for any length of time the plant will often refuse to yield. To obviate this, an excellent plan is to plant clumps of the tree on the windward side of the plantation, and thin out to the usual distances when the trees have attained a sturdy stature. Where the land has been originally forest a narrow belt of 
trees should be allowed to remain all round the plantation as a wind-screen.

Weeding is generally regarded as a troublesome and expensive factor in the management of plantation rubber, but in the case of the Manihot it never need cause a moment's anxiety. Where the tree is planted at the proper distances (not less than 500 to the acre) weeds find existence a terrible struggle, and after a short season's effort they give it up. Of course there will always appear a certain amount of undergrowth, which is desirable, as it conserves the soil in the rainy season, and when cut down provides splendid top-dressing or mulch for the free-feeding roots of the tree itself, which also relishes a moderate manuring now and again with slaked lime just before the rainy season commences.

Interplanting, especially in the case of the Manihot, should be avoided. The tree is intolerant of a surrounding subsidiary crop, and, even if this were not the case, interplanted rubber never yet paid the cost of the labour expended upon it.

When the trees have attained an age of two years they should be individually measured and gauged, both as to height approximately and girth actually. If the trees have gone on the right way they will show a minimum height of ${ }_{15}$ feet and a girth of at least 16 inches three feet from the base. But in the main the plantation will present a mass of stalwart Manihots 25 to 30 feet high and possessing an average waist girth of 18 inches. In the third year the tree will produce its seed abundantly, and when the trunk shows a measurement of anything between 


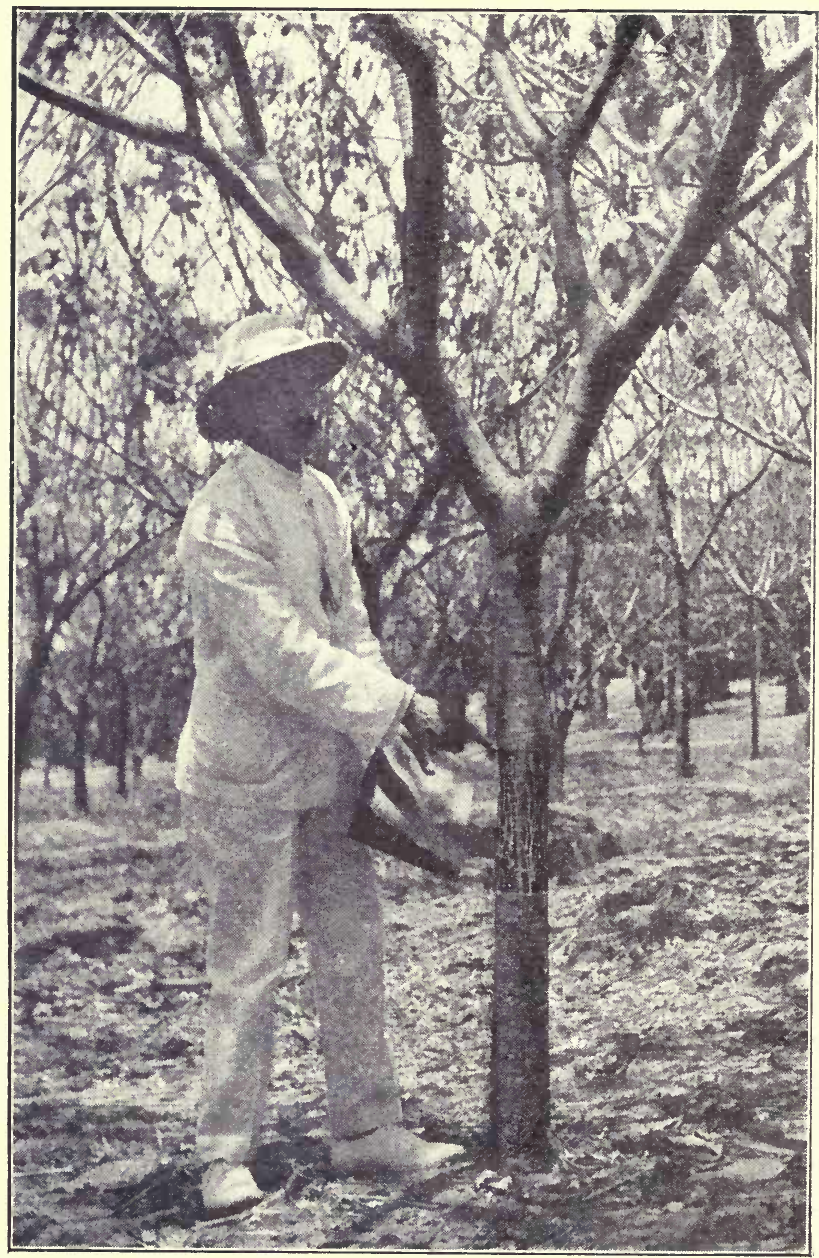

The Author showing the correct way to tap M. Glaziovii, Bark first taken off: inner bark containing latex immediately tapped by pricking. 


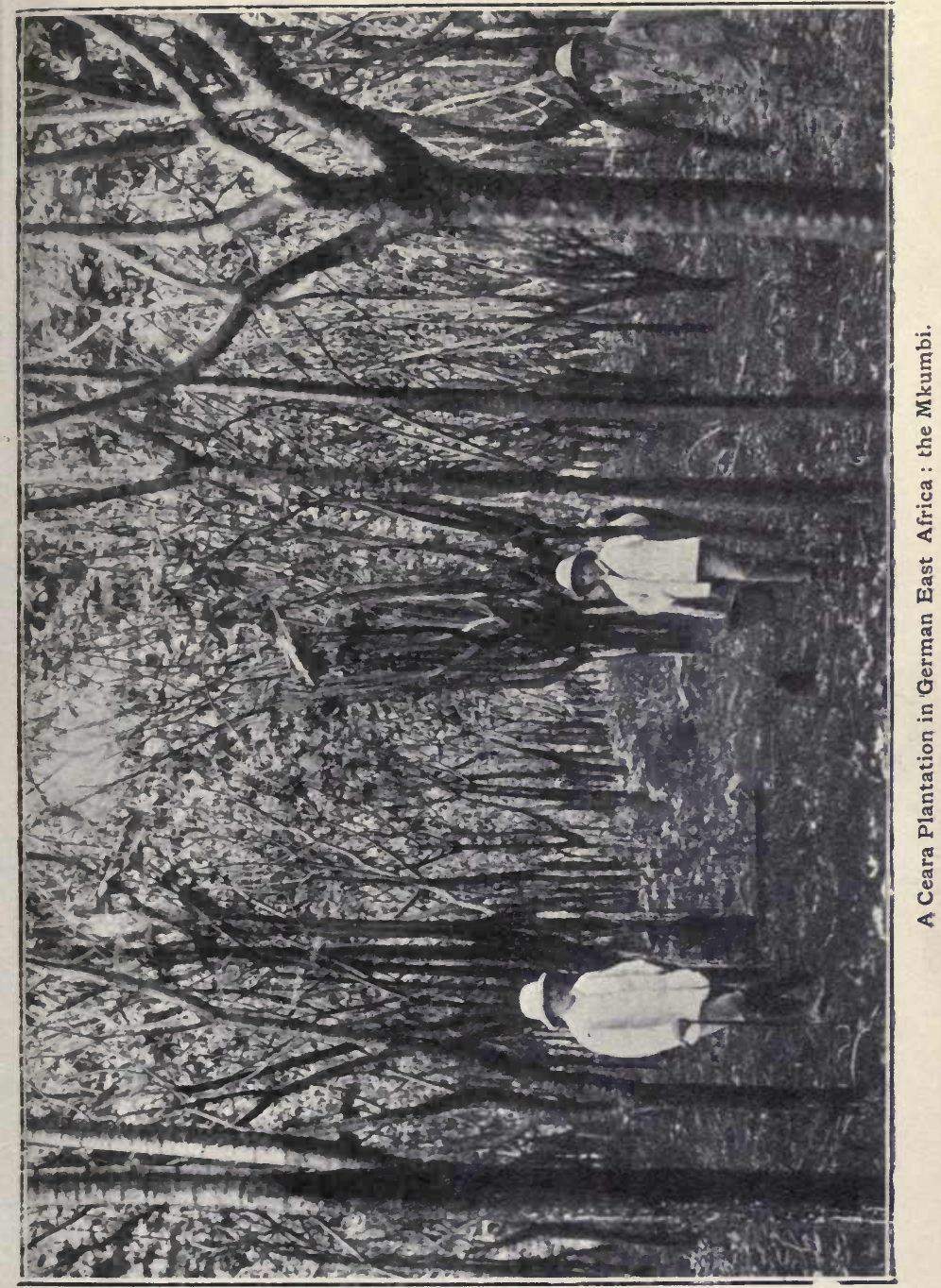


17 inches and 20 inches it may safely be tapped. These initial tappings must be undertaken with care and system. It is not advisable to attack the tree at this stage as though it were a milch cow, although later on the Manihot will delight in repeated tappings: in return for which it will always give of its best, whereas it deliberately " sulks " in cases where only haphazard and uncertain visits of the operator are the rule.

Initial tapping is best performed by first removing the outer bark in a circle six inches wide on the portion of the trunk 24 inches from the base of the tree. The exposed bark, which will show green and be tender to the touch, can be then lightly pricked in a series of small punctures at $\frac{1}{2}$ inch distances all round the tree, the latex being allowed to run down and coagulate on the bark. This is what may be termed "proving the Manihot," for on the results of these initial operations depends the after manipulation of the tree in the general exploitation of the plantation.

Approaching its fourth year the Manihot usually puts on a pronounced appearance of maturity, and, other things being equal, the tree may then be subjected to the rigorous treatment to which it naturally lends itself. Tapping may be performed twice a year - viz. before the fall of the leaf and after, or it may be carried on as long as the exigencies of labour permit over a period of a hundred or more days. In either case it will be found that in a general way the tree will not object, but on the other hand yield copiously as long as there is any substance in the 
lactiferous vessels. Here is a system in vogue in German East Africa. The inner bark, having first been dressed with a rubbing of the flesh of a fresh gathered lime, is pricked as already described. The latex coagulates as it runs down the bark, and is afterwards collected in the form of " scrap ", taken to the factory and ultimately turned out as smoked sheet, crêpe, or block as desired. Both the Mkumbi and the Manihot Rubber Estates are now marketing their Ceara rubber in this form.

The Manihot always produces its best and largest quantity of latex during a drought. It often happens that attempts to tap the tree in the rainy season result in apparent complete sterilisation. It is a good plan then to expose and tap severely the largest of the bulbous roots. An excellent flow of latex generally results, and the tree is not affected in any way by such drastic treatment, providing the operation is carefully performed and the roots well covered up afterwards. 
CHAPTER VI.

\section{Trees that Count-Manihot Glaziovii.}

TAPPING FREAKS IN CEYLON-PROPAGATION IN INDIA, EAST AFRICA AND ELSEWHERE-EXPERIMENTS - THE WEST INDIES, HAWAII, AND CEYLONPECULIAR HABITS OF THE MANIHOT-PROPAGATION AND RATE OF GROWTH-VALUE TO THE MANUFACTURER.

FOR many years the Manihot was cultivated with much energy in the island of Ceylon. But owing to a lack of knowledge in tapping the tree it was rejected, and ultimately large areas were grubbed up to make room for tea and other favoured crops.

We have evidence of this from the authorities themselves. For instance, in his report for the year I 883 Dr. Trimen speaks of the plant thriving on the new estates in the Trincomalee district, and further on says: "A planted area of 977 acres is credited to this cultivation, but rubber has not yet appeared among our exports ". At that time the cultivators were, he tells us, quite convinced of the excellent quality of Ceara rubber, but they had not yet discovered a means by which the milk could be obtained at a cost sufficiently low to give a return with encouraging results.

As already described, it is the custom to re- 
move the outer bark (which is usually a thin, peely, separable substance) of the Manihot in tapping, and to expose the under bark for the actual incisions. In its native habitat the wound is always found to heal rapidly and to produce a new bark exactly uniform in character with the original. But in many cases of these alienated plants a strange freak of nature invariably happened in connexion with this operation. It was found that on healing taking place the new bark was of a totally different character. It was a much darker colour, very thick and coarse and hard, and quite inseparable a second time from the green layer beneath. Here, then, was a botanical puzzle which baffled the most experienced, and would have perplexed a Ceara State seringueiro could he have seen it. Moreover, the tree had now apparently become quite useless as a rubber-producer, since none of the existing tools were of any avail in extracting the latex to an appreciable amount. One experimenter, however, tried repeated " prickings " of hundreds of young trees daily for over 200 days, and was rewarded with an average yield that clearly demonstrated the futility of the older methods, and at the same time pointed the way to a system which would enable the trees, many of which were now six years old and therefore at their prime, to live up to the character they had earned in other parts of the world. Subsequently various instruments were devised for tapping without removal of the bark, but they never came into general use. Discarding the knife altogether, many planters were content to remove the outer bark in vertical strips of not more than 2 inches 
wide and not less than 4 inches apart. The exposed bark, being green and tender, was then blistered by the sun and the latex allowed to exude from the wound. In this way as much as a pound of dry rubber of a sort (dirty of course, and imperfectly coagulated) has been gathered from three-year-old trees. This system had the advantage over the plan of knife excisions in that the bark closed up in the course of the year and retained all its old characteristics as to colour, texture, and general appearance. In short, the tree remained a true Manihot Glaziovii, and did not deteriorate as its compeers had done into a mere botanical parasol for keeping the fierce rays of the sun from the tenderer plants around.

The Indian Government, through its Agricultural Department, evidently having the results of these experiments in mind, strongly urged in $188_{3}$ the planting-up of the large areas, then in private hands and growing nothing but lantana and weeds, with the Manihot Glaziovii. But the advice was not followed, and in 1890 Dr. Trimen was forced to admit in his report for that year that interest in Ceara rubber had very much died away in Ceylon. Only trees that had attained an age of eight years were operated on and not more than $3 \mathrm{oz}$. of dry rubber taken therefrom. A ten-year-old tree was expected to give $\frac{1}{2} \mathrm{lb}$. only. When the planter had obtained these averages he religiously left the trees alone until another year or, it may be, two years. He selected the wet season (June to October) for the work. The outer layers of bark were peeled off, the inner bark stabbed or hacked carelessly until the $3 \mathrm{oz}$. or the $\frac{1}{2} \mathrm{lb}$., as 


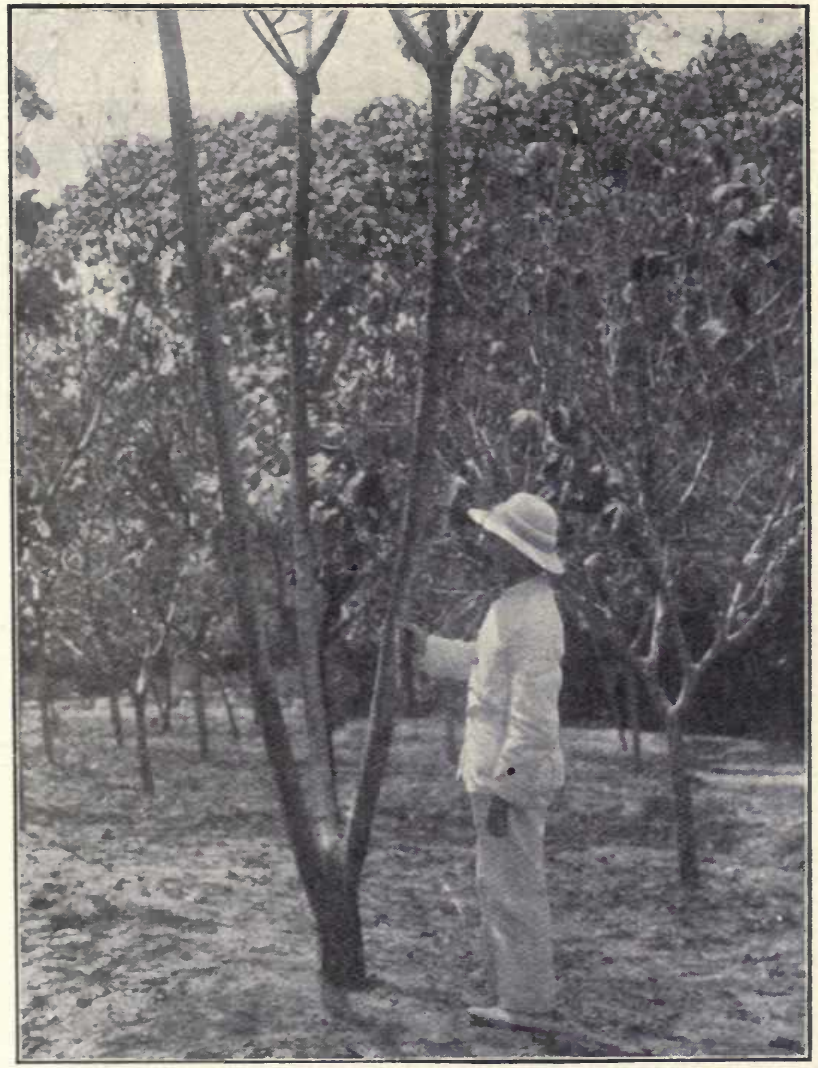

Ceara Trees: How not to gtow Ceara. This plant was placed out as a stump, with result it commenced to fork. Ceara should be grown from " seed at stake." 
the case may be, were gathered. It never occurred to him that the poor tree itself ought to have some say in the business, or that perhaps a mometee was not the most dignified of tools wherewith to tap a rubber tree.

So much for Ceara in Ceylon. Fortunately for the future of Manihot Glaziovii in the Mid-East a different story can be told of it in the plantations of Southern India, Burma, and East Africa, where the plant had also been introduced. In Madras (in the Nilgiris) the Manihot soon proved its sterling qualities planted at a height of 2400 feet. In two years it had attained a stature of 30 feet, and the following year presented a girth 3 feet from the yround of over 20 inches, and was therefore ready for tapping. Similar results were experienced in South Malabar, where at Nilambúr the tree was impatient to produce itself everywhere.

With regard to Mysore, Mr. J. Cameron has placed on record an interesting statement of his own experience with the Manihot in his " Report on the Lal Bagh Gardens ", dated April i886: “Further experience " (he tells us) " has justified my opinion that the Ceara rubber tree is adapted to the climate. Its cultivation progresses so favourably that every encouragement is offered to plant on an extensive scale. The tree loses its leaves during the driest period of the year, and is thus preserved in a semidormant state until the vernal showers excite growth again. Judging from our own experience, the Ceara rubber tree requires no pampered treatment, although, like most plants, it prefers a little kind- 
ness to starvation and utter neglect. It grows very rapidly in vegetable mould, but, planted in any ordinary soil at the break of the south-west monsoon, the seedling will shift for itself, and possibly have taken such a hold on the ground that no artificial watering is required during the subsequent dry season. This is what I have done with a hundred seedlings six months old on poor, gravelly soil, and I am certain that nearly the whole will burst forth into fresh growth when the rain sets in."

In Mauritius the Manihot, which was introduced into the gardens at Pamplemousses in $188_{3}$, made extraordinary progress. The late Mr. Scott made many interesting experiments with them whilst in charge of the gardens there. He tells us that he lifted many of the trees when they were three years old. " When they had shed their leaves " (he says) "they were lifted carefully, but without balls of earth attached to the roots, and planted in another part of the plantation. These transplants all held, and although they have not made such a strong growth as the other trees, it proves that this tree can be transplanted with impunity."

Furthermore, Mr. Scott gives proof of the remarkable facility with which the Manihot lends itself to propagation. During the season when the trees were at rest he cut them back to within 3 feet of the ground, and the stems, some of which were 8 feet long, were cut into lengths of 6 inches, tied up in grass-enveloped balls of earth and then set out in beds under shade. Here they soon formed rootlets, and threw up a fine sturdy stem, when they were at 
once planted out. In this way nearly 6000 plants were obtained for distribution in other parts of the iisland.

The behaviour of the Manihot Glaziovii under cultivation in the West Indies was originally so satisfactory that it is astonishing planters did not take the trouble to test its capabilities over a wider area than was actually the case. Operations seem to have been principally confined to the various experimental gardens, although in Dominica several hundred acres were put down to Ceara and prospered abundantly.

Both Mr. Esme Howard and Dr. Biffen, who had travelled extensively throughout Brazil and Mexico examining the habits of the different rubber plants on behalf of the British authorities, strongly urged the widest possible cultivation of the Manihot in the West Indies.

In Ceara itself they purchased many thousands of the seeds of the tree solely for distribution among the planters in these possessions. They had seen the plant growing well on hillsides on poor soil 3600 feet above sea-level, and flourishing under a singularly wide range of conditions, which included desert plains where the rainfall was less than $5^{\circ}$ inches and the vegetation scorched up for the greater part of the year, and also on mountains like Monte Alegre, where the rainfall is over Ioo inches and the temperature falls below $60^{\circ} \mathrm{F}$. at night. Although supplementary to the labours of Messrs. Cross and Wickham, the observations of these distinguished botanists were not in vain, for it is 
mainly due to their discoveries and to the strenuous investigations of certain German experts that the United States authorities were led to embark upon those remarkable experiments which are recorded periodically in the "Hawaiian Agricultural Bulletins ", and upon which the local planters now rely for most of the data for carrying on their work. We learn from these experiments a great deal concerning the results of various modes of tapping to which trees of different ages were subjected, but unfortunately we get nothing definite or conclusive as to which system might be accepted as the standard for general adoption.

Many of these experiments were carried out quite as recently as 1906. An estate in the island of Kauai was selected, a grove at Koloa possessing trees thirteen years old being marked in juxtaposition to another at Lihue, where the trees were seven years old and under. Funds, were subscribed locally, preliminary operations being confined to the testing and determining of tapping tools, latex cups, etc.

The first experiments were directed to the tapping of a few isolated trees not more than four years old. Two of these were tapped for nine days consecutively, and yielded $12 \frac{1}{4} \mathrm{oz}$. of dry rubber. In June a number of four-year-old trees averaging 19 inches in circumference were tapped for nine days, and yielded $\frac{1}{2}$ lb. of dry rubber. These trees were entirely bare. It was found that the Manihot is peculiarly susceptible to atmospheric influences so far as the flow of the latex is concerned. Trees tapped at midday or in the afternoon yielded almost no latex, whilst 
at sundown there was apparently a great increase of tension, as the latex always flowed more abundantly at that time. The general results in this particular case showed that four-year-old trees yielded at the rate of $10 \mathrm{oz}$. of dry rubber per tree, whilst those of seven years yielded as much as io $1 \mathrm{~b}$. per tree on an average. The thirteen-year-old trees at Koloa gave as much as ${ }_{5} \mathrm{lb}$. These trees were in a swampy situation, whilst those at Lihue, yielding quite as satisfactorily, were choked with guava and lantana and overrun with vines. All the tappings were made when the trees were at rest and bare of leaves. At a trunk diameter of 7 inches or 8 inches many of these trees yielded an enormous quantity of rubber.

It was found that the peculiar habit that the Manihot possesses of shedding its leaves and remaining bare for two or three months in the year was here a pronounced feature of the tree. At the end of the resting period, however, the renewed vigour thus gained was exhibited in a remarkable fashion. Both leaves and flowers burst forth almost simultaneously, and the tree put on a rapid growth.

At Lihue itself a small staff devoted their attention solely to the habits of the growing trees. The grove here is surrounded by a forest, a stream running through the land preserving it for the greater part of the year in a moist and swampy state. The trees were found to vary in size from a circumference of trunk of only 6 inches to 30 inches three feet from the ground. No care appears to have been taken of the trees during the entire period of their growth. 


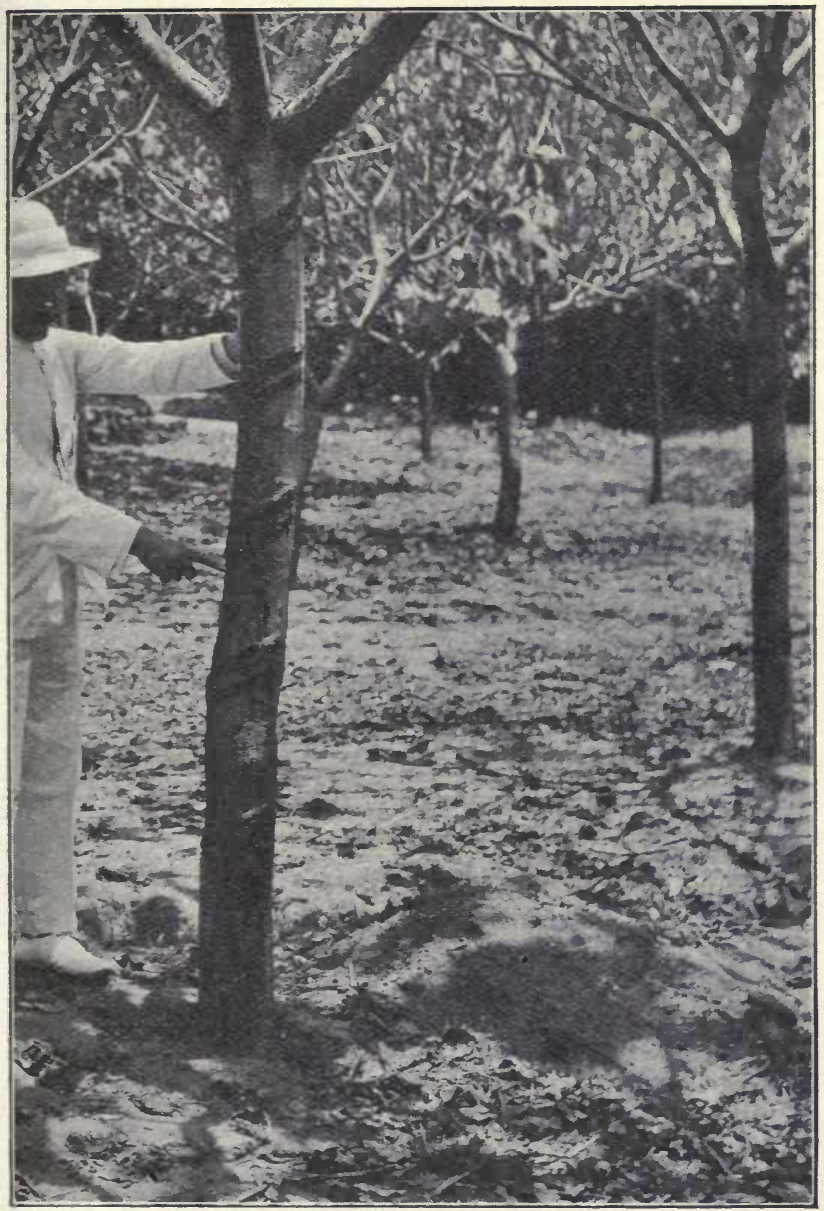

Ceara Tree: How not to tap; effect of bark excision on young tree 2 years 4 months old. Note distortion of trunk. Spiral system employed. 
Many of them showed a clean straight bole of 20 feet, which is typical of the well-grown Manilot, whilst others had branched at 4 feet from the ground, and were dwarfed and bent in consequence. Seventy per cent. of the whole were found suitable for tapping. The kind of knives used for tapping Hevea in Ceylon were found to be useless at Hawaii owing to the fine texture of the outer bark of the Manihot, and a special form of cutter had to be devised. After many experiments the half-herring-bone system was adopted, the full herring-bone being found to result in the partial strangulation of all the milk-yielding vessels situated between the upper and lower laterals. The half-herring-bone system, as is well known, consists of one vertical cut, with the laterals I 2 inches apart halfway round the tree. As in the case of all true Manihots, the latex was found to coagulate very quickly - almost immediately-on the opening of the laterals. To prevent this a system of water-dripping over the cut surface was tried with some success, but it was found that by the addition of a small proportion of ammonia to the water coagulation was entirely suspended for several days. Tapping was always done either in the early morning or late in the evening, and in a general way it was found that the flow of the latex was more certain, more uniform, and greater in output at the evening tappings.

Manihot is propagated either by seeds or cuttings. In East Africa the latter method is preferred. The cuttings are taken from the bestgrown trees. They should not exceed seven-eighths 
of an inch in diameter and a foot in length. But the top and bottom of the cutting should show the bud or leaf scar close to the terminal ends, the bottom bud being buried two inches in the soil and the terminal above ground dressed with white lead (in a thin coat) or paraffin to prevent canker and decay. They should be set out 6 inches apart in rows 2 feet wide, and shaded for the first few days if possible, although this is not absolutely necessary where cuttings are plentiful and the rainfall not too heavy.

In the Philippines it is the custom to protect the seed beds and newly planted areas by sowing among the rubber a crop of corn or palay. This provides shade, prevents washing of the soil by the rains, and at the same time obviates weeding. From an economic point of view this is an enticing departure in rubber culture, as palay is a very profitable crop, but it cannot be interplanted with rubber that has entered upon a second year's growth. If planted in over-rich soil Manihot invariably shows a marked tendency to branch low down, which spoils its appearance and depreciates its value as a latex-yielder. But if it be planted on hard ground, it throws up a fine long bole 9 feet to ro feet in length before it begins to branch at all.

That Ceara will yield at two years of age has been proved at Witu, East Africa, and on the San Nicolas Plantations, Nicaragua (Central America). From a report on the latter experimental station we gather that twenty-one trees aged fourteen to twenty-one months, with an average age of eighteen months, were tapped, and gave together $7 \frac{1}{2} \mathrm{lb}$. of dry rubber. 
A tree fifteen months old gave $5 \mathrm{oz}$. of rubber. Many other trees were subjected to similar trials with like results. In all cases the large $\mathrm{V}$ cut, which Central Americans invariably apply to all their rubber trees irrespective of species, was used, and the latex collected as scrap in the manner familiar to the seringhals of Brazil.

The average rate of growth of the Manihot Glaziovii is well illustrated by the following table of a return provided by the Ceylon authorities some time ago. The rate of growth and development is for the first five years.

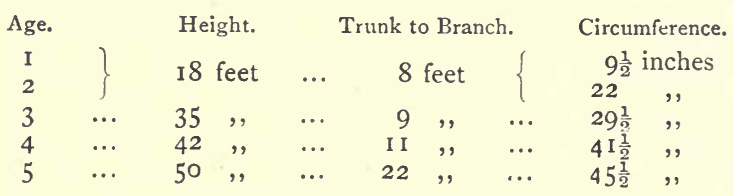

In a general way tapping of this tree commences when it is 22 inches in circumference. A reference to the above table shows that this measurement was attained when the trees were just two years old.

The botanical points of the Manihot are sharply defined and therefore readily distinguished from those of any other rubber tree. It is of moderate size, from 30 feet to 58 feet high and 8 inches to 24 inches in diameter. The leaves are palmate, cut somewhat deeply into three, five or seven oblongovate lobes, smooth on both surfaces, thin in texture, deep bluishgreen above and light beneath. The flowers are large, unisexual and very numerous. The fruit is a 


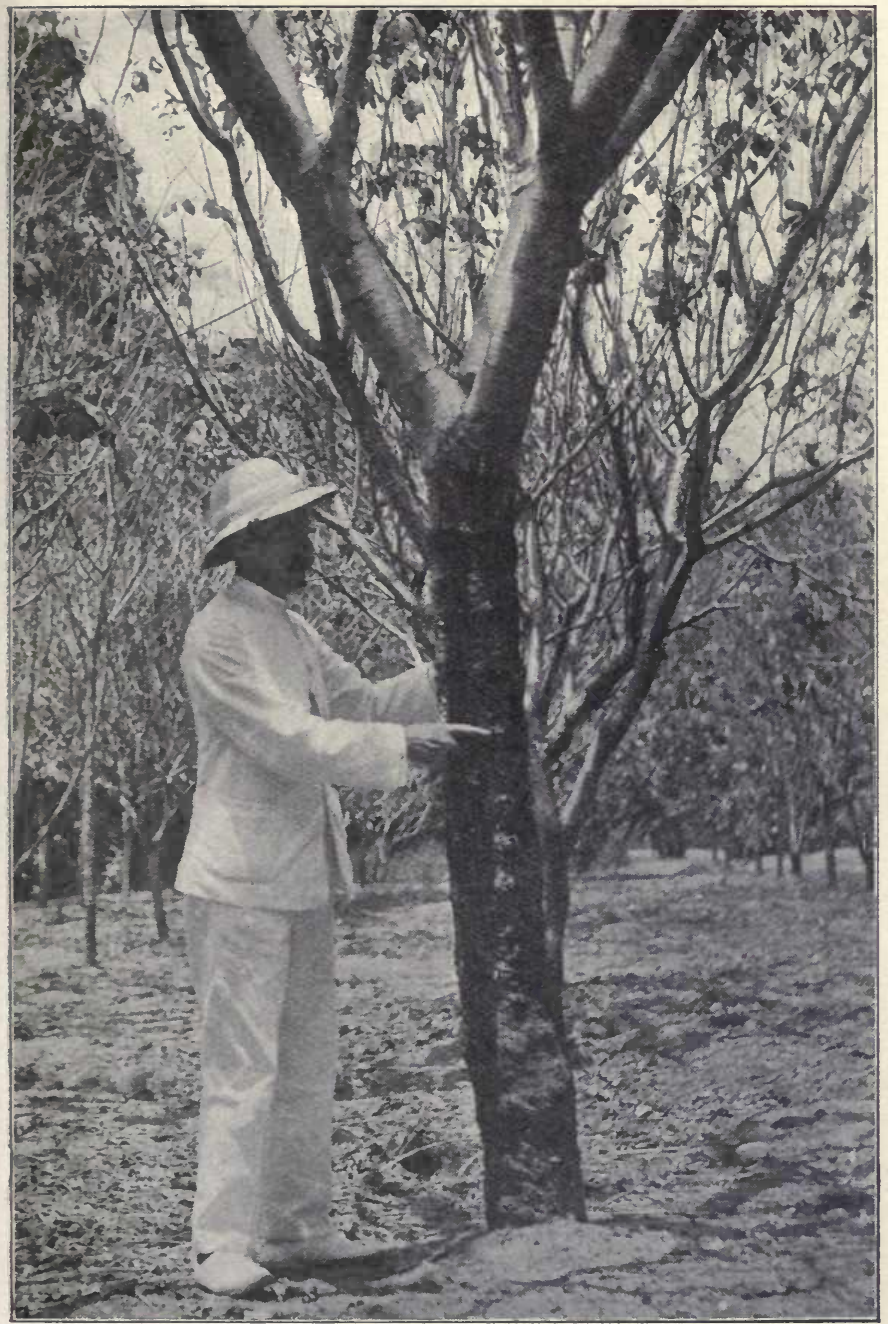

Ceara Tree : 2 years old. First deprived of outer bark; when weeks later the inner bark had hardened by exposure to sun and air, the tree was subjected to vertical bark excision but refused to yield latex. 
round capsule, less than I inch in diameter, containing three polished seeds mottled in colour. The coat of the seed is very hard. Its fertility is much greater than that of any other rubber tree. The seed capsule explodes under the influence of very dry weather, and the seed is thereby scattered great distances. The product of the Manihot is known to commerce under the name of "Ceara scrap ". The definition correctly describes the crude, simple manner in which the latex of the Manihot is gathered in Brazil. Before beginning his labours the collector sweeps the rubbish from the base of the tree, and after stripping off the thin outer bark to as high as he can reach, he hacks and cuts the exposed surface, and allows the latex to trickle in tears about the trunk and on the ground round about. Coagulation takes place rapidly by natural means, the collector generally allowing one or two days to elapse before gathering the rubber for market. Manipulated in this fashion, it is of course full of impurities, and graded by the factors. accordingly.

Nevertheless, it is a rubber that is highly esteemed by the manufacturer. When turned out in a clean, sensible fashion Ceara rubber possesses a beautiful amber colour and is nearly transparent, a property which cannot be claimed on behalf of any other kind of rubber. It is indisputable, moreover, that the latex of the Manihot is at least equal if not superior to that of the Hevea (Para). It contains less moisture and fewer of those nitrogenous substances which produce tackiness and decomposition of the article by fermentation. 
On that account it is in great demand by tyre manufacturers and others who require a rubber adaptable to hard usage. There is not the slightest doubt that the Ceara tree will be very extensively planted during the next few years. 


\section{CHAPTER VII. \\ Manihot Glaziovii.}

SOVEREIGNTY AS PLANTATION RUBBER-PLANTING AND ENVIRONMENT-TAPPING METHODS.

THE Manihot Glaziovii, strange as it may appear, plantation rubber than does the Hevea or Para rubber tree, and it is therefore astonishing to find existing throughout the whole of the MidEast a grounded prejudice against this valuable and exceedingly profitable tree. Especially was this the case among planters in Ceylon, where, strange to say, notwithstanding the fact that Manihot Glaziovii found its primary alienation in the island as long ago as 1876 , and hundreds of acres have actually been laid down to its exploitation, there existed an absence of the practical knowledge required in the cultivation of Ceara rubber generally. I found this intensified in the case of an estate I visited in the Kurunegalle district, which contained a very large number of these trees, of a good age and valuable as rubber producers. I was informed by the superintendent that they were chiefly used for firewood! He admitted that they produced a splendid rubber, but owing to the ignorance of the 
method of dealing with the tree it had been condemned and was giving place to Hevea.

After making careful inquiries in other districts, I found that the real cause why these unfortunate trees had been condemned was that the planter, after having got his tree to maturity, did not know what to do with it; and there appeared to be nobody who could assist him in the matter. The areas of Ceara rubber that would be priceless now as producing lands had been sacrificed to this want of knowledge.

From my own observation I should say that the existing tree is not that introduced into Ceylon by the botanist Cross, but is from seed obtained very largely in the Rio de Janeiro district, with the result that most of the Ceara in Ceylon is of a hybrid character, and therefore the true Manihot is only to be met with in a few isolated districts. It is, nevertheless, a very good tree, and, if properly handled, will always be more profitable to the planter than any other kind of rubber he can grow, provided that the climate and other conditions are suitable.

The best altitude for Ceara rubber is from 800 feet to 3700 feet; it requires to be closely planted-at least 600 to the acre. It does not like its " feet wet ", or, in other words, it requires full measure of $5^{2}$ inches of rain, but delights in four or five months of dry, hot weather. It is rather intolerant of wind, and, being a very quick grower, will shoot from 12 to 18 feet in a year from seed at stake! It is a good plan, as already stated, to provide wind belts on all exposed positions by planting the Darien 
Castilloa rubber, which is the Castilloa now growing in Ceylon.

After the ground is cleared, all dead wood should be burnt; then follows the planting, made for preference direct from seed at least two years old and which has undergone six or seven days' soaking in tepid water to soften the tough outer coatings. In about eighteen days the cotyledons make their appearance. Thereafter growth, under normal conditions, is rapid and continuous, and with a plentiful falling of the weeds and undergrowth around the young roots, as mulch and top-dressing, the trees will have no difficulty in attaining during the first year sufficient stature to ensure their arriving at the tapping stage in the third year from planting.

There should not be the slightest difficulty associated with the tapping of this tree; yet throughout both Ceylon and Southern India planters unanimously agree that this difficulty does exist, and to such purpose that any attempt to exploit Ceara on the lines that the Hevea is exploited-viz. by bark excision and herring-bone cuts-invariably results in the death of the tree. This is not surprising when we remember that the Manihot Glaziovii does $n \cdot t$ possess a bark that permits excision without endangering its very existence. It possesses a twinbark. The outer one, which might be termed the " mother" of the tree, is a thin but tough papery structure $\frac{1}{8}$-inch thick, while the other is merely a kind of semi-transparent green bandage that keeps the lactiferous vessels from swelling and bursting when exposed to the air and sun after the stripping 


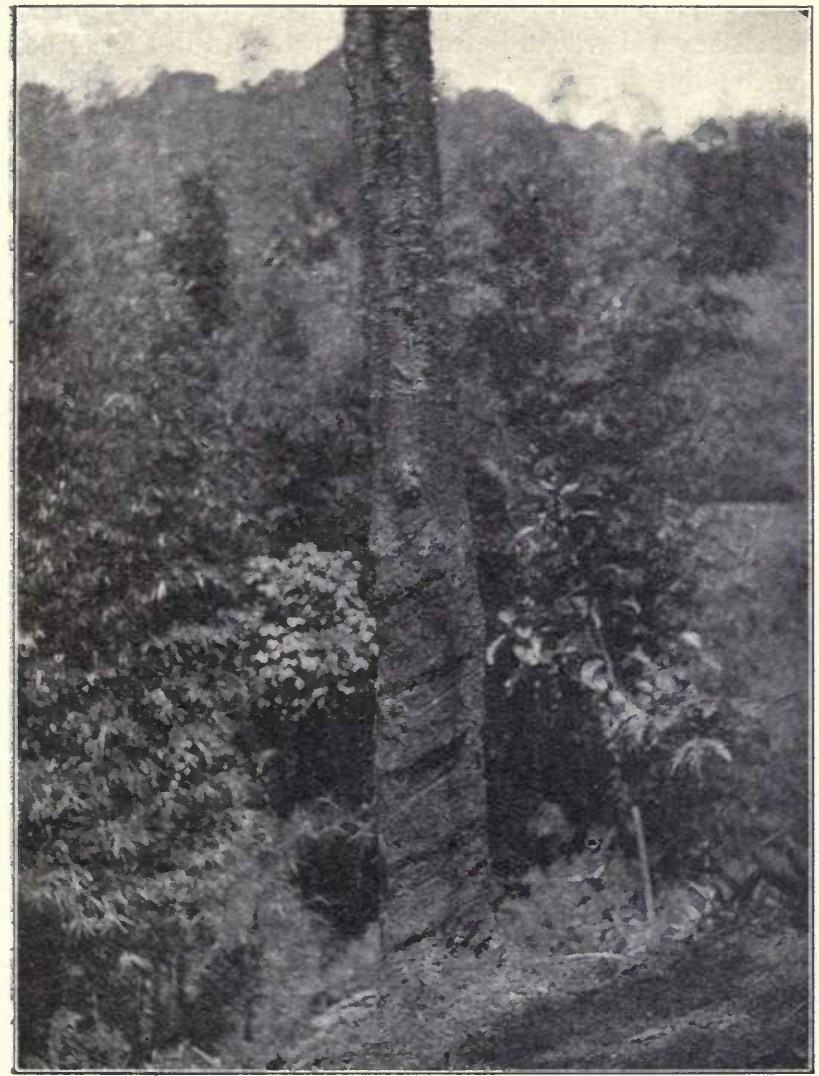

Ceara Tree: 20 years old; subjected to spiral system of tapping by bark excision; yields $4 \mathrm{lb}$. to $5 \mathrm{lb}$. rubber per annum. 
of the " mother" bark. It was the fashion with the Ceylon and Indian planters to take off the outer bark several weeks before attempting to tap the tree, with the result that their Cearas immediately "sulked", shedding their leaves prematurely, and ultimately going off into a long, long sleep which looked so much like death that destruction invariably followed without the poor tree having a chance to prove its latent vitality.

Now it should be a cardinal principle in the exploitation of the Manihots that under no circum-

A $5^{\prime \prime}$ to $6^{\prime \prime}$ diameter of tree, 3 feet from the ground. At this growth Ceara trees may safely be tapped.

B Third and last section, 12', to be stripped in one fall season.

c Second section, $\mathbf{r}^{\prime \prime}$

D First section, $12^{\prime \prime}$, showing outer bark stripped and inner bark tapped.

E Length of a full season's tapping area, viz. $36^{\prime \prime}$.

F Distances and position of tapping "jabs".

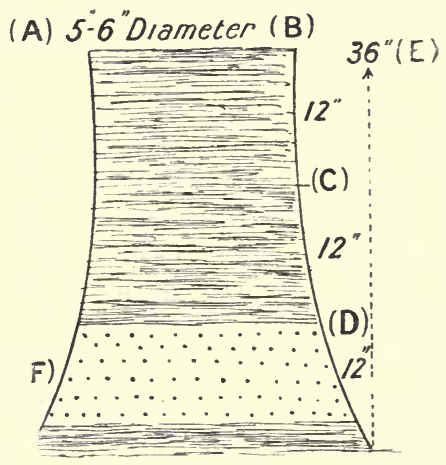

stances must the outer bark be removed without at once releasing the consequent tension of the tender inner bark by tapping the whole of the area thus exposed. The proper way to do this is to " jab" the tree, as shown in the following sketch, with the recognised Ceara knife. This is a tool that may be handled safely by the most careless of coolies, inasmuch as it is provided with a " shoulder" guard 
that absolutely forbids any possibility of damaging the cambium. The tree should be stripped from the bottom upwards, and one foot at a time. Such a stripping will permit of six tappings carried over a period of fourteen days. Thus the tapping period for the first part of the season may be said to last from fifty to sixty days. The second period occurs after the fall of the flower, and lasts about fifty days. Not more than forty punctures should be made at any one time, and where the latex is apt to flow very freely the exposed bark should be lightly dressed with a weak solution of acetic acid to promote instantaneous coagulation. Otherwise the fluid will run away over the unstripped bole of the tree, either to sheer waste or to become dirty and unsaleable scrap.

In many cases alienated Manihots assimilate habits of marked eccentricity, due doubtless to local climatic conditions and environment against which it is powerless to struggle in a proud attempt to assert its own inherited characteristics. This is very marked in regard to the behaviour of the latex, which is generally thick and sluggish of movement, and therefore extremely difficult to manipulate except in the form of "scrap" or naturally coagulated " ball" rubber. In Ceylon, however, and also to a very large extent in India, Hawaii, and the Philippines, the Ceara tree yields a latex as fluid and as ready as that of Hevea, with the result that a very fine, translucent, elastic, resilient, amber-coloured " biscuit" is being produced. 
Elsewhere I have made mention of the fact that one of the many extraordinary characteristics which environment has conferred upon the Ceara tree in Ceylon is that of the behaviour of the latex of a manipulated tree. In its native country this peculiarity does not exist. The plant is very shy and requires repeated gentle coaxings before it will respond freely to the knife, and even then the milk flows very sluggishly, is thick, and coagulates hurriedly without the aid of acid or any other reagent but the air.

In Ceylon, however, the latex flows freely and instantaneously, which is a great advantage, as it enables the planter to prepare his rubber on up-to-date lines and to obtain for the product a price absolutely impossible when prepared in the familiar "scrap" form in which Ceara rubber usually reaches the market. Unfortunately there are not many owners of Ceara rubber plantations acquainted with these methods, the most important details of which are perhaps centred in the system under which the tree is tapped, and only the oldest trees can be subjected to this treatment with any degree of safety.

A sketch of the system is appended. The tree is first stripped of its outer bark and the green inner bark exposed for several weeks until it presents a very hardened surface. Tapping is then commenced. Having marked off the height limit -42 inches from the base-to which the tree is to be tapped, the bark is incised over the whole of the operating area by a straight vertical cut made down the 
centre of the section-which must on no account face the sun. Into this channel the communicating incisions or ribs of the herring-bone converge, and the latex is thus conveyed to the collecting-cup at the base. The vertical incision must be a full $\frac{1}{4}$ inch wide, whilst the proper width of the communicating cuts depends of course upon the length of the period over which it is intended to tap the tree. Thus, if it is intended to exhaust the tapping area in one season, it will be necessary to make $\frac{1}{4}$-inch incisions over each of the I 2-inch sections, embracing

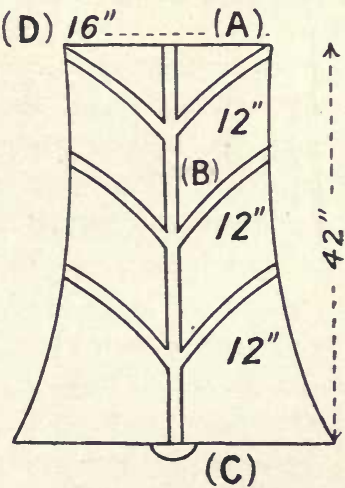

(A) Length of tapping area.

(B) Tapping sections, which ar operated upon every other day.

(c) Latex-collecting cup.

(D) Lircumference of mature tree. the full herring-bone, every other day. A solution of I per cent. ammonia water should be employed to prevent premature coagulation in the collecting-cups. Tapping should begin soon after 6 A.M. and finish by 9 A.M. Evening tapping is to be recommended, as the latex invariably flows more freely at that period, but the work should be concluded before sunset. All reagents in coagulating the latex of the Manihots exercise a more or less deleterious effect on the finished product, and should if possible be avoided. In the case of a large plantation where time and expediency are of prime importance, and it is essential that the rubber should be made and despatched 
without delay, the employment of reagents is a necessity, and all that remains to be done in these circumstances is to see that a combined coagulating and disinfecting acid is used, such as hydrofluoric, and dissolved carbolic acids in their proper proportions. Ceara latex coagulates perfectly, however, in ordinary water (five parts to one of latex), but the process is a long one and somewhat tedious. Following coagulation, the mass should be fashioned into oval biscuits $\mathrm{I} 2$ inches in diameter and $\frac{1}{8}$ inch thick and smoke-dried without delay. In this form Ceara rubber will always run Fine Para very close in the open market.

When Ceara trees are two years old they should be tapped lightly and tentatively without removing the bark, and then allowed to rest until they have almost reached their third year. This tends to bring the plants more rapidly to the bearing stage than if they were allowed to remain sterile over that period. The yield is also much greater when the tree is under full tap, whilst one of the most pronounced and satisfactory features of this treatment is the remarkable increase in the girth and general dimensions of the tree over those that are not so tapped. For the first two years all weeds and undergrowth should be kept down. After that period, however, the plantation, owing to the shade afforded by the close-standing trees, will give little or no trouble in this respect. 


\section{CHAPTER VIII.}

\section{Trees that Count-The Ficus.}

THE RUBBER OF THE EAST-AGE FOR TAPPINGVALUE OF THE LATEX-AN EPIPHYTE-THE SEEDGROWTH-IN PLANTATIONS-UNCERTAINTY OF YIELD - HABITS IN VARIOUS LANDS.

( $F$ the many varieties of Ficus that have from time to time entered into the range of com. mercial possibility, there are only two which require notice in a work of this character. They are the Ficus elastica (Rambong), or Assam rubber tree, and the Ficus Vogleii, the Abba rubber tree of the West Coast of Africa. The latter is only deserving of mention because it is now fast disappearing, and also because it was once the staple rubber tree of a vast area of country that has now to depend for the most part for its supply of exportable rubber on the forest vines of the far-inland zone.

The Ficus is of the order Moraceæ, and is one of the most important in the whole vegetable kingdom, comprising as it does more than 600 species scattered all over the world, and including, of course, the popular and indispensable fig. But the plant with 
which we are at present concerned is pre-eminently the rubber tree of Eastern Asia and the Malay States. Lately large areas in Borneo have been planted with it, and the Dutch greatly favour it as against the Hevea, which they find capricious and uncertain in behaviour. The Ficus elastica grows rapidly, and yields a high-class rubber, the percentage of pure caoutchouc in its latex being nearly 87 per cent. It is indifferent alike to drought or humidity, and is readily propagated from seeds, cuttings, or layers by marcottage. The product of the Ficus is popular on the Hamburg market, where it is much sought after by buyers interested in the ebonite and kindred trades.

Being a very free-branching tree, it cannot with satisfaction be planted closer than 40 to the acre. Formerly it was the custom to allow the Ficus to attain the age of eight years before attempting to tap it; but during the last few years experiments have proved that a most profitable latex can be secured from trees four and a half to five years old. It has one drawback, however, from a planter's point of view, in that it does not increase its yield in proportion to age, which is such an attractive and certain feature of both the Hevea and the Manihot Glaziovii. A close relationship, botanically and commercially, exists between the Ficus Vogleii and the Ficus elastica.

The Ficus Vogleii derives its name from the German botanist Vogel, who separated it from the other innumerable Ficus of West Africa which do not produce a commercial latex, but which are all 
known by the native generic term "Abba ". Owing to the excellent keeping qualities of the latex, the F. Vogleii was at one period favourably regarded by the Lagos authorities as a possible successor to the beautiful Funtumia elastica, which had almost disappeared owing to the greed and ignorance of the West African natives. It was found, however, that the rubber was of little value unless mixed with that of the Landolphia or other of the indigenous rubbers of the forest, and it was generally in this compound form that the product of the F. Vogleii reached the European market.

Moreover, F. Vogleii requires plenty of ground if it is to enjoy a healthy existence. As a rule the tree branches at six feet from the base, and Alvan Millson records measuring a thirteen-year-old F. Vogleii having a girth of $6 \mathrm{ft} .4$ in., measuring $60 \mathrm{ft}$. high and possessing a foliage area of a quarter of an acre. It goes without saying, therefore, that a plantation of F. Vogleii of this strain would cover too much ground for the average planter. The tree, nevertheless, enjoys a certain amount of popularity in the Lagus district, where it is found to make excellent shade and to be unfailing in the supply of its latex. Commercially, however, it has now been displaced by the Ficus elastica, the most valuable of all the Ficus family. In Queensland the tree is known as the Moreton Bay fig. Ficus elastica possesses in its natural state the quality of an epiphyte, reproducing itself in the forks of trees 30 to 40 feet above the surface of the ground. In the course of years the roots reach the soil beneath, where they rapidly grow 
and spread, and ultimately the tree that has nursed them is killed that the Ficus may survive.

It was the custom to raise the seedlings of the Ficus elastica by planting in the forks of trees, but the system was found to carry with it an infinity of labour in the dry season in order to keep the plants alive, and was abandoned in favour of the common and more rational method of sowing in seed-beds and planting out in the ordinary way.

The seed, produced in a fig, is very small and light, over a quarter of a million going to a pound. On ripening the fruit falls to the ground; it is then collected and dried and sown on the surface of the soil, where it is often three months or more before germination takes place. The better plan is to sow in pans or bamboo boxes, so that the drainage, which is essential to success in raising the Ficus, may be regulated and controlled. When the seedlings have reached a stature of $2 \frac{1}{2}$ to 3 inches they should be placed in the nursery bed 12 inches apart each way. At 2 feet high the plant is impervious to ordinary cultural risks, but needs protection from animal pests. When the trees are 6 feet in height they may be planted out, care being taken to stake them until they have secured a hold in the soil. After that they give little or no trouble. A vigorous tree six to eight years old may with perfect safety be tapped twice a year, much in the same way as the Manihot Glaziovii is tapped in Brazil. Incisions low down in the trunk invariably give greater and more regular yields than those made at a height of 5 feet and over, which is the general custom in the older plantations. Inter- 
planting in the case of Ficus is not to be recommended, but weeding in the early stage of its growth being essential, many Dutch planters raise a secondary crop so as to utilise profitably the labour that necessity demands.

The Government of India for years has been assiduous in its endeavours to cultivate the Ficus elastica in the Assam district, where fully 2000 acres are under Government control. It was from Assam that British West Africa obtained its supply of the Ficus seed that was to replace the wholesale disappearance of the rubber tree indigenous to that country-viz., the Funtumia elastica aforementioned. The seeds were despatched from Shillong on 24 July 1890 by Mr. Gustav Mann, Conservator of Forests, plants were raised at the Botanical Station at Lagos, and afterwards distributed in the colony, where the tree soon made itself at home.

In despatching the seed to Lagos Mr. Gustav Mann gave some interesting facts concerning the epiphyte habit of the Ficus elastica. In Assam the seed ripens from January to March, and where the tree grows naturally in the forest germination invariably takes place in the forks of trees. In describing the phenomenon Mr. Mann tells us that many of these nursery forks " are 30 to 40 feet and more above the surface of the ground, and the young trees grow, in consequence, for some six to ten years as epiphytes, after which the aerial roots reach the ground, increase rapidly in size, until some of them reach a girth of from 4 to 6 feet. They are very numerous, and it is not uncommon at a later stage that they are thrown 
out also from the upper branches 60 to 80 feet from the ground, being first as thin as whipcords but very soon increasing in size after they have reached the ground. It thus frequently happens that the trees on which the young rubber seedling first germinated is killed by the more vigorous growing Ficus elastica, which in this respect resembles the wellknown banyan tree, and is one of the largest growing members of our mixed forest in Assam". The seedlings, when raised, are not planted on the ground in the common way, but on small mounds, 3 to 4 feet high, of earth and the cut wood and rubbish close at hand, which suits the epiphyte habit of this tree.

To ensure the greatest possible amount of moisture in the atmosphere, the plantations of Ficus elastica have been made in moist evergreen forest near the foot of the hills, through which lines 40 feet in width were cleared roo feet apart from centre to centre of the lines, thus leaving 60 feet of forest standing between the lines. On these cleared lines the mounds for the planting of the seedlings or saplings are thrown up at distances of 25 feet apart; care has to be taken afterwards to prevent the forest trees left standing closing in above over the lines and the rubber trees planted on them, which they have always a tendency to do. High ground is always best, and swampy ground where water lodges should be avoided; but the tree grows very well on alluvial flats on the banks of rivers, even though they be inundated for a few days once or twice a year.

Uncertainty of yield has always been an unfavourable feature with the Ficus, and for this reason the 
Indian Government relaxed its efforts in regard to the Assam plantations in the year 1892 , and the following year much of the work was entirely suspended. It was found that whereas mature trees gave as much as $26 \mathrm{lb}$. of dry rubber per tree in one season, the yield next year was as low as $\mathrm{I} \mathbf{l b}$. or even less. The reason for such a disparity has never been explained, but it may be due to some undiscovered property in the flow of the latex which probably varies according to local climatic surroundings, and not so much to the seasons. Thus, the Ficus will flourish with remarkable vigour and luxuriousness in situations remote from the hills (its native habitat), but it will yield no rubber. As a matter of fact, the tree changes its character absolutely on the plains of Bengal as against its behaviour in Malabar and the hill country of Assam generally, where it exhibits every one of its true characteristics and stands out as the Ficus elastica pure and simple. The same thing occurs in Queensland, where the trees planted on the low plains produce nothing but a valueless gum, whilst the same tree rearing its magnificent proportions on the heights of New Caledonia yields abundantly a highly valuable latex.

In 1897 the Ficus was introduced into Egypt through the agency of the Kew authorities, but little information is forthcoming as to the results. It would appear that the chief difficulty that faces the planter in regard to the Ficus elastica is the enormous elbow-room which the tree requires if left to itself. Consequently a large acreage is necessary to ensure a profitable return. 


\section{CHAPTER IX.}

\section{Trees that Count-Castilloa Elastica.}

THE DESPISED DARIEN-CASTILLOA ELASTICA COMPARED WITH HEVEA-CHARACTER OF LATEX-METHOD OF 'T.APPING.

THE Castilloa or Castilla rubber tree is indigenous to Central America, where it is highly prized as a caoutchouc producer, and as a hardy droughtresisting tree that flourishes alike on the plain or at an elevation of 3000 feet above sea level. It derives its name from Castillo, the Spanish botanist who was killed in the forest in 1793 whilst engaged on the Flora of Mexico for the Government. The Castilloa sports a great variety of species. During a recent visit to Ceylon I saw several plantations that were labelled Castilloa, but which I recognised as bein merely the old Darien Castilloa, the despised Caucho tree of the Isthmus of Panama. I was, therefore, not at all surprised to learn that the Castilloa in Ceylon was not a success, that it was difficult to tap, and that the yield was both small and very uncertain. As a matter of fact the Darien Castilloa was up to quite recently always cut down when it arrived at the tappable age, in order to obtain from it anything like an adequate yield of latex, and for this reason it never entered into favour with cultivators who desired to plant rubber as an investment in tropical agriculture. 


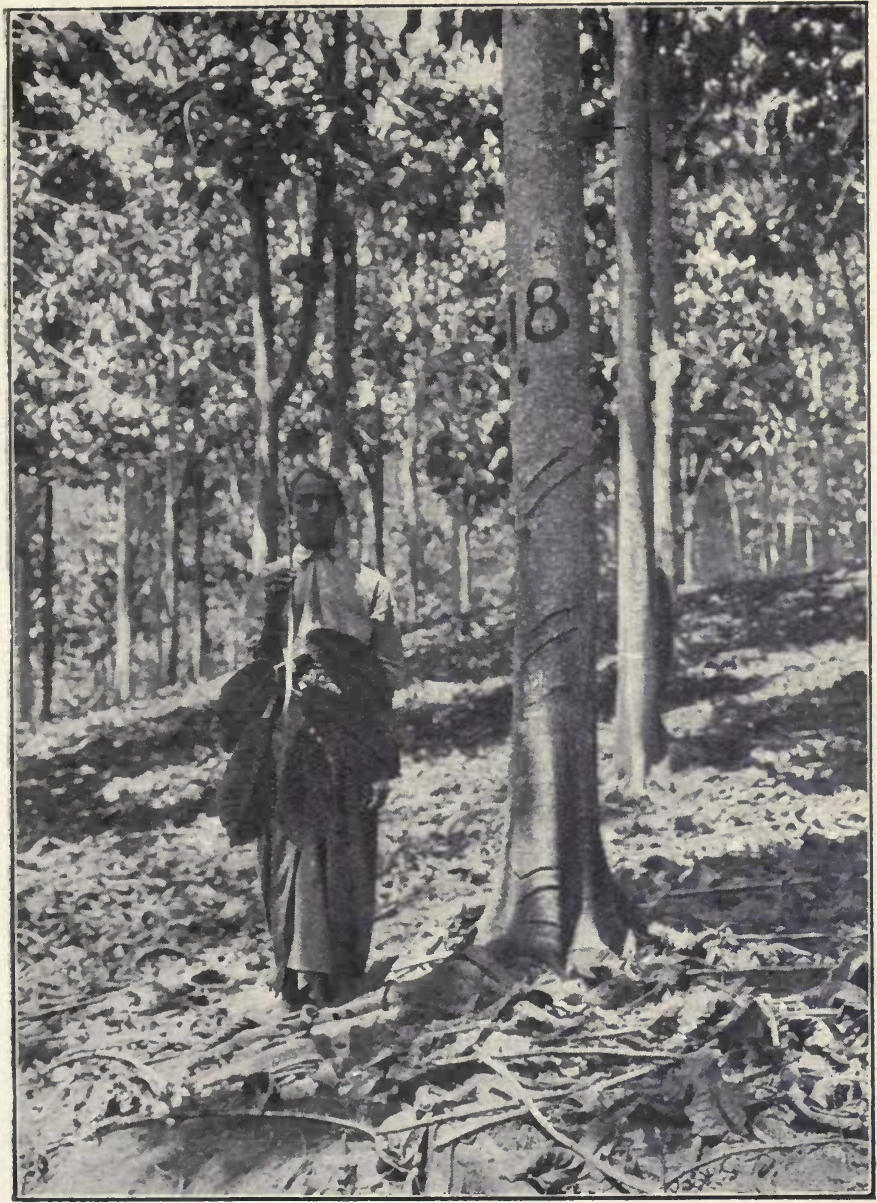

Castilloa Elastica (Darien) tapped under V system : yield $40 z$. per tree. Coolie holding sample branch showing hybrid character of the variety. 
It is difficult to explain how Ceylon became possessed of such a disappointing tree. The original stock, which was introduced into Kew by Cross in 1875 for the Indian Government, was obtained from the neighbourhood of Gatun, where it grows like a weed. It is curious that no plants subsequently distributed from Kew to various places. in the tropical colonies are identical with those familiar to Central America, nor do they possess. characteristics of the true Castilloa elastica, which Cross might have seen in all its native beauty and glory a few hundred miles away in Nicaragua or in British Honduras.

Castilloa elastica is one of the Artocarpaceæ (natural order Urticaceæ) to which the jack tree and breadfruit tree belong. It is a tap-rooted plant, like the Hevea brasiliensis. It delights in partial shade for the first few years of its life, and revels in a deep, moist cloggy loam, although at the same time it is quite at home in any other soil where it can grow fast and uninterrupted by violent changes in the atmosphere. Close planting is strongly recommended in the case of Castilloa, as the tree is intolerant of root exposure and resents the presence of the sun among its tender basal developments. Rapid in it's growth, Castilloa will often at four years of age obtain a height of 80 feet and a diameter 3 feet from the ground of 8 to 9 inches! I know of no other tree except the Manihot Glaziovii which can equal the vigour of such a plant.

The Castilloa differs from any of the other important rubber-producing trees in that its latex does: 


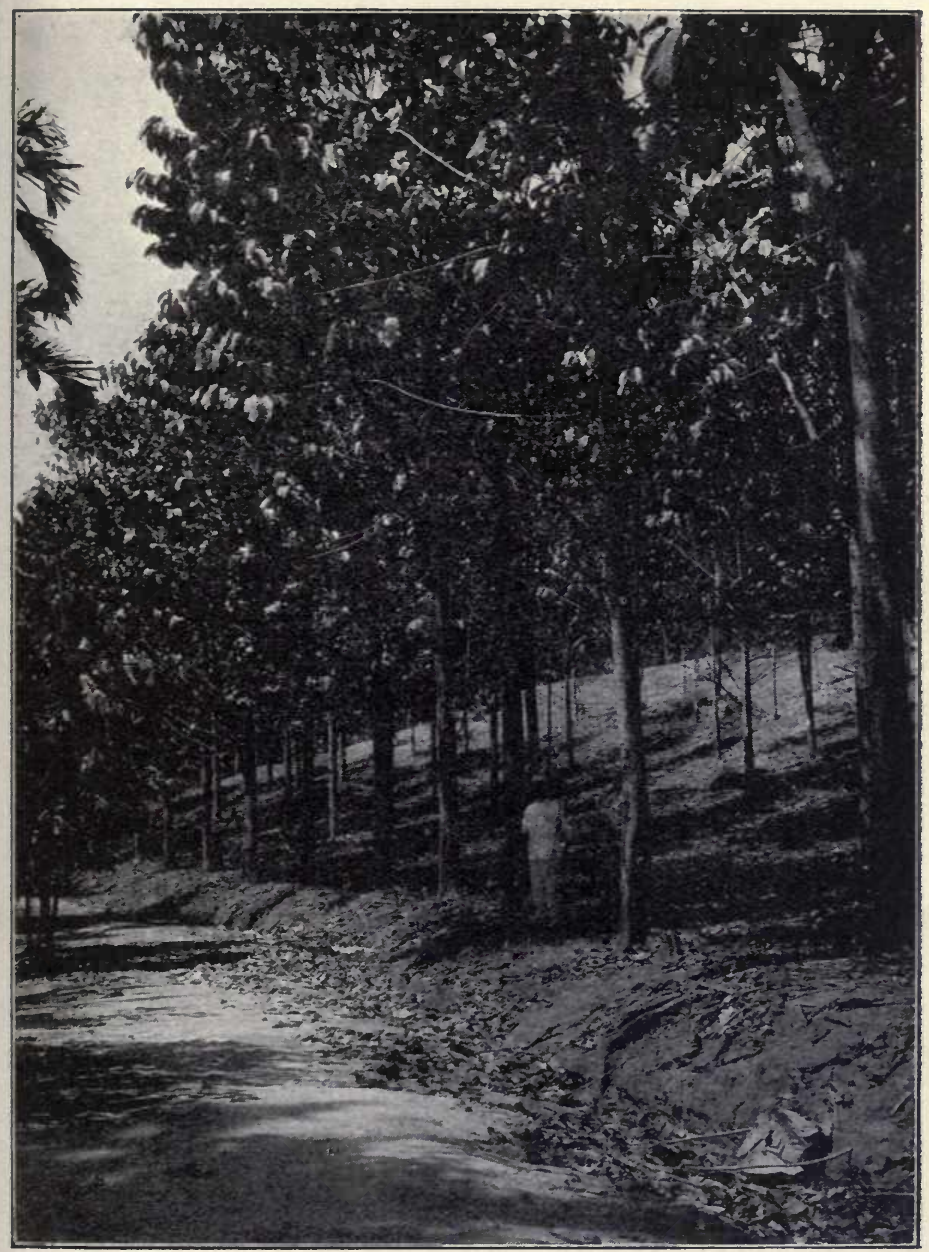

Castilloa Elastica (Darien) : 7 years old. Very small number of these trees tapped: yield under 2 oz. per tree. 
not yield to acid coagulants, neither are the lactiferous vessels confined, as in the case of the Hevea and the Manihot, to the system between the cambium and the bark, but are found running through the wood itself and yielding upon the layer of the soft pith that covers it. Its latex is thick and creamy. Owing to the peculiar structure of the bark, which is somewhat soft and spongy, Castilloa is not amenable to the scientific methods associated with the tapping of the Hevea in Ceylon and elsewhere. For this reason alone one may perhaps forgive the native " ulero", as the rubber-gatherer of Central America is called, when he turns a deaf ear to any suggestion that will relieve him of the deadly looking machête with which he hacks his trees. The ulero makes diagonal lines of gashes that open channels along which the milk can flow until it is all brought to a point on one side of the tree, whence it is led down to a basin-like cavity in the ground which is lined with the leather-textured leaves of the Calathea. In this fashion it is gathered and conveyed to the pouch, where the calabash awaits it, and in this vessel it is finally carried away to be coagulated.

In its natural habitat amid the Nicaraguan forests the tree yields copiously. The collector employs a modified $\mathrm{V}$ system, often cutting the tree at a height of $\mathrm{I} 5$ feet from the ground, the gashes being 24 inches long and 3 feet apart. It is a common thing for a collector to obtain 30 gallons of latex per tree by this method, the whole of the latex often flowing from the tree in the space of an hour.

The only coagulant which will satisfactorily deal 
with the Castilloa is the juice of the moon vine, which abounds wherever the tree in its wild state is to be found. The latex, so different from that of the Hevea, gives an acid reaction and will therefore yield to the introduction of alkalies as a coagulant. Often enough, however, the only coagulant used by the native is the leaf of the Calathea aforementioned. This is a large banana-like leaf upon which the latex is spread in a thin coating. Exposure to the sun and air quickly solidifies the milk and a second layer is thereupon spread. Finally two of the leaves have. their rubber-covered fronts placed together, and, after being pressed by treading upon them for a time, the leaves are removed and a leaflike sheet of prepared rubber is the result.

Coagulation by creaming has been found to answer well. The method is simple and effective and follows that associated with the creaming of Hevea latex in some parts of Ceylon to-day. The latex is put into a barrel having a tap at the bottom. To every part of latex three parts of hot water are added. At the end of twenty-four hours the water is run off and the process repeated until the rubber appears in a mass separated on the surface of the water. It is then taken out, pressed and dried. In this form it has an appearance equal to the finest Para, and, moreover, is comparable thereto in elasticity, resiliency, durability and strength.

No rubber tree requires to be more carefuliy tapped than that of the Castilloa family. The tubes which produce the milk run in such a direction that only horizontal gashes with the machête serve to release 
the maximum of latex in the tree. The system, however, has serious drawbacks, the chief of which is the difficulty of bark renewal and consequent attack by depredatory pests. The best time to tap Castilloa is the period following the fall of the leaf and just as the new ones are appearing. During the rainy season the latex becomes shy in its yield and is rarely or never visited during that time. Immediately the fruit appears then comes the collector, and he is kept busy until the first signs of leaf-fall appear, when the tree is allowed its annual rest.

The Castilloas possess the habit of shedding their axillary branches wholesale. These fall away neatly leaving a layer of tissue which is, however, quickly covered with bark, so that even the scar becomes scarcely distinguishable. Planted $\mathrm{r} 2$ feet by I 2 feet, Castilloa will always thrive much better than if subjected to wide planting. It is easily propagated from seed, which is raised in nursery beds, the young plants being placed in their permanent position when the seedlings are about six weeks old. Great care must be taken that the tap root, which is larger and more tender than that of the Hevea species, is not damaged in planting. A deep hole wide and long enough to take the whole length of the tap root should be made. In this the delicate structure will find a congenial home, the subsidiary roots being spread carefully near the surface. Planted after this fashion, the Castilloa never falters, but runs away at a great pace, often putting on a sturdy growth in stature of a foot per month for the first year or so.

The true Castilloa elastica would be invaluable as 
wind-belts to those Hevea plantations which at present have to make such an awful flight for existence in the hill districts of Ceylon and Southern India. It grows rapidly and yields, at an earlier age than is possible in the case of the Hevea, a fine translucent, resilient product that will always find a ready demand in the markets of the world 


\section{CHAPTER X.}

\section{Trees that Count-Funtumia Elastica.}

A TRAGIC STORY-PURELY AN AFRICAN SPECIES-A FOREST AUTOCRAT-RUTHLESS NATIVE ACTION-PROSPECTS AND ACCLIMATISATION.

I $\mathrm{F}$ one were to look for an element of tragedy in 1 the short history of the remarkable growth of the rubber industry it can be associated with the story of the Funtumia elastica. This, perhaps the handsomest of all the rubber-producing tribe, is a forest tree indigenous to the West Coast of Africa and the hinterland beyond. It was discovered about 1883 in Accra, where it was known as the Iré tree, and for nearly ten years was silently exploited by a small knot of Europeans and natives, who, guarding jealously the secret of their discovery, were able in that period to pile up many fortunes from the rubber those trees produced. At length the Fanti men, who had been introduced from the Gold Coast, where the tree had already been identified under another name, located the forests in which the Funtumia abounded. The Fanti men are born foresters, and, being keen, skilful rubber collectors, they were not slow to take advantage of the oppor- 
tunities thus afforded for opening up a brisk and profitable trade with the merchants at Lagos. Meanwhile Olubi had collected specimens of the plant, which were forwarded to Kew for identification. The authorities at home possessed little or no previous knowledge of the tree. The seeds were in many respects similar to those of the Kickxia, whilst the description accompanying the specimens tallied so closely with the well-pronounced features of that particular plant, which had hitherto been allocated to a small area in the Malayan peninsula and the Philippines, that Kew had no difficulty in determining the tree to be that of the Kickxia africana, Benth., and under this description it was added to the official catalogue forthwith.

It was not until 1905 that Stapf, however, was able to separate the species. He saw the marked difference between them, and clearly and conclusively demonstrated that the name Kickxia would have to be kept for the Malayan group and none other. Stapf accordingly sought a distinct nomenclature for the species, and selected that of Funtumia-from Funtum or O'Funtum, a vernacular name for all the rubber-yielding species of the Gold Coast, Lagos, and the Cameroons.

This tree is indigenous to the hill forests of the Agome Mountains and in Togoland, the Boäm country, the basin of the Upper Mungo, the coast regions of the Cameroons, and of the hill slopes near Libreville, whilst previous to the advent of the Fanti men it abounded in the forests of Ibadan and Jebu. 
Funtumia elastica is of the order Apocynaceæ. It is generally found in clumps averaging $25^{\circ}$ to the acre. A large glabrous tree, 50 to 60 feet high, it is a veritable aristocrat among forest giants, possessing as it does a stately beauty all its own, refusing to be influenced in the slightest by the sprawling clumsiness of its neighbours.

Prior to the discovery of the Funtumia little or no rubber was exported from Lagos, and one may trace the beginning of that short but marvellous trade in the following notice issued by Sir Gilbert $\mathrm{T}$. Carter, K.C.M.G., the Governor of Lagos, in 1894 : " His Excellency the Governor desires to notify to the mercantile community of Lagos that he has been able to induce a party of natives from the Gold Coast experienced in rubber collecting to come to Lagos with a view to the development of this important and valuable industry. The men have already inspected certain districts, which they report to be rich in rubber-producing plants, and it is confidently hoped that Lagos will shortly be able to compete with the sister colony of the Gold Coast in the great export of the product."

Immediately following this announcement came the intelligence that whole forests of a new rubber plant, which the natives called the "Iré " tree, had been found in the interior, and a general exodus began in search of it.

In April r895 Captain Denton, the acting Governor, was able to send some specimens of the tree to Kew. He informed the authorities there that a very large trade was being done in the pro- 


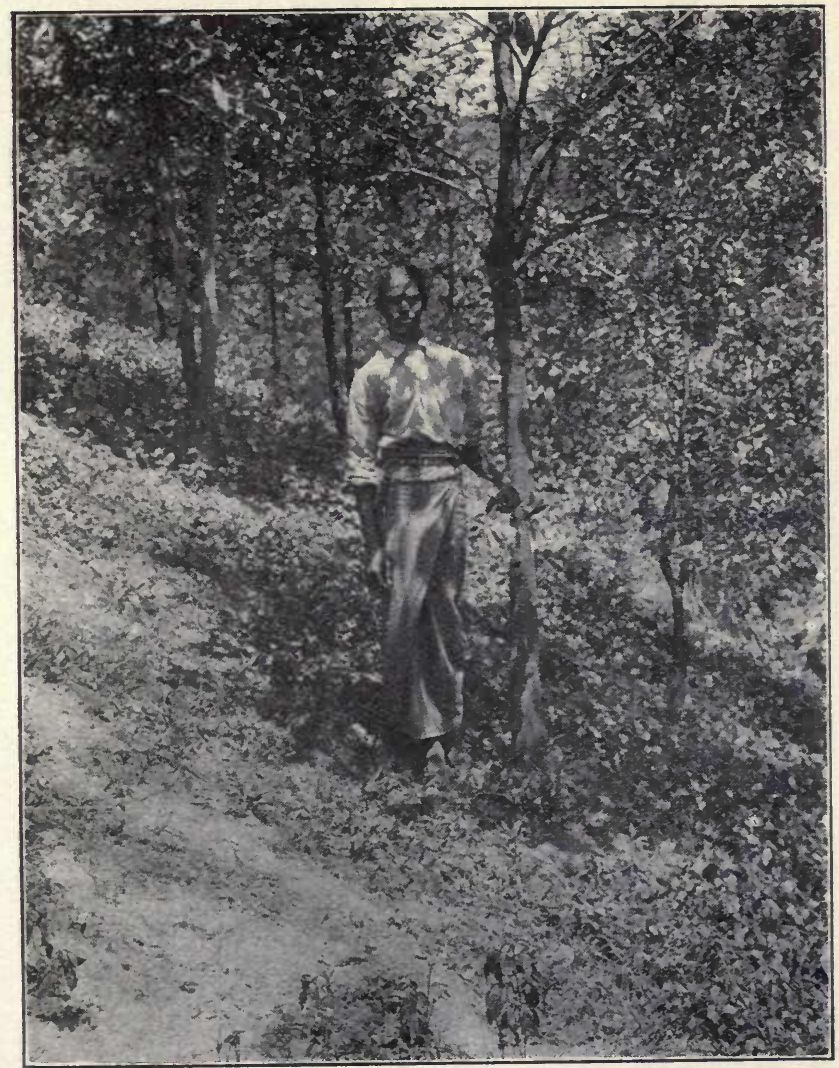

Funtumia Elastica: Trees seven years old, not yet fit to tap. 
duct, and that there was every sign of the output increasing. The specimens in question were obtained from the district between Ilogbero and Ilaso, where the tree was then being actively exploited.

The following month, viz., in May 1895, Mr. Jonathan C. Olubi, F.R.G.S., was able to supply Kew Gardens with some excellent specimens. These were obtained from the Ibadan district, and, as already stated, wrongly identified as a Kickxia. Olubi describes the tree as averaging 60 feet in height, with a diameter of $\mathrm{I} 2$ to I4 inches. The trees contain their maximum of milk in the rainy season, towards the end of which they are tapped. If the work is properly done a tree will produce ro to $15 \mathrm{lb}$. of dry rubber during the season. Coagulation of the latex of the Funtumia was always regarded by the natives as more or less a secret of the trade. There were employed, however, several methods, the one most generally followed being too objectionable to be countenanced by the European trader, and it was soon abandoned in favour of natural coagulation by means of concentration of the latex in the hollowed-out trunk of a certain soft-wooded tree, which possessed the property of absorbing the resin in the latex and detaching the pure caoutchouc in a solid mass ready for immediate drying and export. The system of tapping employed by the natives was that of the magnified herring-bone. First the bark was cut in a vertical direction from the bottom to the top, the line traversing the whole length of the bole, and being about $\frac{5}{8}$ inch broad, and deep enough to reach the inner bark. This formed the main 
TREES THAT COUNT-FUNTUMIA ELASTICA 105 channel, which in its turn was joined by several oblique cuts 24 to 30 inches apart, made on either

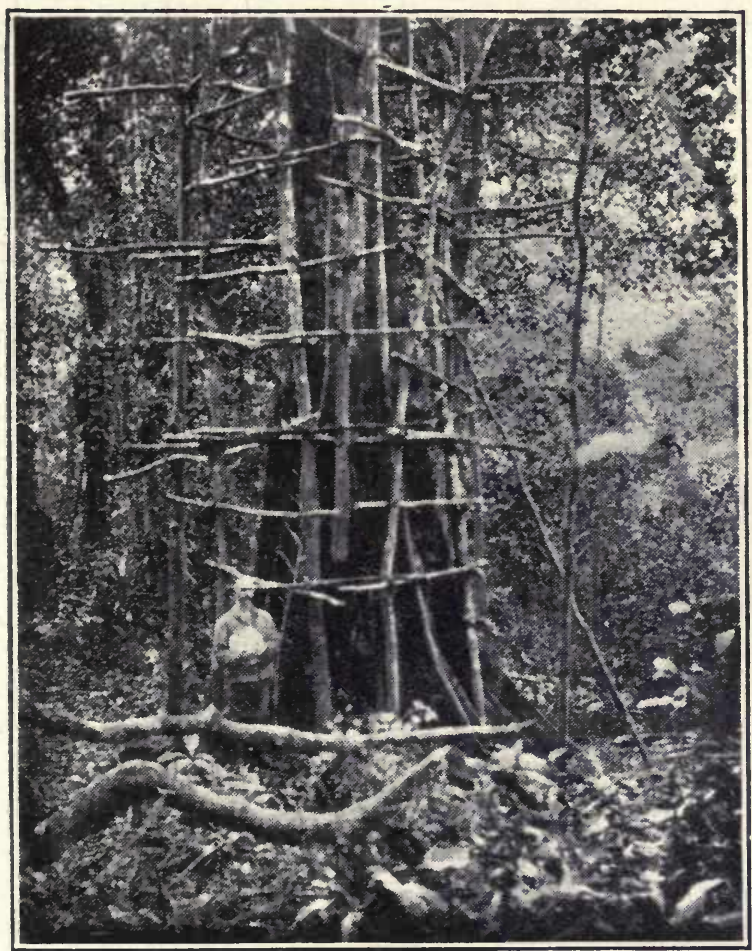

High-tapping Funtumia (Mabira Forest).

side as the daily tappings proceeded until the whole space, measured by the vertical cut, was gradually manipulated. The milk flowed from the oblique 
cuts into the main channel, and reached the collecting cup placed at the base of the tree.

The extraordinary growth of the Lagos industry may be gathered from the returns published by the Customs Department at this period. In January 1895 the rubber exported from Lagos amounted to $21,13 \mathrm{I}$ lb., by June the same year it had reached 268,619 1b., whilst in October the figures were $\mathrm{I}, 059,158 \mathrm{lb}$. The actual returns for the year ending I 89.5 were 5,069,504 lb., valued at $£ 269,892$. With results such as these to encourage them it is small wonder that the Lagos community laid itself out for greater things to come, taking up as it did with rare enthusiasm the invitation of the Governor to assist in the development of the new industry. But both the colonial officials and the merchants took no count, unfortunately, of the guile and the greed of the West African native, who, being debarred by no restrictions and governed by no regulations, simply slaughtered the tree wholesale in order to obtain the greatest amount of rubber possible. It was not a question of tapping the tree to death, it was simply extermination by hacking the tree till it died, or by actual felling where their purpose could not be effected otherwise. A destructive policy of this kind was enough to exhaust the richest of rubber lands. The supply accordingly fell off. In less than two years it had dropped 33 per cent., a very serious thing for a young colony which had drawn to itself a large surplus population almost wholly dependent on the trade in rubber, and which, anticipating a continuous expansion of the high revenues of the 
last few years, had already committed itself to expenditure wholly beyond its means, unless the new industry was adequately and immediately protected.

Writing from Government House, Lagos, on 24 June 1897 to Mr. Joseph Chamberlain, then Secretary of State for the Colonies, Governor McCallum (now Governor of Ceylon), referring to the wholesale destruction of rubber trees in the hinterland, reported that he had sent two officials of the Botanical Department to Ibadan to make an investigation into the subject. Their statements were enclosed. These officials had already visited and reported on the ruined condition of the Jebu and Ibadan forests, and they were now in a position to make a comprehensive survey of the situation applicable to the colony as a whole. Not a district remained that had not been spoiled by the destroyers, and as a result peremptory orders were sent to the kings, chiefs, and headmen of the various localities concerned to prohibit rubber collecting in the forests for two years, to stop all strangers from entering the forests, and to compel the planting of a young tree for every Funtumia destroyed or ruined by the collectors.

Very promising are the results following such a policy. Gradually year by year the output of Funtumia has increased, until at the present time there is a possibility of the trade reaching before long the records marked down for the famous seasons of 1894 and 1895 .

Meanwhile Funtumia elastica has been tried in Ceylon and other places in the Middle East, but it 
does not thrive as an alien. In Ceylon I have seen some very handsome specimens six and seven years old, but they give no latex, whilst every year they are attacked by a caterpillar pest which denudes the tree of every vestige of leaf in a few days. They are accordingly put into quarantine annually, and neither master nor workman will have a kind word to say for Funtumia. Nevertheless it is a very valuable tree, and, provided the right soil and suitable climate is found for it, Funtumia elastica will always repay careful acclimatisation. On the Ivory Coast this plant is being extensively exploited. Owing to the facility with which it reproduces itself, and the little trouble it gives to the planter, Funtumia will undoubtedly prove to be the mainstay of the rapidly growing rubber industry of this part of French Africa. The same may not perhaps with equal certainty be said of Funtumia in German West Africa, except in the Cameroons, where large areas are being devoted to its cultivation. It is generally planted Io feet apart each way, and tapped by straight vertical cuts 6 feet in length down the lower bole of the tree nearly to the base. Not more than six such cuts are made in a season, so that bark conservation is adequately provided for by this system, which I am convinced might with advantage be tried in Ceylon and other places where the practice of bark paring for the greater part of the year is already leaving its effects on the young Hevea growing there.

In Uganda Funtumia is establishing itself rapidly, and increases daily in favour with planters on account 
TREES THAT COUNT-FUNTUMIA ELASTICA IOG

of the ease with which it is cultivated and the close planting to which it lends itself, thus saving enormously the labour expenses associated with clean weeding that would appear to be a sine qua non with the widely planted Hevea brasiliensis. 


\title{
CHAPTER XI.
}

\section{Trees that Count-The New Manihots.}

\author{
(A) M. Dichotoma ; (B) M. PIAUhyensis ; \\ (C) M. HEPTAPHYLLA.
}

A BOUT four years ago the botanical world was Manihots, distinct in every way from the wellknown Manihot Glaziovii, had been discovered in Brazil-one in the province of Jequié, the second growing on the mountains of the Rio San Francisco, and the other confined to the country adjoining the State of Piauhy. The first was named M. dichotoma, the second M. heptaphylla, and the third M. piauhyensis. The botanist who made the discovery was Dr. Ulé, a distinguished savant of the Berlin Botanical Gardens.

His claim was subsequently endorsed by the Kew authorities, who declared that the tree was not to be confounded with the Manihot of Ceara (Manihot Glaziovii), from which it was said to be separated by features of a remarkable and distinctive character.

But a great deal has been learnt about these Manihots since I906. They have been introduced into East Africa, Ceylon, Malay States, Hawaii, the 
Philippines, and South India, tried and-found wanting, to spare a harsher phrase. The particular species that has earned this indifferent character is the M. dichotoma, the others being too slow in growth to prove their worth under a period of at least five years from the time of " stumping".

The Dichotoma-should it not rather be termed Trichotoma?-is indigenous to the Bahia region of Brazil, where it forms huge forests amid a bush scrub that clearly denotes the poor quality of the surrounding soil and the small and uncertain rainfall in these parts. As a matter of fact, the rainfall in the Dichotoma lands rarely reaches 30 inches a year. The soil is a deep, porous clay, of a character that retains the moisture for a long period, thus ensuring zontinuity of growth to the thousands of young plants that from the nature of the seedfall are annually called upon to face the severe droughts that obtain for the greater part of the year.

Like all the Maniçobas, Manihot dichotoma is very brittle and of tender structure; so much so, that unless planted very closely - certainly not less than Iooo to the acre-there is sure to be grievous destruction whenever a high and strong wind gets play among the branches. The few plantations of Dichotoma that at present exist in Ceylon suffer heavily in this respect, as the photos taken on the spot abundantly prove, especially so during the southwest monsoon, and perhaps it is chiefly for this reason that planters are not very enthusiastic regarding it. Personally, from what I have seen of the plant I am inclined to think that Dichotoma will 


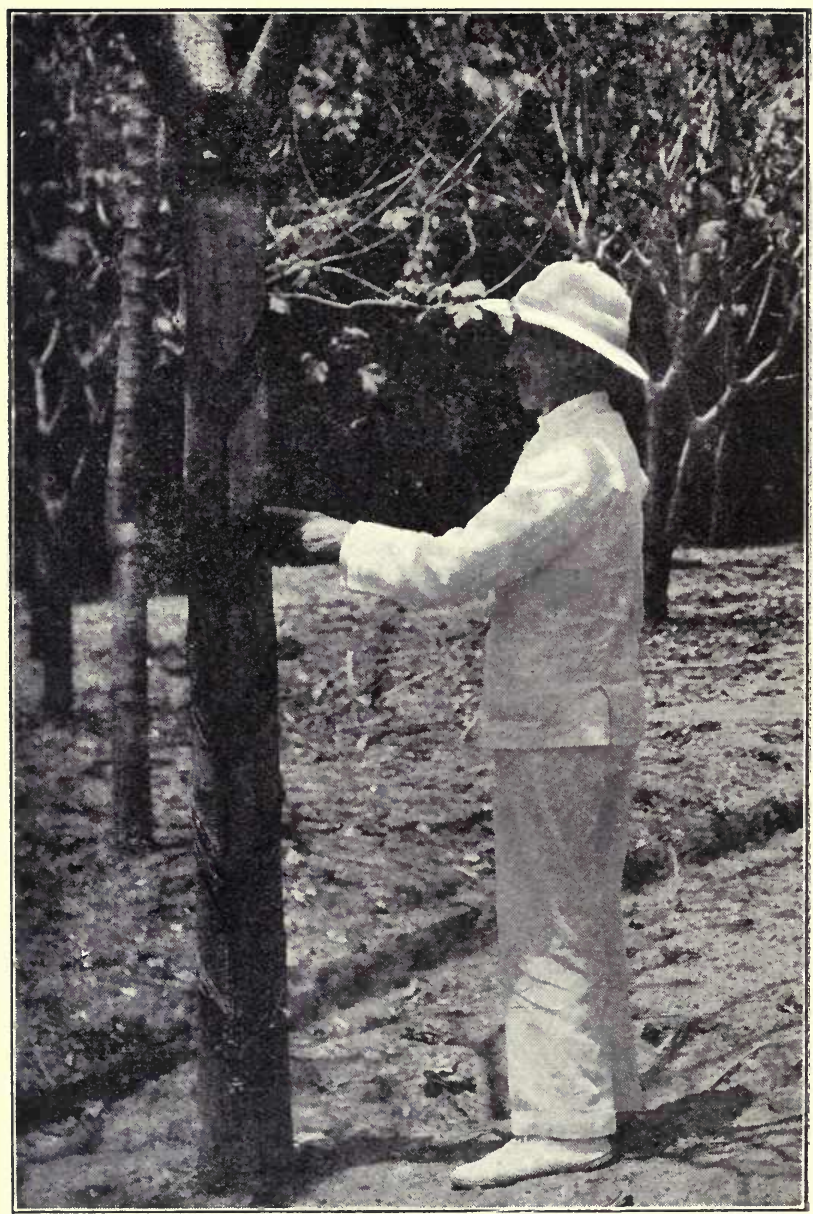

Manihot : Dichotoma : $2 \frac{1}{2}$ years old. Effect of tapping by herringbone system of bark excision. Tree has shed all its leaves and branches and is.dying. 


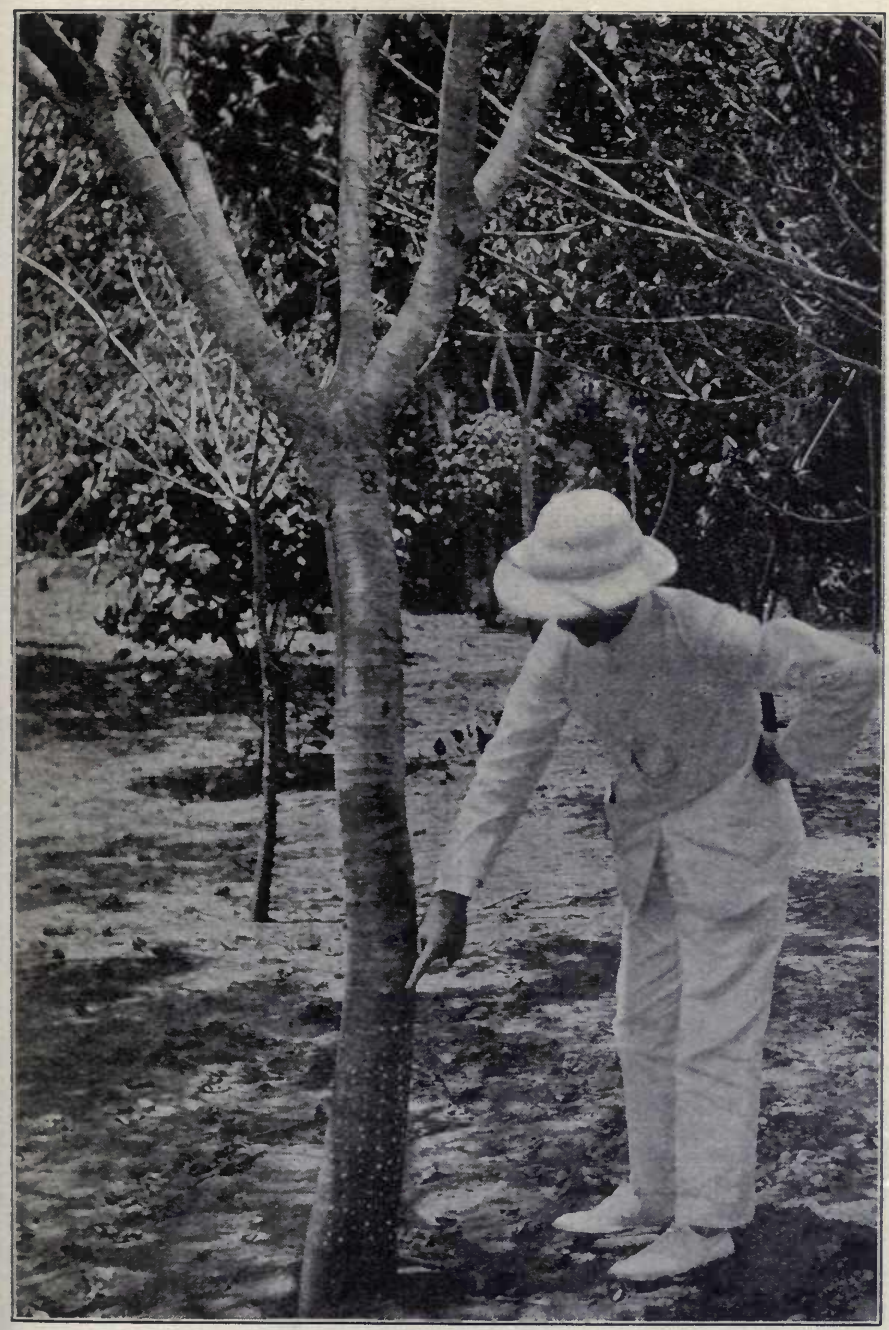

Correct method of tapping Mauihot Dichotoma. Tree $2 \frac{1}{2}$ years old. 
never answer in Ceylon or elsewhere, unless it can be associated as nearly as possible with just those elements-both of soil and of climate-that are peculiar to the country in which it is found. I am, however, of opinion-speaking again from my own observations, that there are large tracts of land available in Ceylon which would grow the Dichotoma profitably. Thus the whole of the country shortly to be embraced by the new railway line to Mannar and the existing line from Anuradhapura to Jaffna appears to be admirably suited to Dichotoma culture, judging from the behaviour of the plants under experiments at Maha-Illupalama. Many of these trees scarcely eighteen months old have a stature of I 5 feet or more, and I was much struck by the great length of bole which a large number of them presented-a very unusual feature in the Brazilian Dichotoma. It may be that here in what has been for hundreds of years practically abandoned territory Dichotoma will find at last a congenial home. Up to the present the plant has only earned the reputation of being perhaps the most eccentric alien ever introduced into the East. I made a very careful study of the plantation at Peradeniya with a view to determining whether the tree was likely to exhibit permanently in its new home those distinct and pronounced features which enabled Dr. Ulé, rightly or wrongly, to separate it from the Manihot Glaziovii and io bracket it with the M. heptaphylla and M. piauhyensis as one of the trio of new Manihots. Subsequently I found that the official records respecting the history of this experimental plantation justified 
the definite conclusion I had already formed in this connexion, viz. that Dr. Ulé's so-called new Manihots are really the Manihot Glaziovii adapted to, and influenced by, the environments of their emigrant home. Thus I found within a radius of 100 yards no less than six different species, the individual leaves of which are shown in the photographs herewith, each and all, however, emphasising their relationship to their original parent, Manihot Glaziovii, by occasional and promiscuous reversion in leaf structure in many cases identical with that of the Ceara tree.

Dr. Ulé spent many months in the southern parts of Brazil searching for new Manihots, of which there were said to be quite a large number not yet identified, and the three kinds above named were the result of his researches.

But if we are to accept these as being new and quite distinct from the true Manihot (Glaziovii), then Dr. Ulé will have to add materially to his list, inasmuch as nearly every province in south-east Brazil possesses a Maniçoba tree varying in some distinctive feature from its compeers, but possessing at the same time all the essential features of the parent stock. Thus the Maniçobas of the province of Sergipe are named Candelabra, but they are almost the living image of some of the Dichotomas I saw at Maha-Illupalama, in the north of Ceylon.

As a matter of fact the Dichotoma is really the Jequié Maniçoba, the Piauhyensis being the old and well-known Piauhy Maniçoba, whilst the so-called Heptaphylla is only another name for the Manicoba of Rio. 


\section{LEAVES OF MANIHOT DICHOTOMA (JEQUIE RUBBER)}

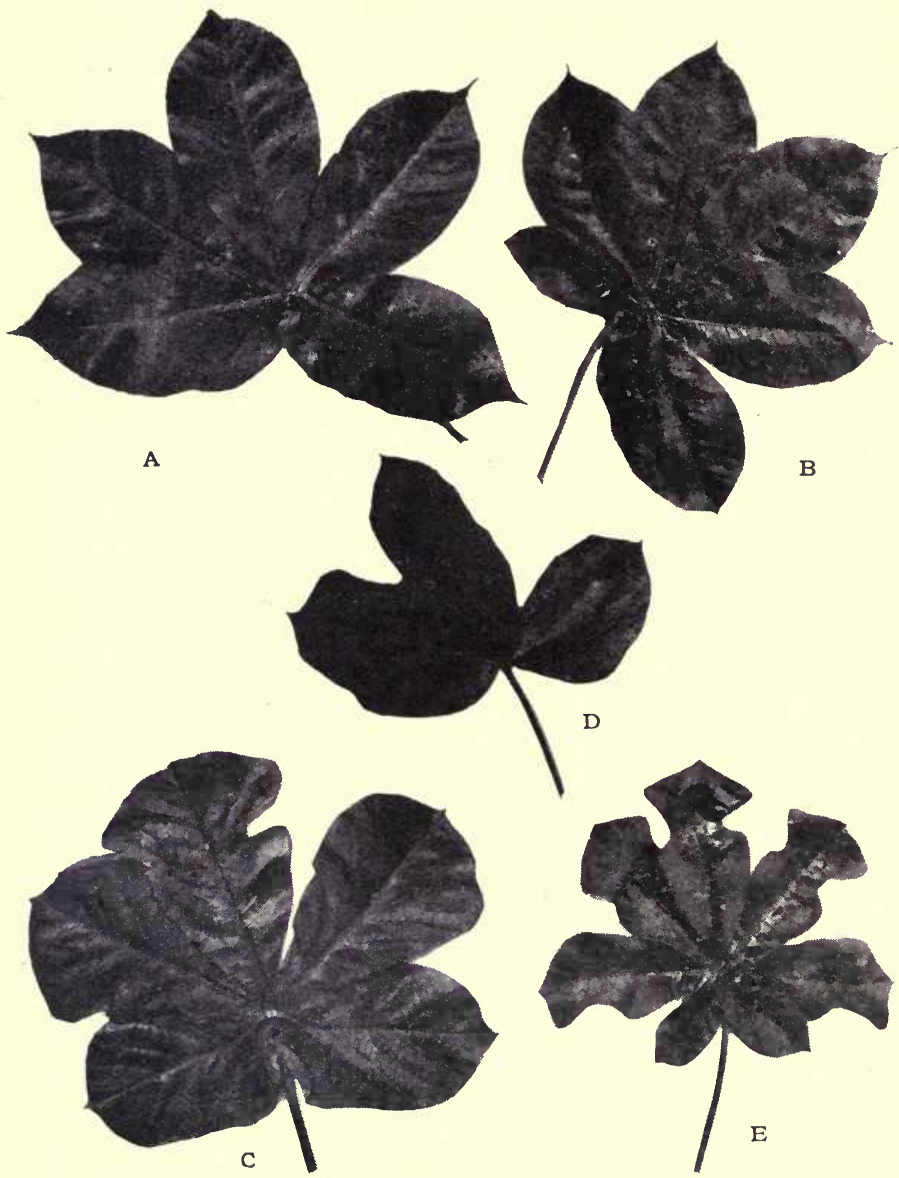

A. Common indigenous Manihot Dichotoma type, howing close affinity to the Manihot Glaziovii.

B. First break away, showing bunch of cix leaves slightly lobed.

C. Second ", " " five leaves, two indented (Dichotoma

D. Third , , , distorted three-lobed leaf.

E. Fourth ", ", ", bunch of seven leaves, five of which are indented, indicati g approach to alienated D.chotoma type 


\section{SHOWING EXTRAORDINARY VARIETIES IN TYPE IN A CEYLON PLANTATION ALL FROM SAME SEED.}

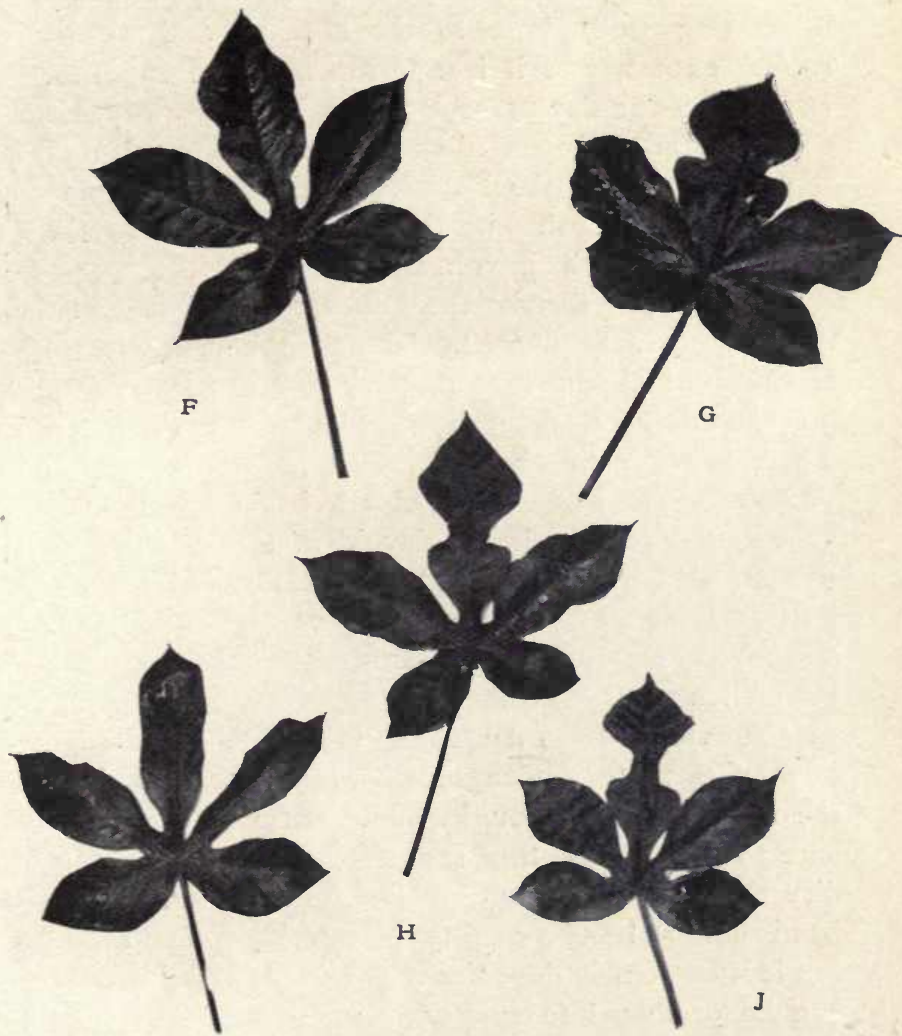

F. Fifth break away, showing five-lobed leaf, the centre indicating Dicho-

G. Sixth toma, the remainder Glaziovii type.

.bunch of five leaves, the largest of which present Dichotoma type, the remainder that of Glaziovi;.

H. Seventh, , " Five-lobed leaf, centre indented, presenting near approach to true alienated Dichotoma.

I. Eighth , " " Another attempt with imperfect indentation.

J. Ninth ", ", Five-lobed leaf true alienated Manihot Dichotoma type. 
Nevertheless, these Maniçobas are a profoundly interesting study both to the botanist and to the rubber expert, and it is not too much to say that Brazil may one day present to us a Maniçoba capable of assimilating in an alien land all the virtues of those great rivals the Para and the Ceara tree, and thus producing the ideal rubber for which the manufacturer sighs in vain to-day.

In the Jequie district the Dichotoma is being just now very widely planted. The neighbouring forest lands in which the tree grows like a weed stand at an elevation of about izoo feet above sea-level. There is an entire absence of the luxuriant tropical vegetation one looks for in this latitude. For miles around the region, being devoid of timber and the usual forest growth, would be a desert but for the hardy Maniçobas that meet the eye on every hand. These are of stunted but sturdy growth, and give their latex plentifully on being tapped. The tapping season extends from August to March, as in the case of the Ceara tree. Coagulation, like unto that of all the Manicobas, is brought about naturally by exposure to the air, and thus requires no acid aids in this direction. The rubber obtained from these Manicobas is said to be of a quality comparable to fine Para, but it is extremely doubtful whether any reliable data can be produced to support such a claim, as it is well known that, at present at least, the products of the South Brazilian Maniçobas are largely used as assimilatives to the highly resinous and therefore poor latices of inferior rubber trees. 


\section{CHAPTER XII.}

\section{Interplanting.}

THE CATCH CROP-THE CHINESE AND TAPIOCA-DISAPPOINTMENTS-THE VALUE OF TAPIOCA LANDGAMBIER, COFFEE, PEPPER, COTTON, PINEAPPLES, COCONUTS, TEA-WHAT EXPERIENCE TEACHES.

THE entry of plantation rubber into the general scheme of tropical agriculture coincided unfortunately with a pronounced dearth of available capital, both locally and in those markets which look for high and quick returns on advances. Hence planters who were tempted into embarking in the new industry looked around for anything which, utilised as a catch crop, could be interplanted among their rubber trees, and thus secure a safe and certain annual return until such time as the rubber came into bearing.

But the difficulty lay in the choice of that crop. To begin with, the planters themselves knew little or nothing of the new rubber tree, and not much was to be learnt from the Government authorities regarding interplanting, inasmuch as accessory crops amongst rubber had not as yet entered into the range of their practical experiments. Nevertheless the 
majority of the planters, concluding that at least eight years would be required to bring the rubber into bearing, felt that they had no choice in the matter, and interplanting accordingly became the recognised rule.

Curiously enough, the Chinese, who may without question be regarded as among the most astute and cleverest agriculturists in the world, had somewhat anticipated the new departure, and at the same time pointed out the most likely crop for the purpose by interplanting their tapioca fields with the new rubber plant. This answered well, especially where the fields were kept clean and the rubber was planted thinly and on rising ground. But there is a material difference between planting rubber among tapioca and tapioca among rubber, particularly where the crops are handled by a European, by European methods, and unassociated in any way with the admirable fertility of resource, the plodding perseverance, and the profound practical knowledge of the Chinese planter. Hence the cultivation of accessory crops among rubber was a disappointment from the start. It is true that many of the estates which to-day occupy a high and proud position in the market owe their very existence to the catch crop which enabled the original owners, never at any time over-burdened with capital, to keep going whilst the rubber was coming into bearing. On the other hand, many less fortunate men found interplanting too costly and troublesome to maintain. This was generally the case where the trees, stubborn and slow of growth, interfered with the accessory 
crop. The planter, compelled in the end to reduce his working expenses, and unwilling from sheer inability to face the prospect of no returns from his rubber for several years, usually took panic, grubbed up the trees wholesale, and returned to the crops he understood, and which he knew would yield a reasonable return on his labour and enterprise. Several of the plantations so treated contained trees that were at the time eight years old and would to-day, of course, be invaluable. Quite recently I rode over one of these properties. When the trees were destroyed the land was put down to tea. But the crop was not a success. The estate changed hands. The tea was eradicated and the ground is now planted with young rubber, which is growing splendidly. Several hundreds of the stumps of the old-time trees-they were Heveas-were overlooked by the coolies in clearing the ground, and, having sprouted again, were permitted to remain. They have become fine, robust, promising trees.

Catch crops other than tapioca have been tried with more or less success. These include gambier, pepper, coffee, and in some cases cotton.

Tapioca is largely cultivated in Malaya and is a recognised source of profitable agriculture. Interplanted among rubber it will yield about $f_{\text {io }}$ per acre net profit before the growth of the rubber demands its abandonment. On this basis it certainly presents great attractions for the beginner, whose only other choice is virgin jungle land. Thus the reference in Malayan and other rubber prospectuses to tapioca land which it is proposed to convert into 
rubber has a peculiar value in itself. It is a mistake to suppose that tapioca unduly exhausts the soil and that the land is consequently unsuitable for rubber. Certainly it is a plant that will greedily absorb all the humus it can, but the same must be said of any other surface-feeding plant, and it is idle to imagine that on that account the land loses any of the value it may possess for a forest tree like rubber. In calculating the advantages tapioca land possesses over jungle for rubber planting, we have to take into consideration the labour cost and loss of revenue that will be occasioned when the tapioca is abandoned. Yet in the general scale this is not a heavy item. As a rule it will work out something like the following :

Value of tapioca land (not interplanted with rubber) $\ldots \quad \ldots \quad \ldots \quad \ldots$

Value of jungle land cleared ready for

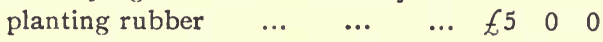

Gost of planting cleared jungle land ... $\quad 5 \quad 5 \quad 10 \quad 0$

Cost of maintaining ditto to producing

$\begin{array}{lllllllll}\text { stage } & \ldots & \ldots & \ldots & \ldots & \ldots & 15 & 0 & 0\end{array}$

Total cost of acquiring, clearing and planting jungle land, and maintaining to producing stage $\quad \ldots \quad \ldots \quad £ 2510 \quad 0$

Here we have an apparent saving of only $£ 5$ per acre (a satisfactory item in itself) in the case of tapioca land; but we have to remember that two or more crops of tapioca may confidently be relied upon whilst the rubber is growing, and the returns per acre may in the aggregate be put down in this instance at $£ 12$ for the period stated. The cost of bringing 
into bearing rubber interplanted is, of course, minimised by the amount of labour expended in the plantation on behalf of the subsidiary crop, since both plants receive, or should receive, coincidental attention. That being the case, we shall find that the returns from the tapioca will go a long way towards balancing the account in this expenditure, and may with ordinary luck, assisted if possible by a leaf out of the book of the Chinese planter, give a small balance to credit, and thus exhibit a rubber plantation ready for tapping at the mere first-hand cost of the land. I believe this actual result has been secured in the case of a certain property in Malaya. But it was only a small area, and the original owner (a Chinaman) was famous as a skilful and exceptionally acute planter.

Gambier is another favoured crop for interplanting. It is produced by an ugly scrub of a bush, $2 \frac{1}{2}$ to 3 feet high. Its botanical name is Uncaria gambir, and the commercial product is obtained from the leaves. The plant is indigenous to the Middle East. In the hands of an untutored European planter it is a risky plant to touch. The Chinese have no great love for it. They prefer tapioca. The net profit yield per acre is about E6 Ios. at present prices. Gambier yields in two years, and four crops may be gathered before the growing rubber will interfere with it.

Coffee has been practically exterminated in Ceylon, but large areas are at present interplanted with rubber in Malaya and the Dutch Indies. They are mostly old trees that have survived the massacre 
that followed the awful drop in prices and Brazilian competition some years ago. Thousands of acres were under coffee at this period. Prices fell 75 per cent., and planters were in despair. At a critical moment Ceylon, through the agency of its experimental gardens at Peradeniya, sent a few plants and a large consignment of rubber seeds to Singapore, and with them came undreamed-of wealth to the Malayan planter.

Coffee comes into bearing in from two to three years. At present prices it yields about $£ 16$ per acre gross profit. The Coffee Robusta is expected to yield much higher returns. It is an expensive plant to manipulate among rubber. The Malayans remove it immediately they find that the shade from the growing rubber interferes in the slightest with the flowering of the plant.

$\mathrm{He}$ must be a very patient and tolerant planter who will choose such a thing as pepper as a crop for interplanting Yet I have seen large areas put down to this crop in conjunction with rubber. It is a tall bush, quite 7 feet in height, and so slender and emasculated that it has to be supported like the vine by poles and frames. The fruit is a small berry which is dried before being sent to market. Pepper reaches maturity in about three years. By itself it is regarded as a very profitable crop.

Cotton cannot be regarded as a catch crop, for the simple reason that it requires special climatic conditions for its well-being. The annual plant yields in seven to nine months, according to situation. A fair average return of lint cotton is $250 \mathrm{lb}$. per acre, 
the net profit is never more than $£$ i 5 per acre as prices rule to-day. It is a troublesome plant among major crops, and should be avoided. A great deal is being claimed for the new tree cottons Caravonica and Mamara, both of which are hybrids and should not be confounded with the so-called tree cotton, the Kapok plant, which is indigenous to the Malay States and yields an inferior pinkish fibre which is largely used in bedding and sofas in the Mid East. These tree cottons are still in their trial period, although it is claimed for a Mexican relation of the Caravonica that a yield of $2250 \mathrm{lb}$. per acre from it has been actually placed upon the market. Tree cottons do not lend themselves to interplanting. They yield in about nine months and are at their maturity at three years old, after which, unless vigorously pruned, they decline and ultimately fail to yield, running up into ungainly forest bushes 30 to 40 feet high. Caravonica cotton is graded into silks, wool, and kidney. The average price is between that of South American and Sea Island. I am of opinion that the extensive area of uncultivated land owned by the Crown and lying between Matale North and the great tanks in the N. Central Province of Ceylon would grow this cotton to perfection, and I would respectfully draw the attention of the British CottonGrowing Association to the subject.

Still another of the crops recommended for interplanting with rubber is that of pineapples. But surely nobody with any practical experience of this plant would ever commit himself to such a suggestion. Nothing impoverishes the soil so much as 
does the pineapple, and, quite apart from this, the pine is a sun plant and is intolerant of the slightest shade. It is not a very profitable crop under any circumstances, and interplanted with rubber would, in my opinion, prove an expensive nuisance.

Coconuts as a subsidiary crop to rubber are a botanical cruelty. Nothing in the whole gamut of tropical agriculture save rubber can compare with it as a money-getter. It is well called the Consols of the East. In Ceylon it is regarded as being even a safer and a more sound investment than rubber. Every bit of the tree's product is marketable. The only drawback about the tree from a planter's point of view is that it takes nine years before a profitable crop may be expected. But it gives no trouble. It is sturdy and thrives in all weathers and under all sorts of climatic conditions. Not more than seventy trees may be planted to the acre, and the yield, commencing in the seventh year at about ten, will gradually and yearly increase until an average of fifty nuts per tree is reached. The net profit at present prices of nuts in Ceylon is about 2s. $6 \mathrm{~d}$. per tree, and coconut estates are selling at over $£ 75$ per acre freehold.

Many native owners in Ceylon are putting down tea among the young rubber, thus reversing the order of things which is responsible for the diminishing output of the first-named product in that islandviz., the planting of rubber among old tea. But the Singalese cultivator, if consulted, could not probably give any better reason for this novel departure than 
that the tea is there in case the rubber fails. He certainly does not look for any profit therefrom !

From the foregoing it will be readily concluded that interplanting among rubber is not recommended as a profitable or desirable undertaking. As a matter of fact, experts are rapidly beginning to recognise that the two prime factors in connexion with it-viz. the cost of labour together with the general returns from the culture-and the undoubted harm it does to the growing rubber and the risks it occasions by providing the medium for introducing insect and fungoid pests hitherto strange to rubber in any situation, make it an absolute duty on their part to condemn the practice and to do all in their power to dissuade planters from following what proves to be in most cases a chimera and in actual practice an expensive and a delusive undertaking. 


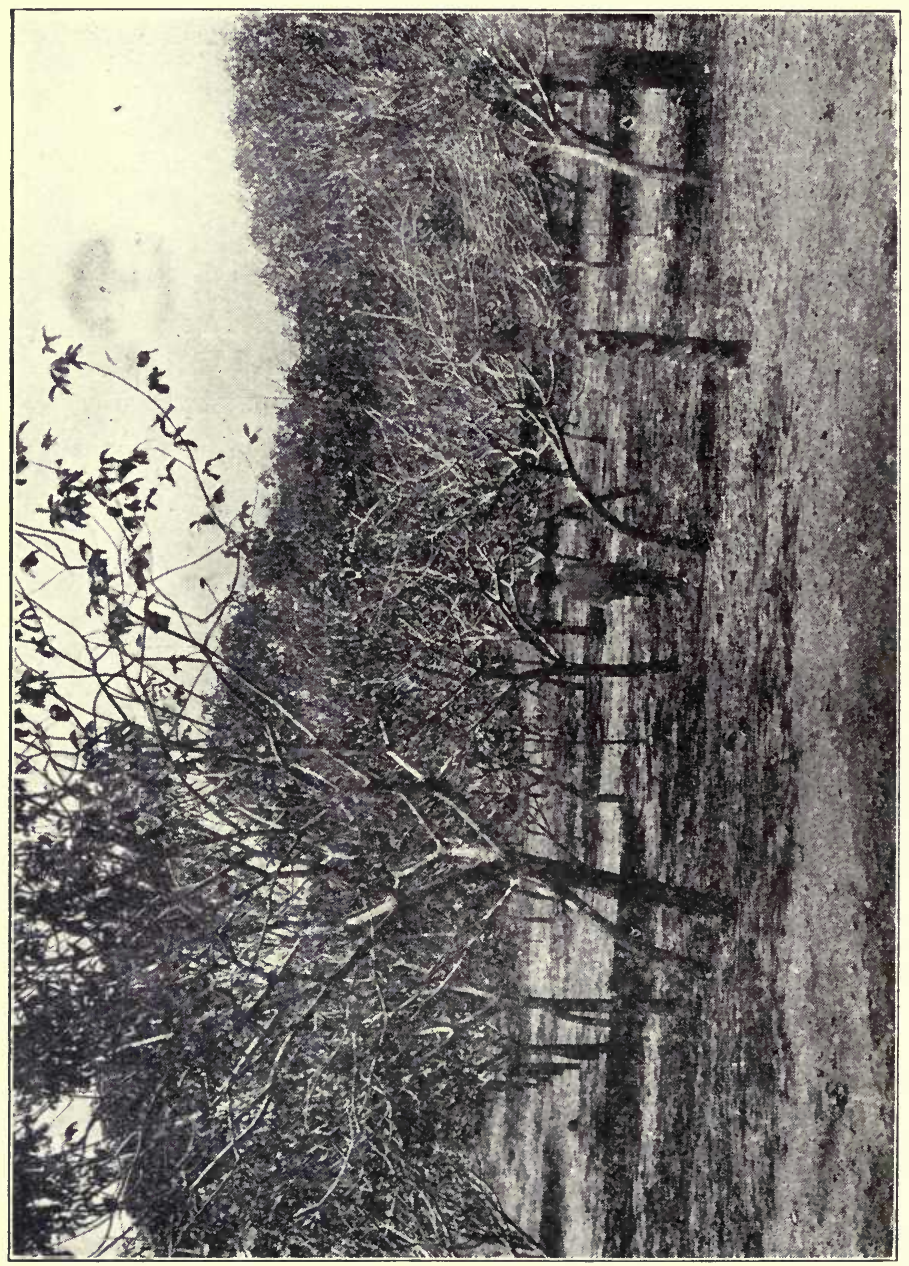

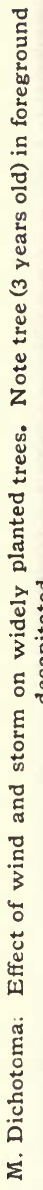




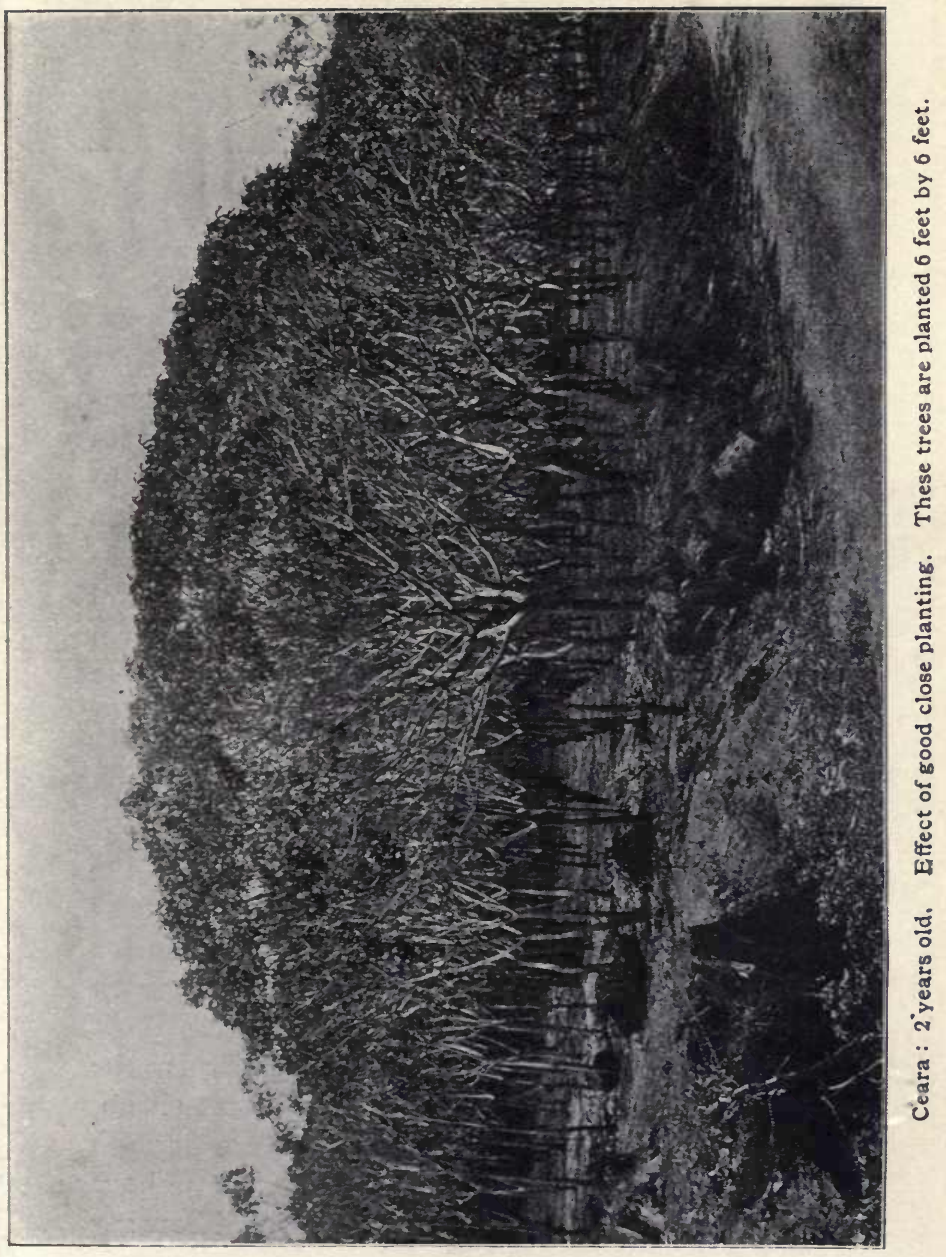




\section{CHAPTER XIII.}

\section{Assimilative and Secondary Rubbers.}

I $\mathrm{N}$ the foregoing essays I have naturally confined myself to those rubber-producing trees which more or less readily lend themselves to profitable exploitation in that particular zone which has become the recognised home of plantation rubber; but there are, of course, several other plants which contribute-many of them heavily - to the world's yearly output of marketable caoutchouc, and for the guidance and assistance of those interested in the problem of the future supply of natural rubber I give a list of the chief secondary rubbers, whose properties may be said to be essentially assimilative, inasmuch as they owe all the value they possess to the aids of costly, secret, and highly scientific machinery to convert their latices into what is at most a cheap and useful adulterant to the pure article of the genuine rubber tree.

Guayule (pronounced Gwy-u-lie).-This is the well-known Parthenium argentatum, a desert shrub, three to four feet high, which kindly nature permits to thrive only in the rainless territories throughout the northern part of Mexico and the neighbouring areas of Texas. 
The Guayule industry is practically in the hands of two non-competing American companies, who, besides controlling output, have effectually cornered all the known sources of supply.

The latex of Parthenium argentatum is found in the form of very small granules throughout the tissues of roots, stems, and branches. To obtain the product, therefore, it is necessary to appropriate the whole of the " heart" of the shrub, which is done by the wholesale removal of it save the few surrounding racemes, from which spring the new plants in the course of time.

Although the manufacture of rubber from Guayule may be said to be a new industry, the Mexican Indian has been accustomed for hundreds of years to utilise it for making his drumsticks and the "catch-balls " of the native village greens by chewing out the gum from the bark.

Modern methods of abstraction are known only to the firms intimately associated with Guayule manufactures. The factories at Barras, Torreon, Saltillo, and Cedros are right in the heart of the Guayule country, the total area of which cannot be less than $6,000,000$ acres. Notwithstanding the enormous yearly consumption of the plant, there is no danger of a Guayule famine for many years to come. The factories are consuming at present about 150,000 tons of the shrub yearly, and the visible supply is not less than $200,000,000$ tons !

Jelutong-or, as it is sometimes called, Pontianak, after the name of the port of shipment -is derived from a large tree indigenous to the 
forests and jungles of Borneo, Malay States, and Sumatra. The Dyaks find the tree standing generally three to four to the acre. Each tree will yield nearly roo $1 \mathrm{~b}$. of latex per year. About 70 per cent. of this is serviceable jelutong, which in its turn will yield probably 8 to Io per cent. of rubber. Formerly it was the custom to ship the jelutong in a raw condition to the United States, where the patents governing its manufacture were in force; but the waste was terrific, and in 1909 a powerful syndicate, embracing the Vanderbilts, the Goelets, and others, was formed with an enormous capital to secure not only the monopoly in jelutong, but also its manufacture. Concessions were secured, and subsequently a company was formed to exploit the material on the spot. Goebilt-the name is derived from an ingenious combination of the first and last syllables in the names of the two chief millionaire proprietors-Messrs. Goelet and Vanderbilt-an ideal position at the entrance to the Kuchling River, Sarawak, was fixed upon for the chief depot, and here are now in active operation a large and up-to-date plant capable of dealing with I00,000 $1 \mathrm{~b}$. of jelutong per day. This is the raw material of the industry, and is manipulated under a secret process invented by M. Féval, so as to produce a high-class finished rubber which can be placed on the market at a cost not exceeding Is. $6 d$. per $1 \mathrm{~b}$.

The main features of the process are as follows: The jelutong is first cleansed by a simple process, and then treated with a resin solvent in specially de- 
signed vessels. After the removal of the solvent, the rubber is found deposited in the extractors in a dry and almost perfect condition. It is then washed,

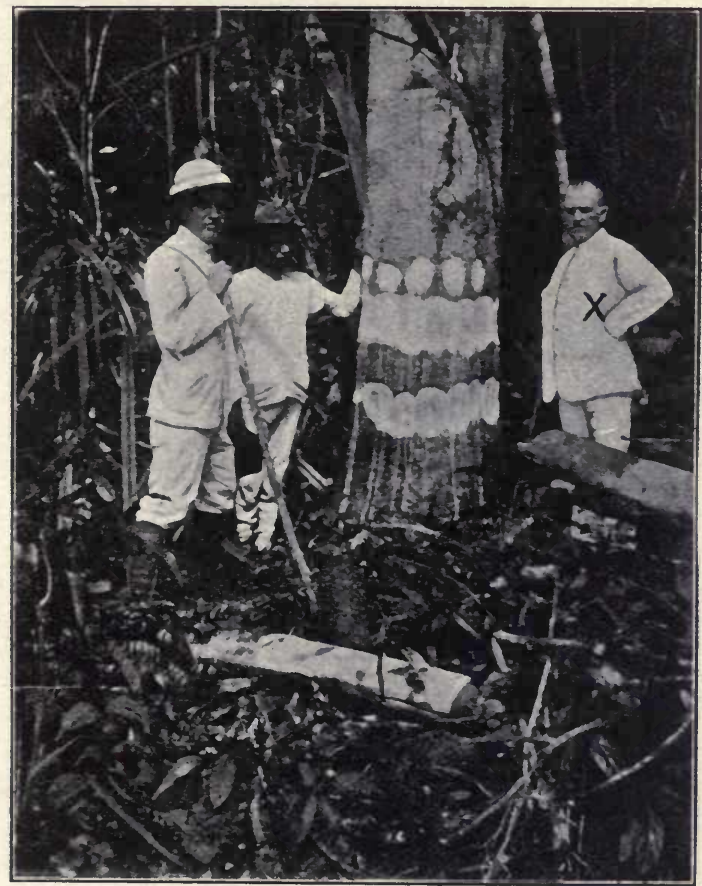

Jelutong Tree (Pulo-Rimau), showing Native Tapping.

smoke cured, and dried, when it is ready for market. The solvent is recovered with a loss of about 3 -Ioths of a pound for each pound of rubber produced, and 
sold in the form of powdered resin. The cost of the raw material, which must be brought to the factory by the Dyaks, amounts to nearly is. per pound of rubber manufactured.

Tirucalli or E. Grandidens and E. Candelabria.This is virtually the African jelutong, and flourishes over a large area of the Tugela Valley, Natal. The natives know no other name for it but the aloe, and under this patronymic it has been known and neglected for years. Latterly the attention of experts.has been called to the plant, with the result that experiments under the auspices of the Natal Government were undertaken with a view to determining the commercial value of the latex. Analysis shows that, like the Dyera of the Middle East, it contains barely i i per cent. of rubber, and a very high percentage of resin, which may, however, repay recovering.

The Landolphias.-The most important of the vine order of rubbers is the L. Kirki and L. owariensis, which are distributed throughout the whole tropical region. With the introduction of modern machinery the exploitation of the Landolphias has entered upon an interesting stage in the production of wild and inferior rubbers, since it is claimed for these machines that they can turn out a product equal to the highest-priced fine Para. But there is no likelihood of such a claim ever being sustained with respect to the vine order, inasmuch as the latices are notoriously deficient in the qualities possessed by the Heveas, the Manihots, the Funtumias, and other forest trees. 
Palo Amarillo.-This is a species of the almost numberless Euphorbia which abound in Mexico and Brazil. It is a handsome, attractive tree, and considerable attention was paid to it by a wealthy American company operating two years ago in the districts affecting the various Plumierias and root rubbers of Mexico, with a view to discovering a really serious competitor of the costly Guayule. But Professor Ohlsson Seffer, who was retained by the Mexican Government to determine and classify the several economic plants of the country, was able to show that Palo Amarillo must be placed very low down in the scale of rubber-yielding trees. Nevertheless the plant is being actively exploited, together with other Euphorbias such as the Chupire and the Vara Leche, and Jatrophas like the curcas and urens and many Plumierias of high yielding quality. The output from these inferior rubbers has been placed by American experts at over 2000 tons for 1910.

Ecanda or B'tinga, known on the Continent as N'tinga.- This is a bulb rubber from Angola, Portuguese West Africa. Its botanical name is Raphionceme utilis. It was originally found at an elevation of nearly 5000 feet, thickly studding the whole of a vast plateau near Bihé, on the road from Benguella to Lake Tanganyika. The tubers, which are an annual, weigh from $4 \mathrm{lb}$. to $5 \mathrm{lb}$. each, and contain, it is said, a very high percentage of excellent rubber. Experiments at Kew and Berlin go to show that the plant is easy of cultivation, and would be likely to prove of economic value if planted 
in the hot sandy loams of the coconut shores of Ceylon, India and Java, and the island north of New Guinea.

Blikrodea Tonkinensis.-Discovered five years ago, the Blikrodea, which is indigenous to the whole of Indo-China, has become one of the most important of the inferior rubbers imported into France. The tree lends itself to ready cultivation, and the Tonkinese have already planted large areas with it, in the hope and expectation of making Blikrodea rubber one of the chief products of the country.

Mangabeira.-The home of this plant is SouthEast Brazil, where it is exploited on a large scale. It is a low-grade rubber, but is in great demand for the manufacture of overshoes, cheap macintoshes, etc. America consumes nearly the whole of the output of Mangabeira. 


\section{CHAPTER XIV.}

COST OF LAYING OUT ESTATES-(I) HEVEA BRASILIENSIS, (2) MANIHOT GLAZIOVII.

F OREST and jungle land suitable for the cultivation of Hevea brasiliensis abounds in most of our Mid-East possessions, and it is these territories that we have in mind in discussing the all-important question of cost in the laying-out of an up-to-date rubber estate. Freehold land will cost from $\mathscr{E}_{\mathrm{I}}$ to $\mathcal{E}_{5}$ per acre according to position, the average being about $£ 2$ Ios. per acre, free of all charges except special survey. In selecting land great care should be taken to avoid ground that presents undue difficulties as to both road-making and drainage, or that presents the least suspicion of water famine, otherwise the outlays in these respects may seriously hamper subsequent development of the property.

The preliminary work of marking off the various fields-which should average 40 acres each, inclusive of paths-detaching the areas which are to provide wind belts, and selecting the sites for cart roads, bungalows, factory, stores, etc., must be done before the clearing contractors are permitted on the land, and a clearly marked sketch of the estate made for the guidance of all concerned. Both in Ceylon, India and the Straits Settlements contracts for this kind of 
labour may be readily placed with the certainty of getting the work done well and expeditiously.

Planting contracts and contracts for buildings, etc., must be arranged separately, and be protected by fines for unnecessary delay or non-compliance with the agreed terms. On the other hand, it is always good policy to offer a bonus for work well and duly completed inside the period allowed.

Hevea brasiliensis are best cultivated from "stumps" and planted 220 to the acre: two important factors which must be taken into account in arriving at an estimate of the ultimate cost of bringing an estate into bearing. The following figures are taken from an estate account appertaining to a property in Ceylon situated nearly eightecn miles from a station and four miles from a Government cart road. It may safely be accepted, in all its particulars as to cost, as a fair example of rubber-planting as a whole, not only in that island but in the Mid-East generally :

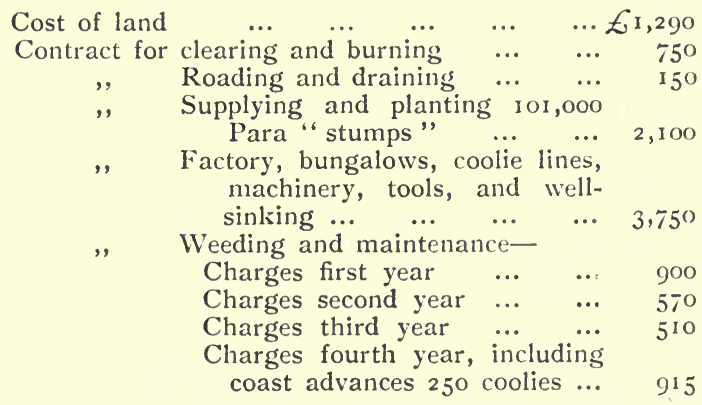

Making a Total of ...£10,935 which is not quite $\mathcal{E}_{22}$ per acre. 
As against this outlay, the estimate of rubber returns for the fifth year (1910) was more than realised. It amounted to $5^{120} \mathrm{lb}$, and sold for $5 s$. Id. per lb. net. The estimates for IgI I fix the output at $30,000 \mathrm{lb}$., the greater portion of which has actually been sold forward at $5 s$. per $1 \mathrm{~b}$. It is quite evident therefore that the proprietors, with ordinary luck, will not be long in recovering the whole of their initial outlay, with the prospect of possessing a fine, heavy dividend-paying property for many, many years. Rubber land in the Malay States, the Dutch Indies and in Borneo is produced at about E20 per acre, whilst in Madagascar, German East Africa, French West Africa and Mozambique, countries that all exploit the Manihot Glaziovii on a large scale, the cost of bringing a rubber-planted area into full bearing is not more than $£ 12$ per acre. It is in this respect that Ceara will always attract the planter with a limited purse.

The clearing of land for Ceara, as already explained, proceeds on much the same lines as that for Para, with the exception that the drainage must if possible be carried right through the plantation in a series of shallow ditches I foot wide and 18 inches deep. When ready for planting - which may be either by cuttings or seed at stake-the ground should be fenced with wirenetting 2 feet high to keep out rodents and wild pig, which are inordinately fond of young Ceara roots, and will soon clear a field if left to themselves.

All this work is more satisfactorily and economically done by contract, a fact which also applies to 
the weeding and management of the estate until the trees are two years old, when they will be rapidly approaching the bearing stage.

At this period the proprietor will be wise to secure his resident labour force, erect the necessary bungalows, coolie lines and factory. Here, again, it is an advantage to call in the contractor, and to arrange with the labour headman-or kangany as he is termed in Ceylon-terms which will attach the coolie force firmly and loyally to the estate.

Where forest land contains valuable timber, such as satinwood, ebony, mahogany, etc., and the planting of Ceara is intended, it is an excellent plan to leave all these woods standing, sacrificing only the softer and useless trees and planting the Ceara seeds in the vacancies thus created. This is termed "Park planting." Strange to say, predatory pests rarely if ever attack young Ceara raised in this fashion. Perhaps the reason is that they find all the food they desire in the forest itself. Apropos of the cost of clearing and planting forest land, it may be said that park-planted Ceara has been tried with great success in the Philippines and New Guinea, where also the Hevea is being cultivated under similar conditions. More will be heard of this departure in rubber-growing, particularly when the absolute certainty of a fall in price to a figure approaching a normal $5^{s}$. per $1 \mathrm{~b}$. will compel owners to turn their attention to the always serious problem of cost of production and its relation to the distribution of high dividends. 


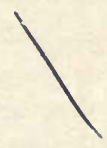

\section{CHAPTER XV. \\ Future Prospects.}

$\mathrm{N}$ reviewing the future prospects of the plantation rubber industry, we need concern ourselves only with those plants which have already acquired an indisputable position among tropical products, and whose general behaviour has secured for them the esteem and confidence of the tropical agriculturist. Of these, two, or at most three, can be placed in such a category. They are the Hevea, the Manihot Glaziovii, and the Funtumia elastica. The first two have proved their excellent all-round qualities in all sorts of soils and climates, ranging from Brazil to Borneo, whilst the Funtumia, despite its failure as an emigrant, is, nevertheless, certain of a brilliant future as an African rubber pure and simple. In our opinion it would be waste of time and money to attempt to acclimatize this tree outside the zone of its native habitat, and much the same may, with equal truth, be said of the Hevea, so far as the home of the Funtumia is concerned.

In the Hevea and Manihot Glaziovii, then, we have two plants which, we believe, are destined to supply, in the main, the output of plantation rubber in the immediate future, and we cannot dismiss the larger 
question of their profitable cultivation without considering for a moment the bearing they are likely to exercise upon the world's output of rubber in the next few years. In this connexion, many farcical attempts have lately been made by mere guessingmen to establish data upon which the industry is asked to base calculations almost vital to its very existence. But the wiser course is patiently to wait upon time and the practical experience that it will bring to determine the matter for itself. One thing may be taken for granted, viz., that the forward policy determined upon by Brazil, and of which much was expected, cannot have any appreciable effect on output for the next five years at least, unless there is an immediate general attraction of foreign capital and foreign effort to deal with the problem, and this, for many reasons, is one of the most unlikely of all unlikely events.

The actual demand for rubber during the year igio can only be calculated by the amount sold, since it is notorious that consumers as a body restricted their purchases in the lively hope that prices would continue to drop, and that at the same time the supply would not fail to increase. Both those expectations were to a certain degree realized, but the comforts of a "bearing" market are always short-lived, and in the case of rubber the operation will never be a profitable one. We are justified in taking this view by the facts relating not only to prices, which will probably reach high averages again, but also to output during rgro. The estimate of the world's production for that year was 72,000 tons, but barely 
70,000 tons actually came in sight. Brazil contributed about 1,600 tons less than that for 1909, and, for reasons already stated, it is practically certain that the output from that country-the cradle of the industry-will not vary sufficiently to influence supply for the next decade. In the case of plantation rubber, the output estimated at 10,000 tons was barely two-thirds of that total, the bulk being contributed by the older and matured estates of the MidEast. As a matter of fact, it is to these estates that we shall have to look for any increase of output until 1912. In that year about 125,000 acres of new plantations will come into line as partly-bearing properties, and if we apply data already proved relating to the probable yield from this great area, there should be no difficulty in arriving at a fairly accurate estimate of the contribution to the world's supply of plantation rubber, not only for the period in question, but for the next few years. Whether the market will receive this huge and sudden increase of output kindly or otherwise is a matter of more than sentimental concern for the new planter, and he should, if possible, be prepared to deal with the situation as it arises, always being careful never to ask too much of his trees until they reach maturity.

We do not possess at present any detailed or reliable knowledge regarding the plantation industry in the Mid-East, and in the following figures we have, therefore, made no attempt to do more than arrive at an approximate idea, gathered from a mass of verified and unverified data, issued from time to time by companies, agents and others interested in 
the industry, of the prospective yield from this quarter.

Southern India and Burma.

$\begin{array}{rrrrrrr}\text { I9I0 } & \ldots & \text { Acres planted } \ldots & 69,000 & \text { I 20,000 } & \text { 210,000 } \\ \text { I910 } & \ldots & \text { Acres bearing } \ldots & 2,120 & 7,400 & 22,000 \\ \text { I9I0 } & \ldots & \begin{array}{c}\text { Average output of } \\ \text { dry rubber per } \\ \text { acre in bearing }\end{array} & 50 \mathrm{lb} . & 75 \mathrm{lb} . & 92 \mathrm{lb} .\end{array}$

Estimates show that in

Southern India

and Burma. Ceylon. Malaya.

There will be in full or partial Acres. Acres. Acres.

beariing in I9II ... $\quad \ldots$.. $27,000 \quad 41,000 \quad 72,000$

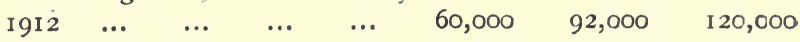

Taking the average output of Ioo $\mathrm{lb}$. per acre for the whole area, we should have

1912 ... Mid-East Plantation Rubber :

Acreage in full or partial bearing-

270,000 acres at $100 \mathrm{ll}$ ). per acre $=27,000,000 \mathrm{lb}$.

or over 12,000 tons, not a formidable total when we look at the figures respecting the output of the wild product. Furthermore, it is extremely doubtful whether I9I2 will see a production of more than Io,ooo tons of plantation, and, the optimists notwithstanding, it will certainly be many years before the Mid-East can hope to compete seriously in tonnage with the yield of wild caoutchouc.

This brings us, therefore, to the point which we would emphasize, with all the power at our command, viz., that no time should be lost by those interested in planting as widely and rapidly as possible. After all we have stated in regard to the "trees that 
count " on a plantation, we make no apology in putting forward the claims of two plants only for this special work. They are the Hevea and the Manihot Glaziovii-the first on hot, moist lowlands, favoured by a rainfall of not less than 85 inches, and the latter on soils that are poor, dry, rocky, high in altitude, possessing a rainfall of $5^{\circ}$ inches and under, and attacked more or less by a long period of yearly drought.

There are enormous stretches of land throughout Ceylon, Southern India, Malaya, Burma, and other British possessions in the Mid-East which answer to these requirements admirably, and if only the investing public at home will grasp these facts, and realize the immense advantages other than pecuniary that accrue from tropical industries fostered under the ægis of the British flag, then there need be no fear for the future of our plantation rubber industry. 


\section{CHAPTER XVI.}

\section{The Soya Bean.}

OYA BEAN (Glycine hispida or Glycine Soja)
is perhaps one of the most valuable legumes in the whole world of industrial commerce. It did not make its appearance in Europe on any large scale until two years ago, when an enterprising Liverpool firm of produce brokers placed on the market about 5000 tons, with an invitation to the seed crushers to test the bean as to its value both as an oil yielder and as a feed for British cattle. The experiments all round were an unqualified and immediate success, and the trade at once placed an order for 6o, 000 tons. Even this large consignment was not sufficient to meet the enormous demands that had been created, for the Continental market became interested, until at the present time supply is short and prices are mounting accordingly.

We know very little of the origin or habits of the soya bean, since there is practically no literature on the subject. We do know, however, that the cultivated soya plant has a congenial home in Eastern Asia, and the present writer has also met with it either in its true form or as the wild Glycine 
ussuriensis in places as far apart as North Mexico, Japan, Java, and Bengal. But, except in the case of Japan, it has no commercial value in any of these countries, being grown more or less as a catch crop among other and better known legumes, or as green food for cattle. It is from Northern China that the world's market in soya bean is at present supplied. Here vast areas are devoted to the crop. Although of rapid growth-it will often attain maturity, and be fit to thresh, within nine weeks of actual sowing - the Chinese are content to raise only one crop a year. The seed is sown in early May, and is raised under the tropical conditions obtaining in Manchuria during midsummer. When ripened the whole plant is pulled bodily out of the soil and laid on the ground for forty-eight hours to dry in the scorching sun. By this method-which is much to be preferred to the system of kiln-drying practised in less sunfavoured Japan-the little legume is plentifully and richly endowed with the greatest oil-yielding properties and undergoes those chemical changes which make its flour one of the most nutritious to man and beast.

There are many varieties of the soya bean, all distinguished by varying colours rather than by difference of shape or texture. Thus we have the yellow Huang-ton, the green Ching-ton, and the black Wuton, all of which are excellent oil yielders and provide valuable feeding material in the pressed residue cake. Neither the white nor the red variety is of much account as an oil-producer, although deservedly cherished among the population of the province of 
Such'uan (where it is chiefly grown) as food for the people.

Early last year the authorities in the Malay States embarked upon a scheme of raising soya on a large scale, but the latest reports point to an all-round failure, first as to yield, and again as to the possible profitable exploitation of the plant. The same thing happened two years ago in Java, and also in the Philippines, where great things were prophesied for the soya by the already optimistic and enthusiastic American colonists. In each case-and generally the same may be said in every instance where, given the proper soil and climate, the soya bean fails to yield profitably - the fault was wholly due to a want of practical knowledge of its cultivation.

Soya bean is a highly nitrogenous plant. Thus it obtains all its nurture from the air, taking nothing from the soil, but at the same time endowing it with qualities of immense manurial value sufficient in a general way to provide for an indefinite period all the necessary elements for raising the crop successively year after year in the same ground.

In breaking new territory, it is therefore essential that the soil should possess in the greatest possible degree all these particular and peculiar elements, otherwise the crop will be a certain failure. There are two methods whereby this endowment of the soil may be accomplished, viz. by the employment of artificial manure and by means of the legume itself. The first is rarely, if ever, satisfactory, and it is therefore needless to discuss it further. But of the other, 
which is the natural method, one can speak with every confidence.

Now, it is extremely doubtful whether there are more than half-a-dozen Europeans who have a practical acquaintance with the successful growing of the soya bean, since the Chinese, always jealous of the secrets of a craft in which they have no rivals throughout the universe, have carefully avoided every attempt by outsiders to become acquainted with the system under which they produce the bean in such enormous quantities, and in so perfect a condition for export to Europe and elsewhere. Nevertheless, the knowledge was obtainable, and the present writer, among others, has been able to conduct many highly interesting and absolutely successful experiments with soya bean in situations and in climates hitherto regarded as being altogether hopeless for legumes of any kind.

I present the secret, therefore, to the reader of these pages with the greatest confidence and pleasure.

The most suitable soil for soya bean is that of a light sandy nature, friable and easy to manipulate. It should be well cleaned and levelled, and inoculated by sowing broadcast four to five bushels of seed to the acre. The best seed for tropical areas is the yellow kind. In two or three days germination will have taken place, and in three weeks the grass should attain a stature of nine to twelve inches. The plant will then begin to branch, and in six weeks at the latest the flower begins to appear. It is at this period that the work of inoculation must be taken in hand, the operation consisting in ploughing in at 
once the whole of the growing crop. When this is done, the ground is again levelled, and the crop proper at once drilled in at a distance of six inches apart in the rows and four inches between the plants. Under this system the soil is thoroughly and effectively inoculated, and the crop, other things being equal, will mature in eight or nine weeks from the time of sowing.

The average yield from inoculated soil is threequarters of a ton per acre. In Ceylon, if planted early enough, three crops should be easily raised in the course of a year.

Many analyses have lately been made of the soya bean, and the percentage of dry weight of oil has been found to vary from $I 7$ to 29 per cent. according to kind grown, the country in which it was raised, and the completeness and method in which the bean was dried. But in a general way the following is a fair average analysis of the bean at present under manipulation in the oil mills at Hull, Antwerp, and elsewhere :

\begin{tabular}{|c|c|c|c|c|c|c|}
\hline Water & & $\ldots$ & $\cdots$ & $\ldots$ & 10 & cent. \\
\hline Album & noids & $\ldots$ & $\ldots$ & $\ldots$ & 35.5 & ", \\
\hline Oil & $\ldots$ & $\ldots$ & ... & $\ldots$ & $19 \cdot 7$ & , \\
\hline Starch & and su & gar &. & $\cdots$ & $18 \cdot 7$ & , \\
\hline Fibre & $\ldots$ & $\ldots$ & $\cdots$ & $\cdots$ & 4 & , \\
\hline Ash & $\ldots$ & $\ldots$ & $\ldots$ & $\ldots$ & $4 \cdot 2$ & , \\
\hline
\end{tabular}

The residue cake gives as much as 79 per cent. of hypophosphites, and is therefore of very high feeding value. During the past year eminent millers both in England and on the Continent turned their attention to this residue material, and have discovered 
in it properties, hitherto unsuspected, of immense value to the milling industry. In short, they find that soya flour ranks nearly highest in the scale of highclass products of this nature, and Messrs. Ranks, Ltd., among others, are now putting on the market a soya flour of great nutritious value as human food. A most delicious biscuit is also being manufactured from the flour by Messrs. Carr, of Carlisle. There seems, in fact, no end to the commercial possibilities of this truly wonderful legume.

It is useless attempting to embark on the cultivation of soya bean for export unless it is undertaken on a large scale, and continuity of supply can be assured. The trade is wholly in the hands of buyers who deal in huge quantities for which they are always prepared to pay prompt cash, but they will make no bids for occasional consignments. Intending growers should therefore select areas of 200 to 300 acres or more of suitable ground for the enterprise, and devote it wholly and exclusively for the culture of the bean.

Careful estimates of the cost of delivery of soya bean at, say, Colombo, assuming cultivation took place in Ceylon, place the figure at about $30 s$. per ton, and the present price in London is over $£ 7$ per ton. The price at Colombo f.o.b. is $£ 6$ perton, so that the profits to the growers are enticing enough for the most timid of investors. 



\section{N D E X}

Bamber, Kelway, Mr., 36

Biffen, Dr., 66

Blikrodea Tonkinensis, 136

Brazil, Plantations in, 11; Largest tree, 26; Ceara, 49; output, $1+3$

B'tinga, 135

Cameron, Mr. J., $\sigma_{4}$

Carter, Sir G. T., 102

Castilloa, $19,43,78,92$; disappointing, 94 ; where it differs from others, 96 ; the only coagulant, 96-7; as wind belt, 99

Catch crops (see Interplanting), Chinese and, 120

Coconuts as catch crop, 126

Coffee as catch crop, 123-4

Cost of preparing and planting, $4^{1}$, $137-9$

Cotton as catch crop, 124-5

Cross, Mr., 14, 26, 47, 49, 50, 51, 66, 94

Cuttings, propagation by, 26

Denton, Captain, 102

Diseases, 19-20, 27, 46, 140

Ecanda, 135

Ficus elastica, $8 \mathbf{5}, 86,87$; seed, 88 ; tapping, 88, and Gastav Mann, 89 , in India, New Caledonia and elsewhere, 89-91

Ficus Vogleii, 85, 86, 87

Fitting, Dr., 33, 34
Funtumia elastica, 100; not a Kickxia, rox; tapping and coagulation, 104-105; failure as an alien, 10\%108; popular on the Ivory Coast, in the Cameroons and Uganda, 108; future, 141

Gambier, as catch crop, 123

Glaziow, Dr., 49

Guayule, 130-I

Hancornia (see Mangabeira)

Heneratgoda Giant, 42

Hevea Brasiliensis on Eastern Plantations, 12; Ceylon Forest Circular, 1888, 15 ; early tapping experiments, 16, 23; Mr. Herbert Wright's experiments, 38 ; $v$. Manihot Glaziovii, 19, it; as rubber producer in alien lands, 21 ; planting, 44; future, $3^{1-2}$

Hooker, Sir Joseph, II

Howard, Esmé, Mr., 66

India, rubber growing in, 12, 22, 23; M. Glaziovii in, 64; Ficus Elastica, 89, 91

Interplanting, 24, and Manihot. 55, 119-126; not recommended, 127

Jelutong, 131-4

Jequié (see Manihot Dichotoma)

Kew, 11, 13, 14, 22, 23, 26, 40, 47, $48,49,91,94,102,135$ 


\section{I54 THE WHOLE ART OF RUBBER-GROWINC:}

Lanadron Block, 21

Landolphia, 87, 134

Macnillan, Mr., $3^{8}$

McCallum, Sir H. E., so 7

Mangabeira, 28, 136

Manihot Dichotoma, 110-114; tapping, 118

Manihot Glaziovii, I3; Introduced to the East, 14,$17 ; v$. Hevea, 19, 74 ; at home, 49 ; seed, $5^{1-2}$; initial tappings, 58 ; bark renewal and pricking, 6r; in India and elsewhere, 64-71, 81; experiments in tapping, $67,77,78$; propagation, $70,7 \mathrm{I}, 78$; botanical plants, 72 ; esteemed by manufacturer, 74 ; proper tapping, 80-4; future, $14^{1-1} 4^{2}$

Manihot Heptaphylla, 110, I14

Manihot Piauhyensis, 110, II 4

Mann, Gustav, Mr., 89

Manuring, 46, 55

Millson, Alvan, 87

Mueller and M. Glaziovii, 49

Olubi, J. C., Mr., 101, 104

Palo Amaíllo, 135

Park planting, 140

Pineapples as catcli crop, 125-126

Rambong (see Ficus elastica)

Root-tapping, 54, 59
Sapium, 13

Scott, Mr., 65

Seffer, Ohlsson, Prof., 135

Silver, Messrs., 23

Sowing to Stake, 53

Soya Bean, 146-151

Stapf and Funtumia, yo1

Tapioca as catch crop, 121-3

Tapping, 27, 28-29, 31; high-tapping. 32 ; vertical, 36 ; Peradeniya experiments with Hevea, 23; Heneratgoda experiments, 38,40 ; roottapping, 54, 59; Manihot, 58,67 . $77,78,80-4$; Ficus elastica, 86, 88; Castilloa, 97; Funtumia, 104-5 Tea as catch crop, 126

Thiselton-Dver, Sir IV. T., 12

Thwaites, Dr., 48

Tirucalli, 134

Trimen, Dr., 23, 32, and M. Glaziovii, 50, 60, 62

Ulé, Dr., 110, 114, 115

Weeding, 55, and maintenance, cost of, 138,140

Wickham, Mr., 13, 66

Wide $v$. close planting, 42

Willis, Dr. J. C., 24, $3^{8}$

Wind, protection against, 27,43 , 54, 99

Wright, Mr. Herbert, $3^{8}$

Yields, 29-3o; Manihot Glaziovii, 67-8, 7 I-2; Castilloa, 96; from Mid. east plantations, 144 





\section{UNIVERSITY OF CALIFORNIA LIBRARY}

This book is DUE on the last date stamped below.

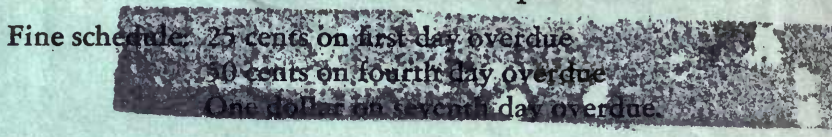

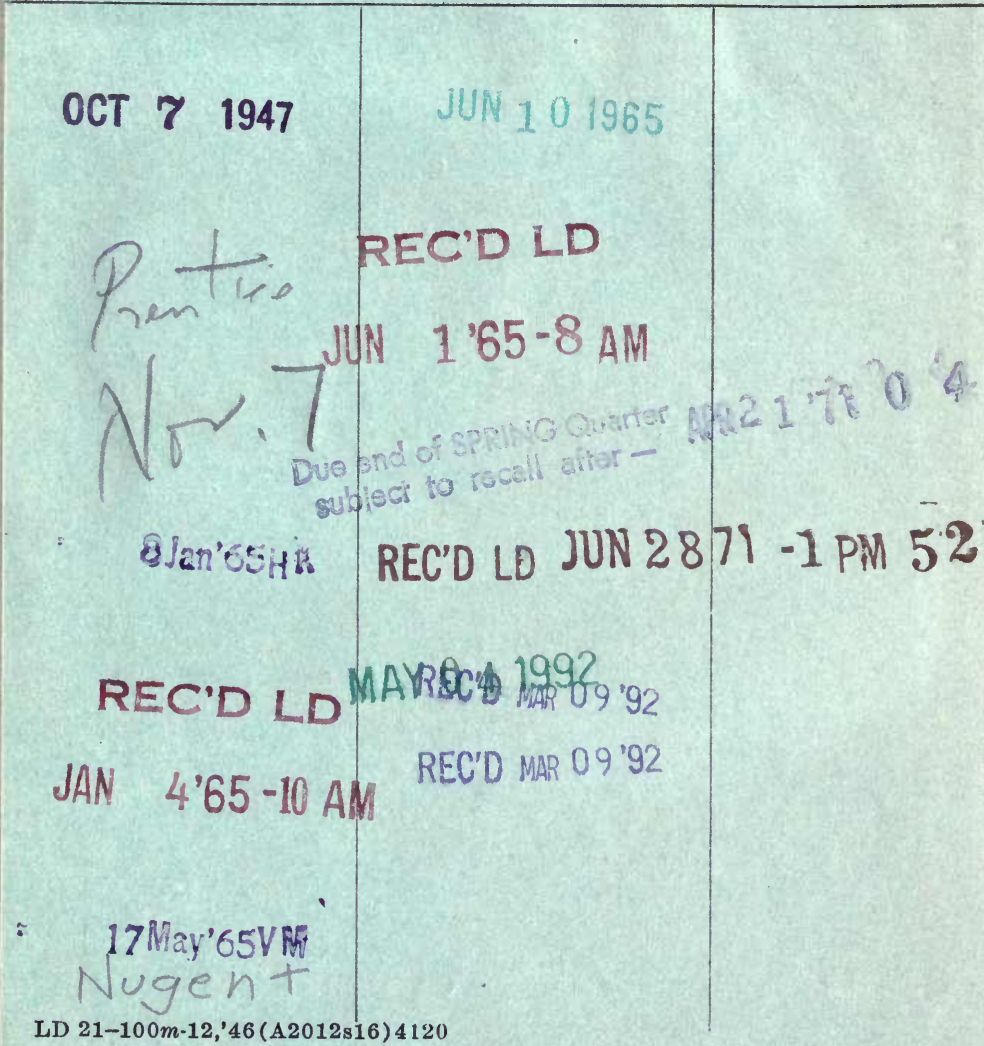




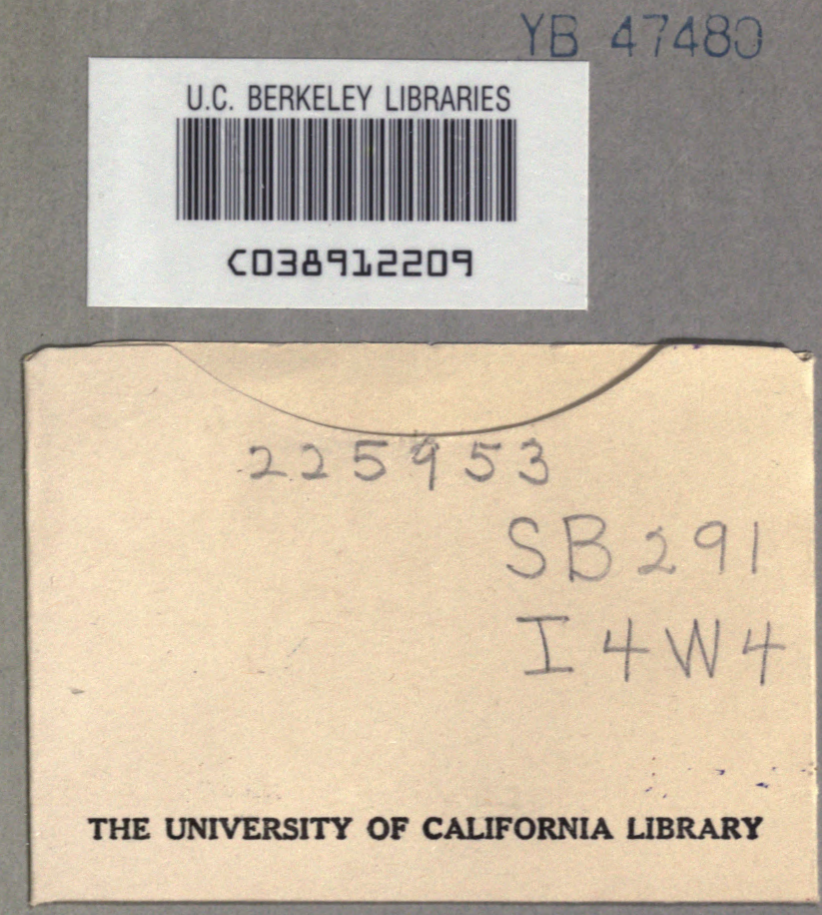


